\title{
Theoretical Analysis of Miscibility Gaps in the Alkali-Borates
}

\author{
Pedro B. Macedo* \\ Catholic University of America, Washington, D.C. 20017 \\ Joseph H. Simmons \\ Institute for Materials Research, National Bureau of Standards, Washington, D.C. 20234
}

(September 5, 1973)

\begin{abstract}
A thermodynamic approach based on the regular solution concept is applied to the description of miscibility gap boundaries in the alkali-borate systems. It is suggested that in each system the structural units which control the entropy of mixing are the stoichiometric compounds at the apparent limit of the alkali-rich edge of the gap, and a complex boron trioxide structure. (The former is inferred by the shape of the gap, and the latter is chosen to fit the regular mixing equation.) The same boron trioxide complex is used for all the systems analyzed. The physical implications of this analysis are discussed.
\end{abstract}

Key words: Glass; immiscibility; phase separation; thermodynamics of solutions.

\section{Introduction}

While miscibility gaps have been measured in a large number of systems [1] ${ }^{1}$, there have been few attempts to analyze their shape. Concentrating on the oxide glass systems, we find that the majority of these gaps have been observed in complex systems consisting of more than two component oxides. Since it is not clear whether these systems separate into two or more phases [2], and since the exact chemical identities of the coexistent phases have largely escaped definition, a first principle analysis of the thermodynamics of their phase-separation is not possible. There are, however, several binary oxide mixtures which exhibit immiscibrity at high glassformer concentrations. These are largely the alkali silicates [3, 4] and borates [5]. Despite this apparent simplification, attempts to describe the shape of the miscibility gap boundaries in these binary systems have not been generally successful $[6,7]$.

The regular-mixing approach [8] which depends upon balancing the exothermic entropy of mixing and an endothermic enthalpy of mixing results in a coexistence or miscibility gap boundary curve which is symmetric in terms of the relative concentrations of the two immiscible liquids. The alkali-borates and silicates, which represent the major binary oxide systems with miscibility gaps, show highly asymmetric gaps. In the case of the alkali-silicates, the miscibility

${ }^{*}$ Work done at Catholic University was supported by Contract Number AF 72-2203.

'Figures in brackets indicate the literature references at the end of this paper. gap is limited at one branch by silica and at the other by the first stoichiometric crystalline compound encountered as alkali oxide is added. Assuming that the two demixing liquids are $\mathrm{SiO}_{2}$ and this stoichiometric compound still leads to an asymmetric gap [6]. This behavior has discouraged the use of regularmixing equations [8] to describe such gaps. The borates pose a more serious problem to this approach, since their miscibility gaps reach beyond several stoichiometric crystal compounds.

The most serious attempt to describe the thermodynamics of phase separation in binary oxide systems was recently presented by R. J. Charles [7]. Assuming that the enthalpy of mixing in the silicates resulted principally from changes of coordination and valence of oxygen ions in the melt and changes in bonding energy at oxygen sites, he was able to show that the enthalpic heat of mixing of transition metal oxidesilica mixtures was endothermic. The addition of this endothermic enthalpy contribution to the exothermic entropy contribution in the Gibbs free energy leads to phase-separation. Following the same considerations, he found that the heat of mixing for the alkali-metal and alkaline-earth oxide mixtures with silica was exothermic thus negating any possibility for phase separation. Since these systems do exhibit phase separation, it was concluded that the partial molar heat of solution of silica, which had been previously overlooked, was a prime candidate for the necessary large endothermic contribution to the heat of mixing. The implications of such an assumption are interesting, since they point to the formation upon phase-separation of a complex 
silica structure larger than a single $\mathrm{SiO}_{4}$ tetrahedron.

This hypothesis, proposed by Charles, serves well to introduce the concepts of our model, although the two were developed independently. Below we propose a model to describe the thermodynamic processes which control liquid-liquid immiscibility in the binary oxide glasses. This is based upon the concept that molten oxides are made up of small structural units which control the physical properties of their melts. The configurational entropy of mixing is therefore determined by the possible rearrangements of these units. As a result, the free energy of the system is not expressed in terms of molar concentrations of the component oxides, but rather in terms of the relative concentrations of the dominant structural units. This approach allows the use of the regular mixing equation and replaces the arbitrary assumption that the glassformer, say $\mathrm{B}_{2} \mathrm{O}_{3}$, mixes as a cell containing two borons and three oxygens, with the more physically acceptable concept that the cell consists of a complex structure, $\left(\mathrm{B}_{2} \mathrm{O}_{3}\right)_{m}$, with $m$ being an integer. In this paper, we will consider the alkali-metal oxide-boric oxide mixtures, since their gaps occur in similar temperature ranges, thus reducing the number of undetermined parameters. The alkali-silicates are covered in a separate paper [3].

\section{Structural Units in the Melt}

The existence of small stable species made up of several molecules in the melts of oxide glassformers has long been suspected. A number of authors have proposed complex species for various structures in order to describe structural, thermodynamic and kinetic measurements [10-17].

In these various studies it seems clear that the structure of the primary network formers $-\mathrm{SiO}_{2}, \mathrm{~B}_{2} \mathrm{O}_{3}$ and $\mathrm{GeO}_{2}$-extends well beyond the nearest neighbor coordination, but the definition of a molecule of glassformer is not clear and may easily depend upon the property analyzed.

The smallest unit which retains its identity when two liquids are mixed may be defined in several ways. Following a correlation function approach, a size corresponding to an ordered region may be obtained. A geometrical approach, emphasizing the structural units (e.g., boroxol rings for $\mathrm{B}_{2} \mathrm{O}_{3}$ ) may be tested by $\mathrm{x}$-ray diffraction. However, it appears that the different investigators do not agree on the various interpretations of the x-ray data. A thermodynamic approach is also possible, whereby the exact nature of the structural units is not specified and only the thermodynamic behavior of the system is analyzed.

In this paper we will restrict our analysis to thermodynamic concepts, since we are only concerned with investigating the variables which determine the shape of miscibility gaps in the oxide mixtures.

\section{Complex Molecule Model for Miscibility Gaps}

In considering the thermodynamic properties of binary mixtures, simple mixing between the glassformers, $\mathrm{B}_{2} \mathrm{O}_{3}$ or $\mathrm{SiO}_{2}$, and the alkali oxides, $\mathrm{M}_{2} \mathrm{O}$ or MO can be rejected on structural grounds, as done by other authors [6], since it is unlikely that such molecules exist in the melt. Let us analyze, instead, mixing between more complex and hopefully, more realistic structures.

As an example, in the phase diagram of the lithiumborate system it will be assumed that mixing occurs between the network former and a stoichiometric chemical compound whose composition can be obtained by extrapolating the immiscibility or coexistence curve to zero Kelvin. By inspection it appears that the coexistence curve can best be extrapolated to the compound $\mathrm{Li}_{2} \mathrm{O} \cdot 4 \mathrm{~B}_{2} \mathrm{O}_{3}$ at low temperatures. The model which we propose thus considers the $\mathrm{Li}_{2} \mathrm{O}$. $4 \mathrm{~B}_{2} \mathrm{O}_{3}$ composition as one of the mixing liquids.

The choice of this stoichiometric compound as one of the mixing liquids is not inconsistent with the existence of a crystalline compound at $\mathrm{Li}_{2} \mathrm{O} \cdot 5 \mathrm{~B}_{2} \mathrm{O}_{3}$, since it is well accepted that borate melts have far different structures than the crystalline states. Thus, it is unlikely that a correspondence would develop between the structures of compounds in the melt and those of crystals, in the high $\mathrm{B}_{2} \mathrm{O}_{3}$ region of the systems.

The significant contribution presented by this paper involves choosing a complex boron molecule, $\left[\left(\mathrm{B}_{2} \mathrm{O}_{3}\right)_{m}\right]$, as the second liquid. The complex molecule is a somewhat stable grouping of boron and oxygen atoms which can be identified as a single species in the entropy calculation. This species, however, once identified for a particular glassformer in a given temperature range, must contribute to the entropy calculations of the other miscibility gaps of that glassformer (i.e., in the alkali-borates) occurring in the same temperature range.

Without committing ourselves as to the geometrical appearance of these species, we propose to use the complex molecules, $\left[\left(\mathrm{M}_{2} \mathrm{O} \cdot n \mathrm{~B}_{2} \mathrm{O}_{3}\right)\right]$ and $\left[\left(\mathrm{B}_{2} \mathrm{O}_{3}\right) m\right]$, in the calculation of the entropy of mixing. In the alkaliborates only one value of $m$ will be used for all the different alkalis, since the miscibility gaps occur in the same temperature range. The silicates, however, present more difficulty due to the vast temperature differences between their miscibility gaps [3].

The composition of the alkali-borate melt is normally written $x \mathrm{~B}_{2} \mathrm{O}_{3} \cdot y \mathrm{M}_{2} \mathrm{O}$, where $x$ and $y$ are the respective molar fractions of $\mathrm{B}_{2} \mathrm{O}_{3}$ and $\mathrm{M}_{2} \mathrm{O}$. In terms of the new components used here the melt composition will be expressed as $\bar{x}\left[\left(\mathrm{~B}_{2} \mathrm{O}_{3}\right)_{m}\right] \cdot \bar{y}\left[\mathrm{M}_{2} \mathrm{O}\right.$ $\left.\cdot n \mathrm{~B}_{2} \mathrm{O}_{3}\right]$, where $\bar{x}$ and $\bar{y}$ are the respective mole fractions of $\left[\left(\mathrm{B}_{2} \mathrm{O}_{3}\right)_{m}\right]$ and $\left[\mathrm{M}_{2} \mathrm{O} \cdot n \mathrm{~B}_{2} \mathrm{O}_{3}\right]$. It is easily shown that

$$
\begin{aligned}
& \bar{y}=y /\{y+[1-(n+1) y] / m\} \\
& \bar{x}=1-\bar{y}
\end{aligned}
$$


Once the identities of the two separated liquids are found, then each original composition (molar concentrations) can be converted to relative concentrations of the two separated liquids (i.e., $\bar{x}$ and $\bar{y}$ ) and then the data can be compared with the ideal mixing equation for the system $\left[\left(\mathrm{B}_{2} \mathrm{O}_{3}\right)_{m}\right]$ and $\left[\mathrm{M}_{2} \mathrm{O} \cdot n\left(\mathrm{~B}_{2} \mathrm{O}_{3}\right)\right]$.

The value of $n$ in the formula $\left[\mathrm{M}_{2} \mathrm{O} \cdot n\left(\mathrm{~B}_{2} \mathrm{O}_{3}\right)\right]$ can be obtained in most instances by visual inspection of the data. The complex glassformer molecule must then be inferred from the data by choosing the value of $m$ necessary to symmetrize the coexistence curve with respect to concentrations of the immiscible liquids. The crucial test then is to see whether all gaps are likewise symmetrized by the same glassformer complex molecule in the alkali-borates.

\section{Calculation of the Regular Mixing Equation}

The regular mixing equations are well known (see ref. 8, for instance) and we will only review the basic derivation here, for completeness. The free energy of mixing can be expressed in terms of an enthalpy and entropy of mixing. When the enthalpy is positive, phase separation may ultimately occur. The molar enthalpy of mixing is expressed in terms of the two concentrations $\bar{x}$ and $\bar{y}$, and an interaction energy parameter $w(w>0)$ as follows:

$$
\Delta H=\bar{x} \bar{y} w
$$

Contributions to the entropy of mixing of two liquids come from two sources. In general, most authors have ignored the effect due to changes in the internal degrees of freedom of each liquid, and have only been concerned with configurational states $[6,9]$. Both terms will be examined here. The configurational molar entropy of mixing is written as:

$$
\begin{aligned}
& \Delta S_{1}=-R[\bar{x} \ln \bar{x}+\bar{y} \ln \bar{y}] \\
& =-R[(1-\bar{y}) \ln (1-\bar{y})+\bar{y} \ln \bar{y}]
\end{aligned}
$$

The molar entropy of mixing arising from changes in the internal degrees of freedom upon mixing is expressed as:

$$
\Delta S_{2}=\bar{x} \bar{y} \delta S
$$

The structural implications of the magnitude of this term will be discussed later. The molar free energy of mixing now becomes:

$$
\begin{aligned}
\Delta G= & \Delta H-T\left(\Delta S_{1}+\Delta S_{2}\right) \\
\Delta G= & \bar{y}(1-\bar{y})(w-T \delta S) \\
& +R T[\bar{y} \ln \bar{y}+(1-\bar{y}) \ln (1-\bar{y})]
\end{aligned}
$$

Phase separation is now obtained by minimizing the free energy of mixing with respect to composition:

$$
\begin{aligned}
\left(\frac{\partial \Delta G}{\partial \bar{y}}\right)_{P, T} & =0=(1-2 \bar{y}) w \\
& +R T[\ln \bar{y}-\ln (1-\bar{y})-(1-2 \bar{y}) \delta S / R]
\end{aligned}
$$

This condition leads to a temperature-composition relationship which represents the coexistence curve:

$$
\begin{aligned}
T_{\text {coex }}=(w / R) \cdot(1-2 \bar{y}) \cdot\left\{\ln \left[\frac{(1-\bar{y})}{\bar{y}}\right]\right. & \\
& +(1-2 \bar{y}) \delta S / R\}^{-1}
\end{aligned}
$$

The critical temperature, $T_{c}$, corresponding to the top of the miscibility gap is found by maximizing $T_{\text {coex }}$ :

$$
T_{c}=(w / R) /(2+\delta S / R)
$$

The dependence of the normalized coexistence temperature on concentration can then be expressed as:

$$
\begin{aligned}
T_{\text {coex }} / T_{c}= & (2+\delta S / R) \cdot(1-2 \bar{y}) \\
& \left\{\ln \left[\frac{(1-\bar{y})}{\bar{y}}\right]+(1-2 \bar{y}) \frac{\delta S}{R}\right\}^{-1}
\end{aligned}
$$

Once the coexistence curve has been established, it is of interest to calculate the spinodal curve, by letting the second derivative of the free energy of mixing with respect to composition go to zero:

$$
\left(\frac{\partial^{2} \Delta G}{\partial \bar{y}^{2}}\right)=0=-2(w-T \delta S)+R T[1 / \bar{y}+1 /(1-\bar{y})]
$$

The spinodal curve is now written as:

$$
\begin{aligned}
T_{s} & =2(w / R)\left[\frac{1}{\bar{y}(1-\bar{y})}+2 \delta S / R\right]-1 \\
T_{s} / T_{c} & =2(2+\delta S / R)\left[\frac{1}{\bar{y}(1-\bar{y})}+2 \delta S / R\right]^{-1}
\end{aligned}
$$

These results may now be transformed into functions of the usual molar fractions of $\mathrm{M}_{2} \mathrm{O}$ (e.g., $y$ ) by substituting the expression for $\bar{y}$, eq (1), into the coexistence and spinodal equations (eqs (9) and (12)). These solutions are represented in our subsequent graphs by solid and dashed lines, respectively.

\section{Comparison with Data}

\subsection{Lithium-borate System}

The data by Shaw and Uhlmann [5] were used to test the equations obtained above. The phase diagram of the lithium-borate system exhibits a liquid-liquid metastable miscibility gap between 4 and 16 mole percent $\mathrm{Li}_{2} \mathrm{O}$. The maximum of the coexistence curve appears at 10 mole percent $\mathrm{Li}_{2} \mathrm{O}$. The stoichiometric 
compound $\mathrm{Li}_{2} \mathrm{O} \cdot 4 \mathrm{~B}_{2} \mathrm{O}_{3}$, therefore, appears to limit the gap in the high alkali region. This then will be one of the immiscible liquids at zero Kelvin.

Let us now consider the immiscible liquid on the borate-rich side of the gap. Assuming regular mixing between $\left[\mathrm{B}_{2} \mathrm{O}_{3}\right]$ and $\left[\mathrm{Li}_{2} \mathrm{O} \cdot 4 \mathrm{~B}_{2} \mathrm{O}_{3}\right]$ yields a maximum in the coexistence curve at 50 percent $\left(\mathrm{B}_{2} \mathrm{O}_{3}\right)$ and 50 percent $\left(\mathrm{Li}_{2} \mathrm{O} \cdot 4 \mathrm{~B}_{2} \mathrm{O}_{3}\right)$ which corresponds to the 17 mole percent $\mathrm{Li}_{2} \mathrm{O}$ concentration. This result disagrees with the measured maximum near 10 percent $\mathrm{Li}_{2} \mathrm{O}$. The choice of a boroxol ring as suggested by Krogh-Moe [18] yields a maximum near 15 mole percent $\mathrm{Li}_{2} \mathrm{O}$, which is also unsatisfactory. The $\left[\mathrm{B}_{4} \mathrm{O}_{6}\right]$ cages of Ottar and Ruigh [12] are no more successful with 14 mole percent $\mathrm{Li}_{2} \mathrm{O}$ for the maximum. The complex $\left(\mathrm{B}_{2} \mathrm{O}_{3}\right)_{m}$ molecule which allows symmetrization of the gap and leads to a maximum at 10 mole percent $\mathrm{Li}_{2} \mathrm{O}$ turns out to be the $\left[\left(\mathrm{B}_{2} \mathrm{O}_{3}\right)_{5}\right]$.

While this choice of a complex $\left[\left(\mathrm{B}_{2} \mathrm{O}_{3}\right)_{5}\right]$ molecule appears arbitrary in this case, it must be remembered that since the other alkali-borates have miscibility gaps in the same temperature range, we are restricted to the same complex for these other gaps. The data are plotted in terms of concentrations of the two demixing liquids $\left[\left(\mathrm{B}_{2} \mathrm{O}_{3}\right)_{5}\right.$ and $\left.\left(\mathrm{Li}_{2} \mathrm{O} \cdot 4 \mathrm{~B}_{2} \mathrm{O}_{3}\right)\right]$ in figure 1 . The

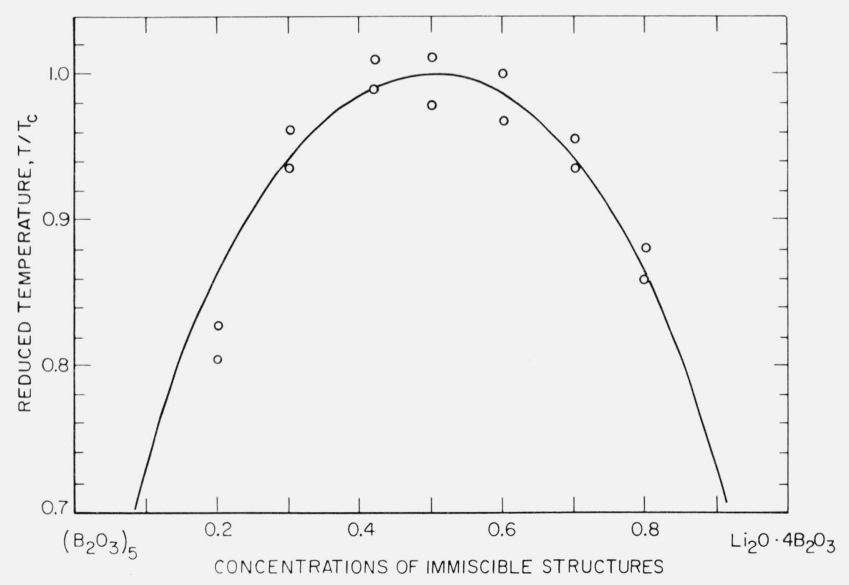

FIGURE 1. Miscibility gap in the lithium-borate system, plotted in terms of concentrations of the two demixing liquids: $\left.\left[\mathrm{B}_{2} \mathrm{O}_{3}\right)_{5}\right]$ and $\left[\left(\mathrm{Li}_{2} \mathrm{O} \cdot 4 \mathrm{~B}_{2} \mathrm{O}_{3}\right)\right]$.

regular-mixing solution is also plotted, and appears to fit the data well. In this case the entropy contribution from changes in vibrational states of the molecules appears to be negligible $\left(\Delta \dot{S}_{2}=0\right)$. A plot of the data and the coexistence and spinodal curves in terms of $\mathrm{Li}_{2} \mathrm{O}$ molar concentration is shown in figure 2 and also demonstrates good agreement between the data and the equations.

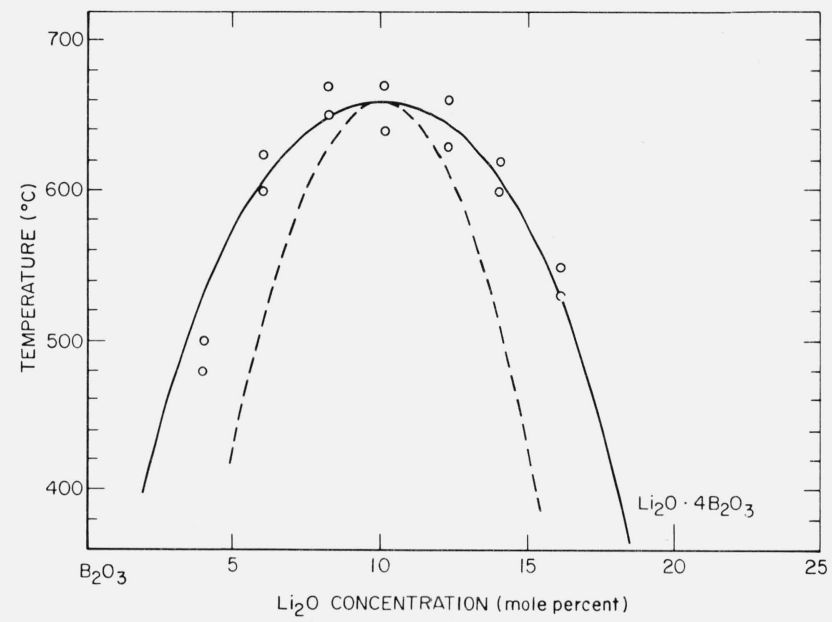

FIGURE 2. Miscibility gap in the lithium-borate system, plotted in terms of $\mathrm{Li}_{2} \mathrm{O}$ concentration.

The solid and dashed lines are the calculated coexistence and spinodal boundary curves, respectively.

\subsection{Other Alkali-Metal Oxide-Borate Systems}

While we have four adjustable parameters in this analysis, $m, n, w$ and $\delta S$, we may only freely adjust $\delta S$, in fitting the shape of the coexistence curve in the other alkali-borate systems. The value of maximum coexistence temperature, $T_{c}$, in general cannot be adjusted by more than 1 percent and determines $w$ directly. The identities of the two demixing liquids at zero Kelvin ( $n$ and $m$ ) are fixed by the data at the highalkali branch, and by the choice of $\left[\left(\mathrm{B}_{2} \mathrm{O}_{3}\right)_{5}\right]$ on the boric oxide side.

Shaw and Uhlmann's measurements in the potassium-borate, rubidium-borate and cesium-borate systems show phase separation occurring between 4 and 20 mole percent $\mathrm{K}_{2} \mathrm{O}, 4$ and 14 mole percent $\mathrm{Rb}_{2} \mathrm{O}$, and 4 and 18 mole percent $\mathrm{Cs}_{2} \mathrm{O}$, respectively. The data for the potassium and cesium borate systems indicates that the compound limiting one of the branches of the coexistence curves is at 25 mole percent alkali oxide. A lack of data in the rubidium-borate system prevents a similar analysis, so we assumed that it would follow the same behavior as the other two. Therefore, the demixing liquid at the high-alkali side of the gap is $\left[\mathrm{M}_{2} \mathrm{O} \cdot 3 \mathrm{~B}_{2} \mathrm{O}_{3}\right]$, where $\mathrm{M}_{2} \mathrm{O}$ stands for the three alkali oxides in question.

A regular mixing between $\left[\mathrm{M}_{2} \mathrm{O} \cdot 3 \mathrm{~B}_{2} \mathrm{O}_{3}\right]$ and $\left[\left(\mathrm{B}_{2} \mathrm{O}_{3}\right)_{5}\right]$ leads to a maximum in the coexistence curve near 11 percent $\mathrm{M}_{2} \mathrm{O}$. Inspection of the data shows good agreement for the $\mathrm{K}_{2} \mathrm{O}$ and $\mathrm{Cs}_{2} \mathrm{O}$ mixtures. Figures 3 and 5 show that the data appear symmetric when plotted as a function of concentration of these immiscible liquids. The regular-mixing equation gives a good fit of the data with the vibrational contribution to the entropy, $\delta S$, chosen at $+0.5 R$ and $-0.8 R$ for the $\mathrm{K}_{2} \mathrm{O}$ and $\mathrm{C}_{s_{2}} \mathrm{O}$ systems, respectively. The data for the rubidium system show only fair agreement with the model and require a choice of $\delta S=-0.5 R$ for the 


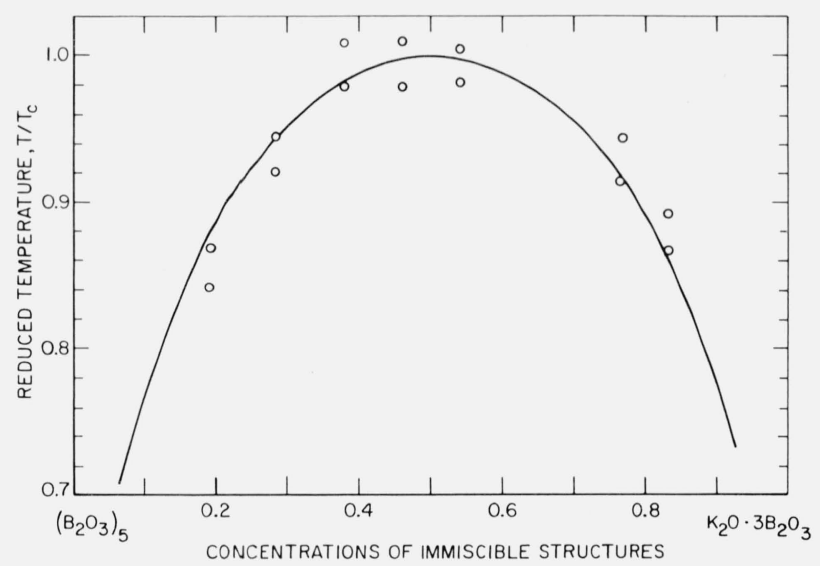

FIGURE 3. Miscibility gap in the potassium-borate system, plotted in terms of concentrations of the two demixing liquids: $\left[\left(\mathrm{B}_{2} \mathrm{O}_{3}\right)_{5}\right]$ and $\left[\left(\mathrm{K}_{2} \mathrm{O} \cdot 3 \mathrm{~B}_{2} \mathrm{O}_{3}\right)\right]$.

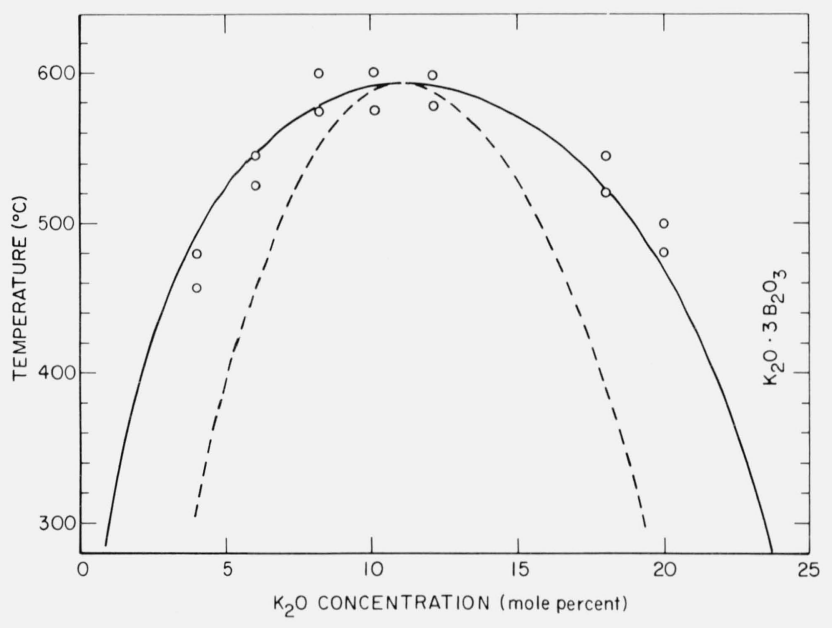

FIGURE 4. Miscibility gap in the potassium-borate system, plotted in terms of $\mathrm{K}_{2} \mathrm{O}$ concentration.

The solid and dashed lines are the calculated coexistence and spinodal boundary curves, respectively.

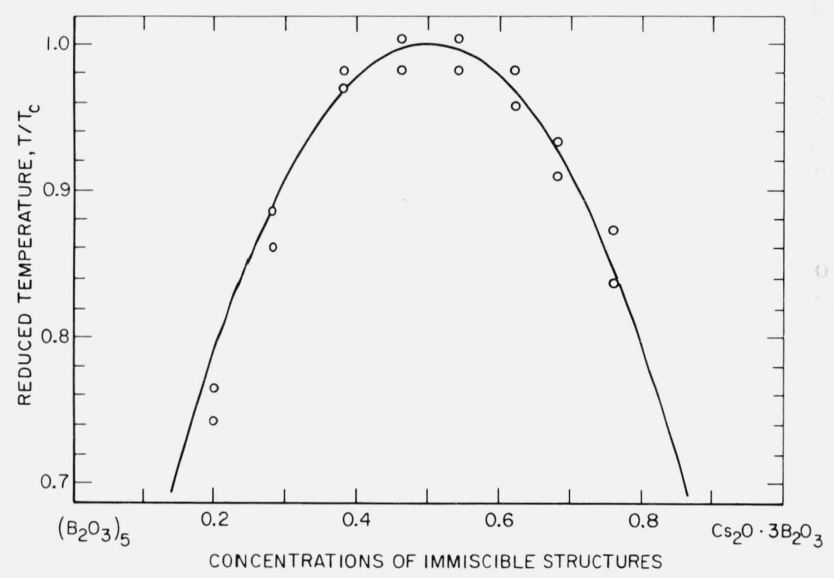

FIGURE 5. Miscibility gap in the cesium-borate system, plotted in terms of concentrations of the two demixing liquids: $\left[\left(\mathrm{B}_{2} \mathrm{O}_{3}\right)_{5}\right]$ and $\left\lfloor\left(\mathrm{C}_{2} \mathrm{O}_{2} \cdot 3 \mathrm{~B}_{2} \mathrm{U}_{3}\right)\right]$.

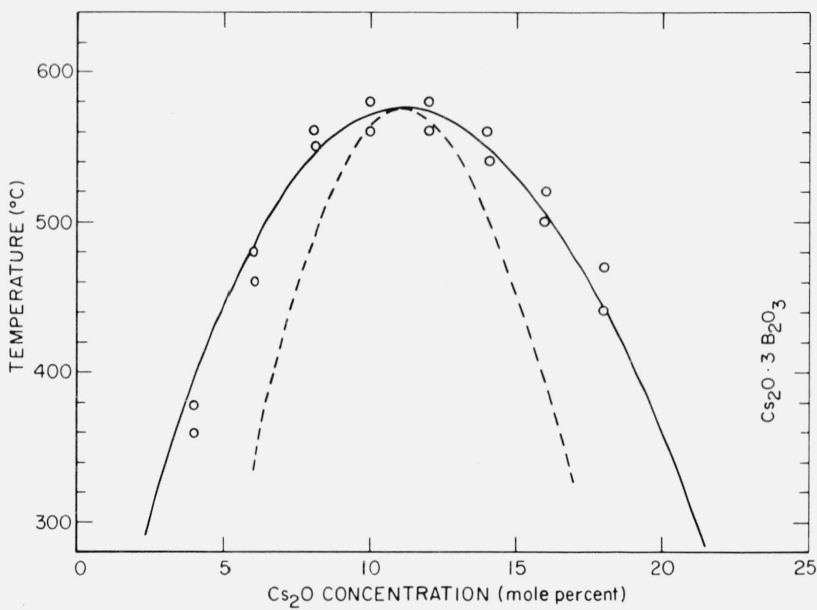

Figure 6. Miscibility gap in the cesium-borate system, plotted in terms of $\mathrm{Cs}_{2} \mathrm{O}$ concentration.

The solid and dashed lines are the calculated coexistence and spinodal boundary curves, respectively.

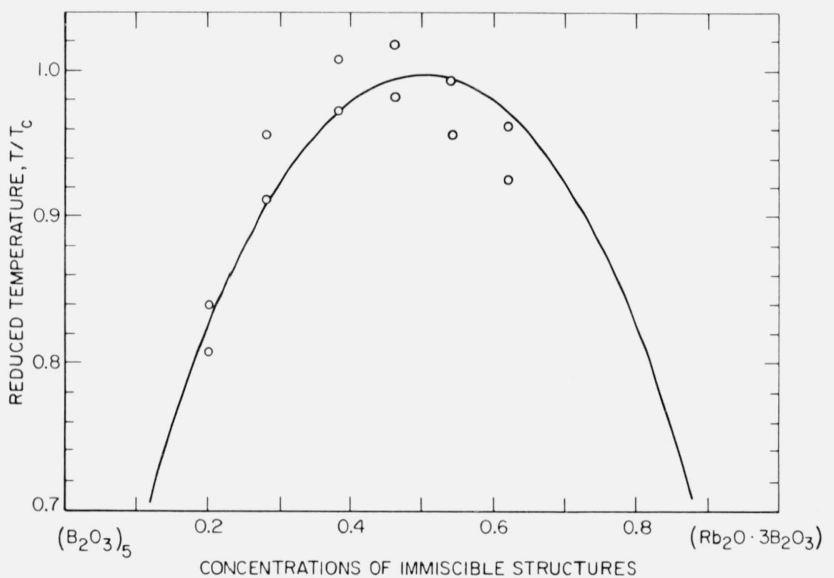

FIGURE 7. Miscibility gap in the rubidium-borate system, plotted in terms of concentrations of the two demixing liquids: $\left[\left(\mathrm{B}_{2} \mathrm{O}_{3}\right)_{5}\right]$. and $\left[\left(\mathrm{Rb}_{2} \mathrm{O} \cdot 3 \mathrm{~B}_{2} \mathrm{O}_{3}\right)\right]$.

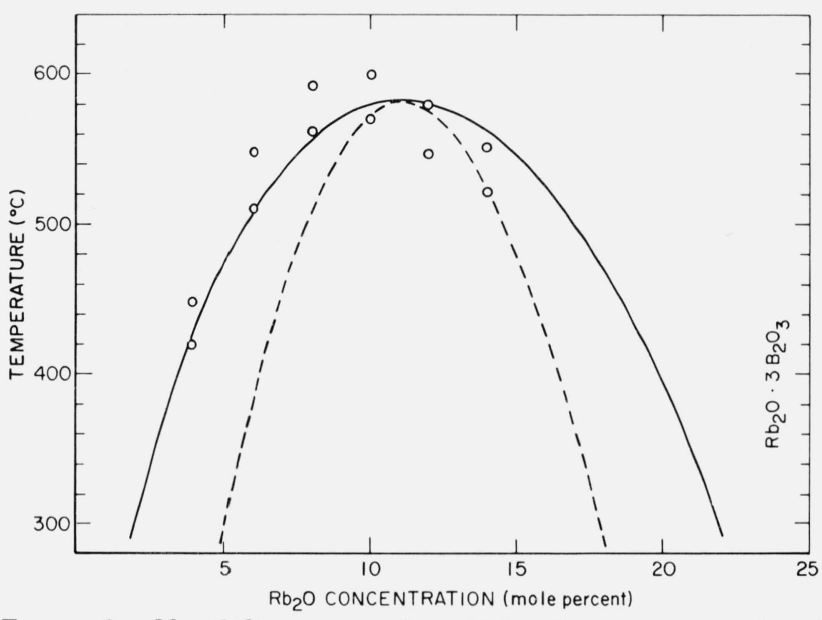

FIGURE 8. Miscibility gap in the rubidium-borate system, plotted in terms of $\mathrm{Rb}_{2} \mathrm{O}$ concentration.

The solid and dashed lines are the calculated coexistence and spinodal boundary curves, respectively. 
fit shown (fig. 7). Plots of the data and the coexistence and spinodal curves in terms of alkali-oxide molar concentrations are shown in figures 4,6 , and 8 . In general, the model satisfactorily describes the phaseseparation data.

The above results confirm our choice of the species: $\left[\left(\mathrm{B}_{2} \mathrm{O}_{3}\right)_{5}\right]$ as the molecular complex controlling the configurational entropy of the system over the observable temperature range, and therefore, support the merit of this approach. We see that in addition to describing the shape of the coexistence curve, a calculation of the location of the spinodal region is also possible. This has potential usefulness in the interpretation of measurements on glasses with compositions far from the critical composition.

We have omitted a description of the sodiumborate system, because the data appeared very different from that for the other systems. Attempts to symmetrize the coexistence curve were relatively unsuccessful. An attempt to measure the gap as a check on the data was equally unsuccessful due to the quick hydration of the samples.

\subsection{Lead-Borate System}

Data for the lead-borate system was reported by two authors $[19,20]$. One of us, J. H. Simmons, has also recently reported the results of careful measurements of phase separation in this system [21]. Figure 9,

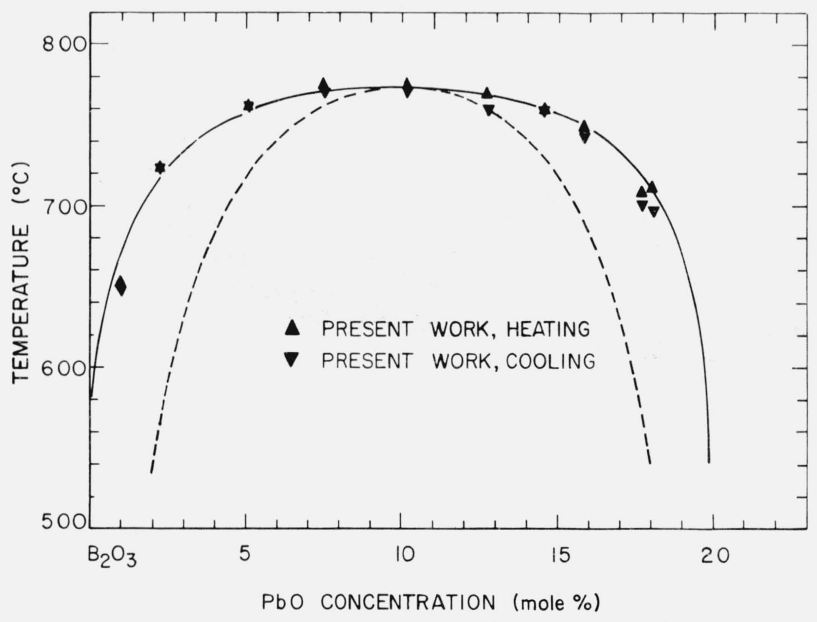

FIGURE 9. Miscibility gap in the lead-borate system, reprinted from ref [21].

The solid and dashed lines are the calculated coexistence and spinodal boundary curves. respectively.

reprinted from his paper, shows his data and the fit of the regular-mixing equations. The two immiscible liquids at zero kelvin are $\left[\left(\mathrm{B}_{2} \mathrm{O}_{3}\right)_{5}\right]$ and $[(\mathrm{PbO}$. $\left.\left.4 \mathrm{~B}_{2} \mathrm{O}_{3}\right)\right]$. Because of the pronounced flatness of the coexistence curve, the contribution to the entropy of mixing from changes in the vibrational states was large, $\delta S=+10 R$. The implications of this result are discussed in the next section.

\section{Changes in the Internal Degrees of Freedom}

The contribution to the entropy of mixing arising from changes in the internal degrees of freedom or vibrational states of the immiscible liquids, $\Delta S_{2}$, is the parameter which most affects the shape of the miscibility gap boundaries in the fits presented above. Its effect on the regular mixing equation serves to either broaden $(\delta S>0)$, or narrow $(\delta S<0)$, the coexistence curve while maintaining symmetry. This is achieved through its effect on the critical temperature, $T_{c}$ : eq (8). A positive value for the additional entropy corresponds to an increase in the internal degrees of freedom. The additional states developed by mixing thus will tend to suppress phase separation. The evidence is mounting in support of the two-dimensional structural description of pure boron trioxide glass. The addition of alkali-metal oxides tends to convert three-coordinated planar borons to four-coordinated borons. This helps form a three dimensional network. The change is small, however, since only the boron ions are affected. Because of their low valence the alkali ions cannot form cross linking. In addition, however, one must consider the effect of changes in the molecular vibrational states. As a simple example, we may look at the phonon density of states of a linear chain with alternating different masses (mixed state) and compare it with that of two chains with equal masses (phase-separated state). The result is a decrease in the available states or internal degrees of freedom upon mixing. The additional entropy, $\delta S$, would be negative thus raising $T_{c}$. The effect is more pronounced for the heavier alkali-borate compounds.

The table below lists the various alkali-oxide compounds postulated with their formula weights and the additional entropy terms necessary for fitting the regular mixing equation. The potassium oxide compound is the lightest and it appears that the entropy contribution from the formation of a three dimensional structure dominates. As the mass of the compound increases to the cesium oxide system, the change in vibrational states dominates and the entropy term becomes increasingly negative.

The lead oxide-boric oxide system is also included. Despite its heavy compound, the entropy term is positive. This is due to the large contribution from the change in dimensionality of the system. The lead ions with their high valence become tetrahedrally coordinated in solution and add a large number of internal degrees of freedom to the system. This apparently dominates over the effect of the mass change.

TABLE 1

\begin{tabular}{l|c|c|c}
\hline \hline Immiscible compound & Molecular weight & $\delta S / R$ & {$[2+\delta S / R]^{-1}$} \\
\hline$\left[\mathrm{K} \mathrm{O} \cdot 3 \mathrm{~B}_{2} \mathrm{O}_{3}\right]$ & 303 & +0.5 & 0.4 \\
{$\left[\mathrm{Li}_{2} \mathrm{O} \cdot 4 \mathrm{~B}_{2} \mathrm{O}_{3}\right]$} & 308 & 0 & 0.5 \\
{$\left[\mathrm{Rb}_{2} \mathrm{O} \cdot 3 \mathrm{~B}_{2} \mathrm{O}_{3}\right]$} & 396 & -0.5 & 0.67 \\
{$\left[\mathrm{Cs}_{2} \mathrm{O} \cdot 3 \mathrm{~B}_{2} \mathrm{O}_{3}\right]$} & 491 & -0.8 & 0.83 \\
{$\left[{\left.\mathrm{PbO} \cdot 4 \mathrm{~B}_{2} \mathrm{O}_{3}\right]}_{\left.\left[\mathrm{B}_{2} \mathrm{O}_{3}\right)_{5}\right]}^{501}\right.$} & +10.0 & 0.083 \\
\hline
\end{tabular}




\section{Conclusion}

We have shown that the thermodynamic equations of regular mixing can be applied to phase separation in the alkali-borate glasses. The concept, which must be introduced to accomplish this, is the assumption that the glassformer phase is structurally represented by a complex molecule and the glassformer-modifier phase by a stoichiometric compound. This transformation symmetrizes the coexistence curve.

The regular mixing equation appears to represent the data well when an additional entropy of mixing arising from changes in the internal degrees of freedom of the system is included in the calculation. Following this approach, five systems were treated successfully. The complex boron trioxide molecule $\left[\left(\mathrm{B}_{2} \mathrm{O}_{3}\right)_{5}\right]$ was used in the regular mixing analyses of all the borate systems considered, since the miscibility gaps occurred approximately within the same temperature range.

The implications of such an approach are interesting but not surprising. As mentioned before, by other authors and in some of our other work, the existence of complex glass-former structures in the melt appears to offer a good explanation for the behavior of an increasing number of physical properties of molten oxide glasses.

An actual geometrical description of the complex boron trioxide structure is not accessible to us by this analysis since thermodynamic treatments do not afford structural descriptions.

\section{References}

[1] Levin, E. M., Liquid Immiscibility in Oxide Systems, Phase Diagrams, Vol. 3 (Academic Press, Inc., New York, 1970).
[2] Haller, W., Blackburn, D. H., Wagstaff, F. E., and Charles, R. J., J. Amer. Ceram. Soc. 53,34 (1970).

[3] Haller, W., Blackburn, D. H., and Simmons, J. H., Miscibility gaps in alkali-silicates, J. Am. Ceram. Soc. (to be published, March 1974).

[4] Andreev, N. S., Goganov, D. A., Porai-Koshits, E. A., and Sokolov, Yu G., Proc. Fourth All Union Conf. on Glassy States (Eng. Transl.) p. 45 (Consultants Bureau, New York, 1964).

[4a] Hammel, J. J., VII International Congress on Glass, Brussels, June 1965.

[5] Shaw, R. R., and Uhlmann, D. R., J. Amer. Ceram. Soc. 51, 377 (1968).

[6] Moriya, Y., Warrington, D. H., and Douglas, R. W., Phys. Chem. Glasses 8, 19 (1967).

[7] Charles, R. J., Phys. Chem. Glasses 10, 169 (1969).

[8] Thompson, J. B., Jr., Thermodynamic Properties of Simple Solutions, Researches in Geochemistry, II, P. H. Abelson, Ed., pp. 340-361. (John Wiley \& Sons, N.Y., 1967).

[9] Charles, R. J., Phys. Chem. Glasses 10, 169 (1969).

[10] Warren, B. E., X-ray Structural Determination of Glasses, Amorphous Materials, R. W. Douglas and B. Ellis, Eds., p. 263 (John Wiley \& Sons, London, 1972).

[11] Ottar, B., and Ruigh, W. L., Phys. Chem. Glasses 3, 95 (1962).

[12] Dunlevey, F. M., and Cooper, A. R., Bul. Am. Ceram. Soc. 51, 374 (1972).

[13] Konnert, J., Karle, J., and Ferguson, G. A., Bul. Am. Ceram. Soc. 51,374 (1972).

[14] Fajans, K., and Barber, S. W., J. Am. Chem. Soc. 74, 2761 (1952).

[15] Mackenzie, J. D., Some Physical Properties and Structure of Liquid Boron Trioxide, General Electric Research Laboratory Report 3550.

[16] Macedo, P. B., Capps, W., and Litovitz, T. A., J. Chem. Phys. 44, 3357 (1966).

[17] Leidecker, H. W., Simmons, J. H., Litovitz, T. A., and Macedo, P. B., J. Chem. Phys. 55, 2028 (1971).

[18] Krogh-Moe, J., Phys. Chem. Glasses 3, 101 (1962).

[19] Leidberg, D. J., Ruderer, C. C., and Bergeron, C. G., J. Am. Ceram. Soc. 48, 440 (1965).

[20] Zarzycki, J., and Naudin, F., Phys. Chem. Glasses 8, 11 (1967).

[21] Simmons, J. H., Miscibility gap in the $\mathrm{PbO}-\mathrm{B}_{2} \mathrm{O}_{3}$ system, J. Amer. Ceram. Soc. 56, 284(1973).

(Paper 78Al-804) 


\section{Publications of the National Bureau of Standards*}

\section{Citations with Selected Abstracts}

J. Res. Nat. Bur. Stand. (U.S.), $77 \mathbf{A}$ (Phys. and Chem.), No. 6, (Nov. Dec. 1973), SD Catalog No. C13.22/sec.A:77/6.

Absolute isotopic abundance ratio and atomic weight of a reference sample of rhenium, J. W. Gramlich, T. J. Murphy, E. L. Garner, and W. R. Shields.

Reflection correction for high-accuracy transmittance measurements on filter glasses, K. D. Mielenz and R. Mavrodineanu.

Temperature-pressure phase relationships in niobium pentoxide, J. L. Waring, R. S. Roth, and H. S. Parker.

Nuclear magnetic resonance of ${ }^{113} \mathrm{Cd}$ and ${ }^{199} \mathrm{Hg}$ in $\mathrm{Cd}-\mathrm{Mg}$ and Cd-Hg solid solutions, V. V. Zhukow, I. D. Weisman, and L. H. Bennett.

Molecular basis of flame inhibition, $\mathrm{J}$. W. Hastie.

The effect of temperature and pressure on the refractive index of some oxide glasses, R. M. Waxler and G. W. Cleek.

The pair correlation function in liquid ${ }^{4} \mathrm{He}, \mathrm{R}$. D. Mountain and H. J. Raveché.

J. Res. Nat. Bur. Stand. (U.S.), 77B (Math. Sci.), Nos. 3 and 4, SD Catalog No. C13.22/sec.B:77/3\&4.

Certification of an algorithm for Bessel functions of complex argument, D. J. Sookne.

Character induced subgroups, R. Merris and W. Watkins.

The characterizations of $\left(A_{q}(U)\right)$, M. E. Sheingorn.

An application of Schur's lemma on irreducible sets of matrices in continuum mechanics, J. T. Fong.

Remarks on a problem of Rademacher in the theory of modular forms, M. I. Knopp.

Performance testing of a FORTRAN library of mathematical function routines $-A$ case study in the application of testing techniques, D. W. Lozier, L. C. Maximon, and W. L. Sadowski.

Bessel functions $I$ and $J$ of complex argument and integer order, D. J. Sookne.

Certification of an algorithm for Bessel functions of real argument, D. J. Sookne.

Triangles generated by powers of triplets on the unit circle, C. R. Johnson and M. Newman.

Tables and graphs of the stable probability density functions, D. R. Holt.

Bessel functions of real argument and integer order, D. J. Sookne.

Monogr. 130. The divergent beam (Kossel) x-ray method and its uses in measuring strain contours in an individual grain of Fe-3 weight percent Si transformer sheet, H. Yakowitz, Nat. Bur. Stand. (U.S.), Monogr. 130, 80 pages (Aug. 1973) 95 cents, SD Catalog No. C13.44:130.

*Publications with prices and SD Catalog numbers may be purchased directly from the Superintendent of Documents, U.S. Government Printing Office, Washington, D.C. 20402 (foreign: onefourth additional). Microfiche copies are available from the National Technical Information Service (NTIS), Springfield, Va. 22151. Reprints from outside journals and the NBS Journal of Research may often be obtained directly from the authors.
Key words: Divergent beam x-ray diffraction; electron probe microanalysis; iron-silicon alloy; Kossel; strain; stress; trans former sheet.

Residual and impressed stresses and strains in $\mathrm{Fe}-3$ wt. pct. Si alloy transformer sheet were studied. Results were obtained by the divergent beam (Kossel) $x$-ray microdiffraction techniques. The optically opaque $\mathrm{Fe}-3$ wt. pct. Si alloy was mapped for residual and im pressed stresses and strains. These maps are roughly analogous to polarized light stress analysis of transparent materials. The results showed that a variable strain distribution existed in the alloy sheet at the time it was ready for insertion into a transformer core. Small applied compressive and tensile loads tended to rearrange this variable strain distribution but not to appreciably alter the total stored elastic energy.

Monogr. 131. Thermal conductivity of solids at room temperature and below. A review and compilation of the literature, G. E. Childs, L. J. Ericks, and R. L. Powell, Nat. Bur. Stand. (U.S.), Monogr. 131, 624 pages (Sept. 1973) \$7.80, SD Catalog No. C13.44:131.

Key words: Cryogenic thermal conductivity; elements, alloys, commercial metals, semiconductors, semimetals, ionic and valence crystals, minerals, molecular crystals, polymers, glasses, disordered dielectrics, thermal conductivity of; review; thermal conductivity.

An extensive compilation is given of the measured values of thermal conductivity for nearly all solid materials from room temperature down to 0.01 kelvin. The reviewed materials include elements, alloys and commercial metals, semiconductors, semimetals, ionic and valence crystals, minerals, molecular crystals, polymers, glasses, and disordered dielectrics. Excluded are foams, powders, earths, fibers, layers of composites, and similar other heterogeneous solids. Data for temperatures below 1 kelvin are presented separately. The tables and graphs are complete for literature references from 1900 to mid-1971. Experimental methods and physical phenomena are discussed in the text and coded in the tables for references for which curves are shown. Supersedes NBS Circular 556.

Monogr. 134. Space groups and lattice complexes, W. Fisher, H. Burzlaff, E. Hellner, and J. D. H. Donnay, Nat. Bur. Stand. (U.S.), Monogr. 134, 184 pages (May 1973) \$4.10, SD Catalog No. C13.44:134.

Key words: Crystallography; crystal point groups; crystal structure; lattice complexes; site sets; space groups.

The lattice complex is to the space group what the site set is to the point group - an assemblage of symmetry-related equivalent points. The symbolism introduced by Carl Hermann has been revised and extended. A total of 402 lattice complexes are derived from $67 \mathrm{~W}$ eissenberg complexes. The Tables list site sets and lattice complexes in standard and alternate representations. They answer the following questions: What are the coordinates of the points in a given lattice complex? In which space groups can a given lattice complex occur? What are the lattice complexes that can occur in a given space group? The higher the symmetry of the crystal structures is, the more useful the lattice-complex approach should be on the road to the ultimate goal of their classification. 
Monogr. 135. Properties of glasses in some ternary systems containing $\mathrm{BaO}$ and $\mathrm{SiO}_{2}$, G. W. Cleek and C. L. Babcock, Nat. Bur. Stand. (U.S.), Monogr. 135, 42 pages (Sept. 1973) 70 cents, SD Catalog No. C13.44:135.

Key words: Barium glasses; barium silicates; glass properties; glass property factors; oxide glasses; silicate substructures; ternary glasses.

The glass forming regions in six ternary oxide systems containing $\mathrm{BaO}, \mathrm{SiO}_{2}$ and a third oxide have been determined. The properties of the resulting glasses were measured and the results are reported. The data on refractive indices, dispersions and specific volumes were evaluated by computer methods in an attempt to identify "substructures" containing the cations present in the glasses.

H112. Examination procedure outlines for commercial weighing and measuring devices. A manual for weights and measures officials, O. K. Warnlof, Nat. Bur. Stand. (U.S.), Handb. 112, 89 pages (June 1973) \$1.10, SD Catalog No. C13.11:112.

Key words: Codes; examination procedure; inspection; meters; outlines; scales; tests.

This handbook presents an operational guide for the field examination of commercial weighing and measuring devices. It includes inspection and test procedures, with code references to National Bureau of Standards Handbook 44, Fourth Edition, "Specifications, Tolerances, and Technical Requirements for Commercial Weighing and Measuring Devices."

SP260-45. Standard Reference Materials: Development of NBS Standard Reference Material No. 1579 Powdered Lead-Based Paint, B. Greifer, E. J. Maienthal, T. C. Rains, and S. D. Rasberry, Nat. Bur. Stand. (U.S.), Spec. Publ. 260-45, 31 pages (Mar. 1973) 50 cents, SD Catalog No. C13.10:260-45.

Key words: Analytical standard; atomic absorption spectrometry; differential cathode ray polarography; electrodeposition; lead-based paint; neutron activation analysis; $\mathrm{x}$-ray fluorescence spectrometry; Standard Reference Material.

The development of NBS Standard Reference Material No. 1579 , Powdered Lead-Based Paint is described. This SRM is intended for use in the calibration of apparatus and methods used in determining lead in paint removed from old housing.

Paints scraped from the interior surfaces of old housing were collected, blended, homogenized, and characterized for lead content. The average lead content was found to be $11.87 \pm 0.04$ percent lead by weight determined by atomic absorption spectrometry and by diferential cathode ray polarography.

The analytical procedures involved sample dissolution by dry ashing in a furnace at $450-550{ }^{\circ} \mathrm{C}$ followed by exhaustive extractions of the insoluble residue with acids and with ammonium acetate solution.

SP370. Research and testing facilities of the Engineering Mechanics Section, National Bureau of Standards, Washington, D.C., by the Staff of the NBS Engineering Mechanics Section, D. J. Chwirut, Coordinator, Nat. Bur. Stand. (U.S.), Spec. Publ. 370, 23 pages (Jan. 1973) 55 cents, SD Catalog No. C13.10:370.

Key words: Engineering Mechanics Section; force generating equipment; research facilities; testing machines.

The principal characteristics of the force measuring and generating equipment and related research facilities available in the Engineering Mechanics Section of the National Bureau of Standards are described.
SP374. Method for determining the resolving power of photographic lenses, F. E. Washer and I. C. Gardner. Appendix added by C. E. Kuyatt, Nat. Bur. Stand. (U.S.), Spec. Publ. 374, 32 pages (June 1973) \$3.00, SD Catalog No. C13.10:374.

Key words: Photographic lenses; resolution test charts; resolving power.

This publication supersedes NBS Circular 533, issued May 20, 1953. It contains the original data and a new appendix describing the NBS Microcopy Resolution Test Charts No. 1010a. It provides the photographer with two sets of charts by which the resolving power of a photographic lens may be numerically measured with respect to a definite scale of values. A detailed description is given of the procedure and technique to be followed in order that comparable values may be obtained by different observers. The test provides an objective method of testing a photographic lens. The six charts of one set are printed in black on a white background to form a high-contrast chart. The six charts of the other set are printed with gray ink on a gray background to form a low-contrast chart. Additional uses of these charts are also described. These uses include the testing of goggle lenses for definition and prismatic power and the testing of telescopes and binoculars for definition. Supersedes NBS Circular 533, issued May 1953.

SP375. An index of State specifications and standards, covering those standards and specifications issued by State Purchasing Offices of the United States, L. L. Grossnickle, Editor, Nat. Bur. Stand. (U.S.), Spec. Publ. 375, 394 pages (Sept. 1973) \$3.70, SD Catalog No. C13.10:375.

Key words: Index of State specifications and standards; KeyWord-In-Context index of State specifications and standards; purchase specifications and standards, State; specifications,

State; standards, State; State specifications and standards.

This computer-produced Index contains the permuted titles of more than 6,000 State purchasing specifications and standards issued by 37 State Purchasing Offices thru 1971. The title of each specification and standard can be found under all the significant key words which it contains. These key words are arranged alphabetically down the center of each page together with their surrounding context. The date of publication or latest revision, the specification or standard number, and an abbreviation for each State appear as part of each entry. A list of these abbreviations and the names and addresses of the State Purchasing Officials are found at the beginning of the Index.

SP377. Index to the reports of the National Conference on Weights and Measures. From the First to the Fifty-sixth 1905 to 1971 , F. C. Bell, Nat. Bur. Stand. (U.S.), Spec. Publ. 377, 46 pages ( Feb. 1973) 75 cents, SD Catalog No. C13.10:377.

Key words: Index; measures; National Conference; reports; weights.

This publication comprises a subject index and a speaker index for the Reports of the National Conference on Weights and Measures from the First (1905) through the Fifty-Sixth (1971). Supersedes Miscellaneous Publication 243

SP383. The creative partnership: Government and the professional services, Proceedings of the Fourth Users-Producers Conference Sponsored by the Technical Analysis Division, Institute for Applied Technology, National Bureau of Standards, in Cooperation with the Center for the Study of Private Enterprise, The American University, held at the National Bureau of Standards. Gaithersburg, Md., January 23, 1973, J. D. Johnson, Ed., Nat. Bur. Stand. (U.S.), Spec. Publ. 383, 142 pages (Aug. 1973) \$2.10, SD Catalog No. C13.10:383. 
Key words: Creative-partnership; management; operating; procurement; services; Users-Producers.

These proceedings are written for the 4th Users-Producers Conference held at the National Bureau of Standards on January 23, 1973. The Conference was designed to highlight the problems and advantages in our present procurement system when Government utilizes the services of professional and Professions Service firms.

The speakers addressed themselves to the many facets of the procurement process. They represent both the private and Government side and bring their views forward in a clear and concise manner. Speakers are grouped into three panels. The first panel describes the development of the problem, the second panel considers the procurement process, and the third panel discusses managing the project. At the end of each group of panel speeches, there is a general discussion with comments and questions by all attendees.

There is also a separate presentation given by the Honorable James C. Corman, United States Congressman (Calif.), Chairman, SubCommittee on Government Procurement of Professional Services. These proceedings include the following papers (indented):

Management information and computer systems, R. M. Davis.

Management consulting, W. P. Sommers.

Architecture and engineering, J. R. Dunn.

Operating level problems in procurement, W. E. Cushen.

Government procurement policy, $\mathrm{P}$. W aterman.

The relationship of private enterprise to Government procurement, R. W. Kreuger.

Legal aspects of Government procurement, G. P. Bond.

A proposed Government system for professional services, J. E. Moriarty.

Government project management, T. F. Noble.

Managing the private contractor, $\mathrm{R}$. A. Walbrecker.

Managing the university research team, R. P. Boynton.

SP384. Annotated bibliography of the literature on resource sharing computer networks, R. P. Blanc, I. W. Cotton, T. N. Pyke, Jr., and S. W. Watkins, Nat. Bur. Stand. (U.S.), Spec. Publ. 384, 95 pages (Sept. 1973) \$1.25, SD Catalog No. C13.10:384.

Key words: Bibliography; computer network; data communica tions; resource sharing.

This bibliography consists of references with critical annotations to the literature on computer networks. A classification scheme has been developed to place each annotation in a category reflective of its content. Five indexes to the bibliography are included: author index, corporate author index, network index, key word out of context index, and report number index.

NSRDS-NBS46. Reactivity of the hydroxyl radical in aqueous solutions, L. M. Dorfman, G. E. Adams, Nat. Stand. Ref. Data Ser., Nat. Bur. Stand. (U.S.), 46, 72 pages (June 1973) 90 cents, SD Catalog No. C13.48:46.

Key words: Abstraction reactions; addition reactions; aqueous solution; biological molecules; electron transfer reactions; hydroxyl radical; oxide radical ion; radical reactions; rate constants; reference data.

The reaction rate data of the hydroxyl radical in aqueous solution are compiled and evaluated in this critical review. The values are reported in a series of tables covering additon, hydrogen abstraction, inorganic electron transfer and radical reactions. Rate constants for the hydroxyl radical with biological molecules are included. In addition, the rate constant data for the oxide radical ion are given. Physical properties are listed and the experimental methods employed in $\mathrm{OH}$ radical chemistry are reviewed. An analysis involving rate constant data comparisons is made.
NSRDS-NBS 50. Resonances in electron impact on atoms and diatomic molecules, G. J. Schulz, Nat. Stand. Ref. Data Ser., Nat. Bur. Stand. (U.S.), 50, 118 pages (Oct. 1973) \$1.35, SD Catalog No. C13.48:50.

Key words: Atoms; compound states; cross-sections; diatomic molecules; electron impact; energy levels; resonances; temporary negative ions.

Two reviews are presented on the energies, configuration and other properties of resonances in electron impact on atoms and diatomic molecules. Included are discussions of the experimental methods which are useful for studying resonances and of the results obtained by various investigations. Much of the information is presented in the form of tables and energy level diagrams.

BSS45. Dynamic thermal performance of an experimental masonry building, B. A. Peavy, F. J. Powell, and D. M. Burch, Nat. Bur. Stand. (U.S.), Bldg. Sci. Ser. 45, 103 pages (July 1973) \$1.25, SD Catalog No. C13.29/2:45.

Key words: Building heat transfer; computer programs; dynamic thermal performance; heat flow analysis; heating and cooling loads; temperature predictions; thermal analysis; thermal behavior; transient heat flows.

Measurements of the dynamic heat transfer in an experimental masonry building were made in a large environmental chamber to explore the validity of a computer program developed at NBS, labeled NBSLD, for computing heating and cooling loads, and indoor air temperatures. This study was jointly supported by the National Bureau of Standards and the Department of Housing and Urban Development, and is a part of a broader research program being supported by both agencies to improve performance test procedures and criteria for housing.

The experimental structure was a one-room house $20 \mathrm{ft}$ long $20 \mathrm{ft}$ wide, and $10 \mathrm{ft}$ high with walls of solid concrete blocks and a flat roof made of reinforced precast concrete slabs. During the tests changes were made in fenestration, the amount and location of insulation, and the indoor mass; and the building was exposed to a diurnal temperature cycle.

It was found that the combination of mass in the masonry walls and roof, and insulation placed on the outside of the masonry was very effective in reducing and controlling the variation of indoor air temperature. The NBSLD computer program realistically predicted the heat storage effects, and maximum heating loads during these tests. For five heating tests, the greatest difference between computed maximum heating load and measured values was 8 percent and the average difference was 4.3 percent. It was shown that steady-state methods of heating load calculation could result in oversizing heating equipment by 30 percent or more for this particular building and imposed exterior conditions if the lowest outdoor temperature was selected as the design temperature.

BSS46. Building practices for disaster mitigation. Proceedings of a workshop sponsored by The National Science Foundation, Research Applied to National Needs Program, and The National Bureau of Standards, held at the National Bureau of Standards, Boulder, Colo., Aug. 28-Sept. 1, 1972. R. Wright, S. Kramer, and C. Culver, Editors, Nat. Bur. Stand. (U.S.), Bldg. Sci. Ser. 46, 483 pages (Feb. 1973) \$5.30, SD Catalog No. C13.29/2:46.

Key words: Building; earthquakes; hazards; land use; structural engineering; wind effects.

The national workshop on building practices for disaster mitigation was concerned with earthquakes, extreme winds, and similar dynamic hazards. These proceedings present recommendations derived at the workshop and addressed to policy makers in government and industry, as well as practitioners in engineering, architecture, land use 
planning, and the earth and meteorological sciences. The recommendations evaluate current building practices, define opportunities for improving current practice from documented research findings, and recommend research to fill gaps in knowledge. Recommendations are made for implementation of improved practices at professional and policy levels. The objectives include avoidance of human suffering, reduction of property loss, and maintenance of vital function in buildings under conditions threatening disaster. Fifteen review articles were prepared by experts in the professions and research disciplines to define the state-of-the-art in disaster mitigation and to guide discussions at the workshop. These articles are included in the proceedings as follows:

Workshop Recommendations.

Values and costs, H. Kunreuther.

Approaches to implementation, P. E. Baseler.

Earthquake hazards for buildings, N. C. Donovan.

The problem of seismic zoning, $S$. T. Algermissen.

Wind hazards for buildings, J. W. Vellozzi and J. J. Healey.

Land use planning and natural disaster mitigation, W. J. Petak, M. McCoy, W. J. Monasch, J. E. Slosson, D. F. Moran, J. H. Wiggins, Jr.

Architectural approaches to hazard mitigation, E. C. Hillman Jr., A. E. Mann.

Procedures and criteria for earthquake resistant design, C. W. Pinkham.

Procedures and criteria for earthquake resistant design, N. M. Newmark and W. J. Hall.

Procedures and criteria for wind resistant design, J. W. Vellozzi and J. J. Healey.

Criteria for building services and furnishings, J. M. Ayres and T.-Y.Sun.

Behavior of structural elements. A review, B. Bresler.

Behavior of structural systems under dynamic loads, R. L. Sharpe, G. Kost, and J. Lord.

Survey and evaluation of existing buildings, F. E. McClure. Abnormal loading on buildings and progressive collapse, N. F. Somes.

BSS47. Structural deflections. A literature and state-of-theart survey, T. V. Galambos, P. L. Gould, M. K. Ravindra, H. Suryoutomo, and R. A. Crist, Nat. Bur. Stand. (U.S.), Bldg. Sci. Ser. 47, 104 pages (Oct. 1973) \$1.25, SD Catalog No. C13.29/2:47.

Key words: Analysis; deflection; design; dynamic; experimental; human sensitivity; loading functions; specifications; static; structural engineering; subsystems; vibration.

A literature survey and state-of-the-art study was compiled using 233 primary source documents, research papers, and texts. Over 800 documents were scanned to arrive at the primary source documents. The problem of structural deflections is discussed and reviewed in its component areas of static and dynamic deflections as related to forcing functions and structural characteristics. Also the interactions of major structural deflections with building structures subsystems and human occupants is reviewed. Emphasis is placed on serviceability limit states of deflections. Detailed comparisons of human response to structural vibrations are also made. This report is broad in scope and covers the areas of analysis, design and experimentation.

FIPS PUB 6-2. Counties and county equivalents of the states of the United States, H. E. McEwen, Standards Coordinator, Nat. Bur. Stand. (U.S.), Fed. Info. Process. Stand. Publ. (FIPS Pub) 6-2, 35 pages (1973) 65 cents, SD Catalog No. C13.52:6-2.

Key words: ADP standards; computers; data elements and codes; data processing; Federal Information Processing Standards; geography; information processing standards; information systems; national government; representations and codes; standards; statistical data.
This publication provides names and codes for representing the Counties of the 50 States or county equivalents thereof for use in the interchange of formatted machine sensible data. Also included in the set of codes are the independent cities of Maryland, Missouri, Nevada, and Virginia and the Census Divisions and boroughs of Alaska. Supersedes NBS FIPS Pub 6-1.

FIPS PUB 8-3. Standard metropolitan statistical areas, H. E. McEwen, Standards Coordinator, Nat. Bur. Stand. (U.S.), Fed. Info. Process. Stand. Publ. (FIPS PUB) 8-3, 20 pages (1973) 55 cents, SD Catalog No. C13.52:8-3.

Key words: Computers; data processing; Federal Information Processing Standards Publication; representations and codes; Standard Metropolitan Statistical Areas.

This publication provides standard identifications and codes for representing Standard Metropolitan Statistical Areas for the interchange of machine sensible data among agencies. It supersedes FIPS PUB 8-2, Standard Metropolitan Statistical Areas, dated 1972 November 1. The general concept of a Standard Metropolitan Statistical Area, commonly referred to as "SMSA" is one of an integrated economic and social unit with a recognized large population nucleus. The codes are available on Hollerith punched cards. The following data elements are provided: SMSA Title (Name) and SMSA Code. Supersedes FIPS PUB 8-2.

FIPS PUB 23. Objectives and requirements of the Federal Information Processing Standards Program, H. S. White, Jr., Nat. Bur. Stand. (U.S.), Fed. Info. Process. Stand. Publ. (FIPS Pub.) 23, 8 pages (1972) 35 cents, SD Catalog No. C13.52:23.

Key words: Computers; data processing; Federal Information Processing Standards; management; standards; U.S. Government.

Public Law 89-306 (the Brooks legislation) was enacted to provide for the economic and efficient purchase, lease, maintenance, operation and utilization of automatic data processing equipment by Federal departments and agencies. Among the other provisions of PL89-306, the Secretary of Commerce is authorized to make appropriate recommendations to the President relating to the establishment of uniform Federal automatic data processing standards. The Federal Information Processing Standards Program was established in response to this part of the legislation. The purpose of this document is to outline the objectives of the Federal Information Processing Standards Program and to identify requirements for specific standards necessary to accomplish these objectives.

FIPS PUB 26. One-inch perforated paper tape for information interchange, P. S. Johnson, Standards Coordinator, Nat. Bur. Stand. (U.S.), Fed. Info. Process. Stand. Publ. (FIPS PUB) 26, 4 pages (1973) 20 cents, SD Catalog No. C13.52:26.

Key words: Data processing; Federal Information Processing Standard; information interchange; information processing; paper tape; paper perforator tape.

This standard specifies the physical dimensions and tolerances of one-inch wide paper tape, including the size and location of the perforations used for recording information.

PS54-72. Body measurements for the sizing of girls' apparel, C. W. Devereux, II, Technical Standards Coordinator, Nat. Bur. Stand. (U.S.), Prod. Stand. 54-72, 19 pages (July 1973) 30 cents, SD Catalog No. C13.20/54-72.

Key words: Apparel, girls'; body measurements, girls'; classifications, girls' size; grading charts, girls' size; size designations, girls'; span charts, girls' sizing.

This Voluntary Product Standard establishes a nationally recog. nized sizing system for girls, based on body measurements. The stan- 
dard covers three classifications: slims, regulars, and chubbies. In each classification, sizes $7,8,10,12,14$, and 16 are defined by 33 body measurements.

TN627. Computation of spectral data for a Josephson junction circuit, E. G. Johnson, Jr. and D. G. McDonald, Nat. Bur. Stand. (U.S.), Tech. Note 627, 63 pages (Nov. 1972) 60 cents, SD Catalog No. C13.46:627.

Key words: Differential equation; fast Fourier transform; Josephson junction; nonlinear integral-differential equation; spline theory.

A computer program has been developed to study power flow between different frequency channels in a Josephson junction circuit. This paper discusses the mathematical assumptions used to get such results. They are the trapezoidal approximation from spline theory and the use of a finite range of frequencies to characterize the frequency spectrum. This paper describes the program and provides the FORTRAN listing, flow charts, and discusses how to use the program. A discussion of possible sources of errors is also included.

TN629. Superconducting quantum interference devices: An operational guide for $\mathbf{r f - b i a s e d ~ s y s t e m s , ~ D . ~ B . ~ S u l l i v a n , ~ N a t . ~}$ Bur. Stand. (U.S.), Tech. Note 629, 47 pages (Nov. 1972) 50 cents, SD Catalog No. C13.46:629.

Key words: Electrical measurements; quantum interference devices; superconductivity.

The report discusses a number of practical considerations concerning the operation and application of rf-biased Superconducting QUantum Interference Devices (SQUID's). In the course of routine operation of these devices one amasses a set of operational rules, many of which never reach the open literature. This report is aimed at filling that void. Topics of discussion include: the readout circuitry, operational limits of the SQUID, rf-coupling to the SQUID, flux transformers, and shielding.

TN630. Developments in cryoelectronics, R. A. Kamper and D. B. Sullivan, Nat. Bur. Stand. (U.S.), Tech. Note 630, 73 pages (Nov. 1972) 70 cents, SD Catalog No. C13.46:630.

Key words: Electronics; Josephson effect; precise measurements; superconductivity.

This is a survey of progress to date in the development of new electronic instruments taking advantage of the unique properties of superconductors.

TN633. Critical two-phase flow for cryogenic fluids, R. V. Smith, K. R. Randall, and R. Epp, Nat. Bur. Stand. (U.S.), Tech. Note 633, 80 pages (Jan. 1973) 70 cents, SD Catalog No. C13.46:633.

Key words: Analyses; analytical models; choking flow; critical flow; cryogenic fluids; helium; hydrogen; oxygen; reviews; twophase flow.

This work presents a state-of-the-art survey intended to be useful to a designer of equipment involving two-phase flow of cryogenic fluids. It is desirable to assess the probability of critical, or choking, flow in such a system and, if possible, estimate the critical flow rate. The literature is surveyed, primarily since Smith (1963), and the predictive results for several analytical models are evaluated and compared with experimental data. These results are discussed; however, no firm conclusions are reached because, often, the spread of experimental data is equivalent to the predictive results from the models. Finally, computer evaluations are presented for oxygen, hydrogen and helium along with some design recommendations.

TN638. A synchronous satellite time delay computer, W. F. Hamilton and D. W. Hanson, Nat. Bur. Stand. (U.S.), Tech. Note 638, 39 pages (July 1973) 45 cents, SD Catalog No. C13.46:638.
Key words: Satellite timing; slant range; synchronous satellites; time delay.

A special purpose slide rule designed to compute the free space propagation delay between a synchronous satellite and points on the earth's surface is discussed. The slide rule was developed to provide users of time information relayed by geostationary satellites a means of computing the propagation delays without dealing directly with the satellite's orbital elements. The delays computed with the slide rule are compared with the values obtained from orbital elements using a high precision digitial computer. The limitations and accuracy of the slide rule are discussed. A sample slide rule which may be cut out and used is included in the report.

TN639. Publications and services of the National Bureau of Standards, Cryogenics Division, Institute for Basic Standards, Boulder, Colo. 80302, 1953-1972, J. R. Mendenhall, V. J. Johnson, and N. A. Olien, Nat. Bur. Stand. (U.S.), Tech. Note 639, 82 pages (Aug. 1973) 75 cents, SD Catalog No. C13.46:639.

Key words: Author indexes; bibliography; cryogenics; liquefaction; metrology; properties of fluids; properties of solids; subject indexes; superconductivity; transport processes.

This NBS Technical Note catalogs the publications of the Cryogenics Division, along with author and subject indexes, for the period 1953 through 1972. It also contains a listing of available thermodynamic properties charts, bibliographies, and miscellaneaous reports of cryogenic interest.

A resumé of the activities of and services provided by the Cryogenics Division is also included.

TN640. Considerations for the precise measurement of amplifier noise, D. F. Wait, Nat. Bur. Stand. (U.S.), Tech. Note 640, 129 pages (Aug. 1973) \$1.25, SD Catalog No. C13.10.46:640.

Key words: Amplifier noise; effective input noise temperature; mismatch error; mismatch uncertainty; noise figure.

For the best accuracy in measuring noise figure, attention needs to be given to the choice of the hot and the cold noise standards and to mismatch problems. Tables and graphs are presented to aid in choosing the proper measurement conditions, and an example is given to demonstrate their use. This paper essentially supplements a previous paper (included in an appendix), treating in more detail topics that become important when state-of-the-art measurements are required.

TN643. Measurement of $\mathrm{rf}$ power and attenuation using superconducting quantum interference devices, $R$. A. Kamper, M. B. Simmonds, C. A. Hoer, and R. T. Adair, Nat. Bur. Stand. (U.S.), Tech. Note 643, 93 pages (Aug. 1973) \$1.00, SD Catalog No. C13.46:643.

Key words: Josephson effect; quantum interference; rf attenuation; rf measurement; $r f$ power; superconductivity.

This report is the product of the first two years' work on a project to exploit an entirely new principle for the measurement of rf power and attenuation, namely the Superconducting QUantum Interference Device (SQUID). This is a simple circuit of superconducting metal, operating at a very low temperature in a bath of liquid helium. It functions as a sensor of magnetic flux with an almost perfectly periodic response over a wide dynamic range. It may therefore be used to measure dc or rf electrical quantitites such as current, power, attenuation, etc., in circuits inductively coupled to it. Measurements of these quantities can be made by counting off periods in the response of the SQUID (flux quanta) in the same way that we measure length with a laser by counting off wavelengths of light.

This work is partly funded by the CCG under project number 72 72. It has reached the stage of a demonstration that the new principle can indeed be used for precise measurement. We have developed 
and tested prototype systems for measuring power and attenuation as accurately as we can test by the conventional means available to us. A single calibration with dc is required to measure absolute rf power in the range of frequency from 0 to $1 \mathrm{GHz}$ at levels from $10^{-8} \mathrm{~W}$ to $10^{-3} \mathrm{~W}$ with an uncertainty of $\pm 0.1 \mathrm{~dB}$ at the port of the SQUID. Transferring this measurement to calibrate a source of power would require a proper evaluation of the intervening network over the full range of frequency. We have demonstrated the feasibility of extending our measurements of power to much lower levels. No external calibration is required to measure of attenuation directly over a dynamic range of $45 \mathrm{~dB}$ with an rms deviation of $\pm 0.002 \mathrm{~dB}$ from calibrations performed by the NBS Calibration Service.

After an elementary exposition of the basic principles of our technique, we describe: the SQUIDs themselves; the prototype systems we have developed to measure rf power and attenuation; systematic errors and fundamental limitations of the measurements that can be performed with them; and the obvious and immediate improvements that can be applied to them. We reserve an appendix for detailed drawings and instructions for the fabrication of components.

In order to make this report self-contained, we have included the material from previous reports that has successfully withstood the test of time.

TN748. An adjoint gamma-ray moments computer code, ADJMOM-I, G. L. Simmons, Nat. Bur. Stand. (U.S.), Tech. Note 748, 23 pages (Feb. 1973) 30 cents, SD Catalog No. C13.46:748.

Key words: Adjoint; buildup factor; dosimetry; gamma-ray transport; moment methods; shielding.

In this paper we discuss a computer code for generating spatialangular moments of the adjoint gamma-ray flux in an infinite medium. The equation for the flux moments is given and techniques used for the solution are described. Details of the input data and a sample problem are also supplied.

TN751. Studies of calibration standards used in the Department of Defense Equipment Oil Analysis Program, D. W. Golightly and J. L. Weber, Nat. Bur. Stand. (U.S.), Tech. Note 751, 48 pages (Jan. 1973) 75 cents, SD Catalog No. C13.46:751.

Key words: Calibration standards; concentration validity; flash point; lubricating oil; pour point; spectrometric analysis; stability; trace elements; viscosity.

At the request of the Naval Systems Air Command, Department of the Navy, studies have been conducted on organo-metallic calibration standards and diluent oil used in the Department of Defense Equipment Oil Analysis Program. Consultation on standards has been provided, and measurements of physical properties of base oil, concentrations of major elements in standards, concentrations of trace contaminants, and stability of solutions have been performed. Results of studies accomplished in fiscal year 1972 are detailed in this report.

TN752. Directory of law enforcement and criminal justice associations and research centers, B. J. Latka, Nat. Bur. Stand. (U.S.), Tech. Note 752, 49 pages (June 1973) 80 cents, SD Catalog No. C13.46:752.

Key words: Associations; criminal justice; directory, law enforcement; research centers.

This directory lists national, non-profit professional and volunteer social action associations and research centers which are active in the fields of law enforcement and criminal justice. The International and foreign organizations which are listed either have a large number of American members, have a United States chapter, or are doing work which is applicable to the United States. The local organizations which are listed either cover several states or are of national interest. The organizations are listed alphabetically with a subject index included. The format of an entry is: title of organization; mailing ad- dress; officer; telephone number; year when founded; number of members, number of staff; description of purpose and activities; affiliations; publications, meetings.

TN753. NBS Special Foreign Currency Program in Yugoslavia 1971-72, H. S. Peiser, S. E. Chappell, E. Horowitz, H. Yakowitz, and D. Bluebond, Nat. Bur. Stand. (U.S.), Tech. Note 753, 72 pages (Jan. 1973) 90 cents, SD Catalog No. C13.46:753.

Key words: Binational research cooperation; international scientific cooperation; physical science research administration; research planning; scientific research abstracts; Special Foreign Currency Program; Yugoslavia science and technology.

An overview is given of grants awarded by the National Bureau of Standards under the Special Foreign Currency Program (SFCP) in Yugoslavia, authorized by Public Law 480 and other legislation. Each grant is identified by title, principal investigator, institution in $\mathrm{Yu}$ goslavia, NBS monitor, and the monitor's organizational unit within NBE. The work is then described briefly under the three headings "Summary Description of Project Goals," "Results and Implications to Date" and "List of Publications that Resulted from the Project." To demonstrate the relevance of such grants to the programs of NBS, the grant descriptions are ordered by the elements of that Program Structure. The significance and purpose of the NBS/SFCP grant program are discussed in the Foreword, the Introduction and an Appendix. The NBS monitors and the program manager judge this grant program to have had a high benefit to cost ratio from the viewpoint of NBS.

TN754. Methods of measurement for semiconductor materials, process control, and devices. Quarterly report July 1 to September 30, 1972, W. M. Bullis, Editor, Nat. Bur. Stand. (U.S.), Tech. Note 754, 55 pages (Mar. 1973) 80 cents, SD Catalog No. C13.46:754.

Key words: Aluminum wire; base transit time; carrier lifetime; die attachment; electrical properties; epitaxial silicon; gammaray detectors; generation centers; germanium; gold-doped silicon; infrared response; methods of measurement; microelectronics; microwave diodes; nuclear radiation detectors; probe techniques (a-c); recombination centers; resistivity; ribbon wire bonding; semiconductor devices; semiconductor materials; semiconductor process control; silicon; thermal resistance; trapping centers; ultrasonic bonding; wire bonds.

This quarterly progress report, seventeenth of a series, describes NBS activities directed toward the development of methods of measurement for semiconductor materials, process control, and devices. Significant accomplishments during this reporting period include design of a plan to provide standard silicon wafers for four-probe resistivity measurements for the industry, publication of a summary report on the photoconductive decay method for measuring carrier lifetime, publication of a comprehensive review of the field of wire bond fabrication and testing, and successful completion of organizational activity leading to the establishment of a new group on quality and hardness assurance in ASTM Committee F-1 on Electronics. Work is continuing on measurement of resistivity of semiconductor crystals; characterization of generation-recombination-trapping centers in silicon; study of gold-doped silicon; development of the infrared response technique; evaluation of wire bonds and die attachment; and measurement of thermal properties of semiconductor devices, delay time and related carrier transport properties in junction devices, and noise properties of microwave diodes. New efforts were initiated in both the die attachment and wire bond evaluation tasks. Supplementary data concerning staff, standards committee activities, technical services, and publications are included as appendixes. A description of breakdown tracks, a primary failure mode of monolithic integrated circuits stressed with voltage pulses, is given in a separate appendix. 
TN755. Some aspects of the setring and hardening of gypsum plaster, J. R. Clifton, Nat. Bur. Stand. (U.S.), Tech. Note 755, 33 pages (Jan. 1973) 55 cents, SD Catalog No. C13.46:755.

Key words: Colloidal theory; crystallization theory; gypsum; hydration; induction period; plaster of paris; setting mechanisms.

The mechanisms by which gypsum plaster sets and hardens have been investigated and the results generally are consistent with the crystallization theory. No evidence for the presence of colloidal intermediates has been found. The crystallization theory is modified to include, as an intermediate species, solvated calcium sulfate hemihydrate molecules. Evidence is presented that supports the belief that more than one reaction is responsible for the setting and hardening of gypsum plaster.

The roles of accelerators and retarders have been studied by calorimetric, differential thermal analysis, and scanning electron microscopic techniques. The cation is more effective than the anion in accelerating the setting and hardening of gypsum plasters; the catalytic order follows the sequence $\mathrm{M}^{+} \mathrm{M}^{2+} \mathrm{M}^{3+}$. Small amounts of retarders can severely retard the setting and hardening processes.

Influences of temperature, impurities, and production conditions on the setting rates of gypsum plasters are discussed.

TN757. The smoke density chamber method for evaluating the potential smoke generation of building materials, $T$. G. Lee, Nat. Bur. Stand. (U.S.), Tech. Note 757, 20 pages (Jan. 1973) 45 cents, SD Catalog No. C13.46:757.

Key words: Building materials; fire; fire services; smoke; smoke density chamber; smoke potential; test method; visibility.

The paper reviews the Smoke Density Chamber Test Method and illustrates its use and application to assess smoke generation of build ing materials in fire situations. It shows how test results may aid the Fire Services and code authorities in evaluating and reducing the potential light-obscuration hazard of smoke in buildings. An example is given for calculating visibility in a simplified fire situation involving material of known smoke generation. The smoke generation of some common interior finish and construction materials is given.

TN759. The NBS lead paint poisoning project: Housing and other aspects, H. W. Berger, Nat. Bur. Stand. (U.S.), Tech. Note 759, 25 pages (Feb. 1973) 30 cents, SD Catalog No. C13.46:759.

Key words: Hazard elimination; lead analysis; lead paint; lead poisoning.

The National Bureau of Standards is providing technical support required by the Department of Housing and Urban Development to carry out its research responsibilities under PL 91-695, The Lead Based Paint Poisoning Prevention Act. The program at NBS has involved three major areas of research: (1) an estimation of the num bers of children at risk and with excessive body burdens of lead and the geographical distribution of those children; (2) the capabilities and characteristics of analytical methods for the detection of lead in paint and other building materials; and (3) the identification and evaluation of materials, techniques and systems for removing or eliminating the lead paint hazard from housing. This paper is a brief presentation of the activities and conclusions of NBS in the areas listed above.

TN767. Microelectronic interconnection bonding with ribbon wire, H. K. Kessler and A. H. Sher, Nat. Bur. Stand. (U.S.), Tech. Note 767, 31 pages (Apr. 1973) 50 cents, SD Catalog No. C13.46:767.

Key words: Aluminum wire; bonding; fabrication (wire bonds); microelectronics; ribbon wire; round wire; testing (wire bond); ultrasonic bonding; wire bond.
The feasibility of using aluminum ribbon wire for ultrasonic bonding of semiconductor microelectronic interconnections was studied, and several advantages over the use of round wire of equivalent cross-sectional area were found. Ribbon wire bonds exhibited little deformation or heel damage, and a greater percentage of bonds of a certain quality (as judged by pull strength and appearance) could be made over much greater ranges of the bonding machine parameters, time and tool tip displacement, using ribbon wire than was possible with round wire. The ease of positioning ribbon wire was indicated by making multiple ribbon wire bonds side-by-side on a 5 -mil square pad, or by stacking up to four bonds one on top of another. However, bonding with harder than normal wire, previously thought to offer certain advantages with respect to higher bond tensile strength, yielded inconsistent results.

TN769. A rigorous correction procedure for quantitative electron probe microanalysis (COR 2), J. Hénoc, K. F. J. Heinrich, and R. L. Myklebust, Nat. Bur. Stand. (U.S.), Tech. Note 769, 132 pages (Aug. 1973) \$2.10, SD Catalog No. C13.46:769.

Key words: Continuum fluorescence; data reduction; electron probe microanalysis; fluorescence correction; quantitative anal. ysis.

This publication describes a rigorous data reduction procedure for quantitative electron probe microanalysis, which avoids simplifications present in conventional schemes. In addition, the program contains a correction for fluorescence due to the continuum, and separate computation of the fluorescent effects of each exciting primary x-ray line. Constants characteristic of elements are stored in a permanent data file, and the constants and parameters needed for the calculation of mass absorption coefficients are contained in a subprogram. These provisions and decision-making sections in the development of the fluorescence corrections reduce the required input considerably.

TN777. Cost analysis of blood banking alternatives, T. Miller, M. King, J. Flannagan, E. Nilsson, and B. Lemieux, Nat. Bur. Stand. (U.S.), Tech. Note 777, 121 pages (Sept. 1973) \$1.35, SD Catalog No. C.13.46:777.

Key words: Blood banks; blood utilization statistics; cost benefit analysis; donor profiles; peer review; regulatory activities; sensitivity analysis.

This report provides a description of the current blood banking system and of the collection and derivation of quantitative information concerning system operation and blood cost. A reasonably accurate but somewhat incomplete profile of practices, attitudes, and likely costs of present and alternative systems has been developed. Among the topics presented are: 1) a discussion of the blood collection process including statistics on present use and future needs; 2) information relating to donor motivation, attitudes and incentives; 3) a brief summary of demonstration programs in the U.S. and national blood programs in other countries which provides some insight concerning means for improving blood quality and availability; 4) a description of blood processing, storage and distribution procedures; 5 ) narrative and statistical information relating to blood utilization practices; 6) discussions of post transfusion reactions and frozen blood programs; 7) a discussion of current governmental and professional standards, regulations and controls which influence many, but not all, concerns involved in blood collection and processing.

This information serves as the basis for the selection of alternatives analyzed in a cost effectiveness analysis of eight apparently viable alternatives to the current system. Because of the possible variation which might be ascribed to many of the parameters used as a basis for costing alternatives, the sensitivity analysis is crucial in the comparison of alternatives. 
TN779. Data communications system throughput performance using high speed terminals on the dial telephone network, D. S. Grubb, Nat. Bur. Stand. (U.S.), Tech. Note 779, 40 pages (May 1973) 65 cents, SD Catalog C13.46:779.

Key words: Data communications; modems; terminals; throughput; TRIB.

Throughput performance of high speed data terminals using the dial telephone network is calculated for signaling rate of 1200 to 4800 bits per second using the ANSI X3.28-1971 control procedures and measured in terms of the proposed ANSI strand TRIB described in X3S35/80. The performance calculations are shown graphically with TRIB as a function of block length, error rates of the telephone connection, signaling rate and telephone line delays. Error rates are based on a published survey involving several hundred telephone connections to geographically distributed parts of the United States.

TN783. Durability and maintenance as related to the selection of flooring, W. C. Wolfe, R. F. Roberts, and M. Russell, Nat. Bur. Stand. (U.S.), Tech. Note 783, 68 pages (Aug. 1973) 90 cents, SD Catalog No. C13.46:783.

Key words: Carpets; durability; economics; field studies; flooring; floor coverings; life-cost; maintenance; user needs.

This report is addressed to the problem of selection and maintenance of flooring to the best advantage in terms of durability, type and severity of service, appearance, comfort, and safety. The selection of flooring is discussed with respect to service life, maintenance, obsolescence, and trade-off advantages. Two articles by maintenance administrators include information and discussion helpful in determining maintenance cost, trade-offs, and selection of flooring for different types of service. Field observations and preliminary field tests by the National Bureau of Standards indicate areas in which research is needed, as in laboratory tests for wear and slip resistance. Observations and field tests are impracticable to use for procurement.

This report is helpful in the selection and maintenance of flooring and floor finishes. More important, it points up areas in which research is needed to develop information for this purpose.

TN785. Scanning electron microscope examination of wire bonds from high-reliability devices, K. O. Leedy, Nat. Bur. Stand. (U.S.), Tech. Note 785, 35 pages (Aug. 1973) 55 cents, SD Catalog No. C13.46:785.

Key words: Aluminum wire; high reliability; integrated circuit; metallization; scanning electron microscope; transistor; ultrasonic bonding; wire bonding.

An examination with a scanning electron microscope was made of the wire bonds of over 75 high-reliability microelectronic devices. The device interconnects were ultrasonically bonded aluminum wires. Of primary interest were the bonds themselves; their appearance and its significance are described. Also described is the appearance of the metallization and the wire. Comments and explanations are given where the phenomena are understood. Although the devices studied had passed preliminary electrical tests and pre-encapsulation visual examinations, many potential reliability problems were identified such as weak bonds, electrical shorts and contamination.

TN786. Methods for testing wire-bond electrical connections, H. A. Schafft, Nat. Bur. Stand. (U.S.), Tech. Note 786, 23 pages (Nov. 1973) 50 cents, SD Catalog No. C13.46:786.

Key words: Bonding; electrical connection; failure (wire bond); integrated circuits; microelectronics; reliability; semiconductor devices; testing (wire bond); wire bond.

A significant fraction of the failures that occur in integrated cir- cuits are due to failures of the wire-bond electrical connections that are used. Therefore, a critical area for reliability improvement is in the methods for testing and evaluating wire bonds. Several of these methods are surveyed. In particular, analyses with regard to the stress that the test imposes on the wire bond in the pull, centrifuge, mechanical shock, vibration, and temperature cycling tests are presented and used in discussing the capabilities and limitations of these methods.

TN788. Methods of measurement for semiconductor materials, process control, and devices, quarterly report January 1 to March 31, 1973, W. M. Bullis, Editor, Nat. Bur. Stand. (U.S.), Tech. Note 788, 79 pages (Aug. 1973) 95 cents, SD Catalog No. C13.46.788.

Key words: Base transit time; carrier lifetime; delay time; die attachment; electrical properties; electronics; epitaxial silicon; four-probe method; generation centers; germanium; gold-doped silicon; infrared response; methods of measurement; microelectronics; microwave diodes; probing techniques (a-c); pull test; recombination centers; resistivity; resistivity standards; semiconductor devices; semiconductor materials; semiconductor process control; silicon; S-parameters; switching transients; thermal resistance; thermally stimulated properties; trapping centers; wire bonds.

This quarterly progress report, nineteenth of a series, describes NBS activities directed toward the development of methods of measurement for semiconductor materials, process control, and devices. Significant accomplishments during this reporting period include (1) development of a comprehensive, large-area test pattern for evaluating planar junction structures, (2) completion of experimental work on the evaluation of the destructive, double-bond pull test for wire bonds, (3) initiation of a scanning electron microscope facility, and (4) completion of the investigation of the mechanism of emitter-base junction reverse breakdown during rapid switching of transistors. Because of the general applicability of the last of these, details are presented in a separate appendix. Work is continuing on measurement of resistivity of semiconductor crystals; characterization of generation-recombination-trapping centers in silicon; study of golddoped silicon; development of the infrared response technique; evaluation of wire bonds and die attachment; measurement of thermal properties of semiconductor devices; determination of S-parameters, delay time, and related carrier transport properties in junction devices; development of a-c probing techniques; and characterization of noise and conversion loss of microwave detector diodes. Supplementary data concerning staff, standards committee activities, technical services, and publications are included as appendices.

TN789. Technical options for energy conservation in buildings, National Conference of States on Building Codes and Standards and National Bureau of Standards Joint Emergency Workshop on Energy Conservation in Buildings held at the U.S. Department of Commerce Washington, D.C., June 19, 1973, Nat. Bur. Stand. (U.S.), Tech. Note 789, 184 pages (July 1973) $\$ 2.35$, SD Catalog No. C13.46:789.

Key words: Building design; energy conservation; mechanical systems.

The purpose of this report is to provide reference material on the technical options for energy conservation in buildings. It was prepared for the National Conference of States for Building Codes and Standards-National Bureau of Standards Joint Emergency Workshop on Energy Conservation in Buildings held at the U.S. Department of Commerce in Washington, D.C. on June 19, 1973.

This report describes actions pertinent to existing buildings and new buildings. Regarding existing buildings, principal topics include summer cooling, winter heating, and other energy conserving features-i.e., insulation, fenestration, lighting, appliances, domestic 
hot water, and human comfort. Suggested actions include those which can be accomplished voluntarily or without expense, and also actions which require some modest effort or expense on the part of the building owner or occupant.

Regarding new buildings, energy conservation actions are described that deal with building design and mechanical systems. The report concludes with a summary of mechanisms for implementation of such actions and criteria for use in evaluation of them.

TN790. MIDAS modular interactive data acquisition system-description and specification, C. H. Popenoe and M. S. Campbell, Nat. Bur. Stand. (U.S.), Tech. Note 790, 49 pages (Aug. 1973) 75 cents, SD Catalog No. C13.46:790.

Key words: Computer-controlled experiment; computer interfacing; data acquisition system; digital interface; instrumentation; laboratory automation; MIDAS; programmable controller.

The task of interfacing experiments to computers and data-logging systems should be made as painless as possible for the scientist. With this intent, MIDAS, a user-oriented, modular digital interface system based on CAMAC hardware and USASCII-bus data communication has been developed. MIDAS modules enable the experimenter to set up, program, modify and operate automated or computer-controlled experiments independently of the experts. Salient features of the concept are described and operating configurations discussed both with and without computer control. System interface requirements are specified in sufficient detail to enable one skilled in the art to design and construct modules operable within a MIDAS system.

TN791. Dose calibrator pilot study, S. B. Garfinkel and G. J. Hine, Nat. Bur. Stand. (U.S.), Tech. Note 791, 7 pages (Aug. 1973) 30 cents, SD Catalog No. C13.46:791.

Key words: Dose calibrators; indium-113m; molybdenum-99; nuclear medicine; radiopharmaceuticals; technetium-99m; tin113.

Results of measurements of six sources in dose calibrators used in nuclear medicine facilities at eight hospitals in the Washington metropolitan area are given.

TN792. Investigation of viscous flow in glass during phase separation, J. H. Simmons, S. A. Mills, A. Napolitano, D. H. Blackburn, and W. K. Haller, Nat. Bur. Stand. (U.S.), Tech. Note 792, 43 pages (Sept. 1973), 65 cents, SD Catalog No. C13.46:792.

Key words: Glass; microstructure; phase separation; viscosity.

The isothermal viscosity of two borosilicate glasses, of which one is a commercial glass widely used for chemical glassware, shows a large increase ( 4 to 5 orders of magnitude) with heat-treatment time (ranging up to $100,000 \mathrm{~min}$ ) near the annealing point. The two glasses have similar compositions, but differ greatly in their phase separation characteristics. Electron micrographs are used to analyze the development of microstructure during the suspected phase separation. In both glasses, it is found that the structure development is primarily responsible for the viscosity increase. An analysis of the data, and a theoretical interpretation of the effect are presented.

TN793. Development of a procedure for measuring the noise of paper caps, M. A. Cadoff, D. E. Mathews, and D. S. Blomquist, Nat. Bur. Stand. (U.S.), Tech. Note 793, 23 pages (Oct. 1973) 50 cents, SD Catalog No. C13.46:793.

Key words: Acoustics; cap guns; children; consumer safety; hearing damage; noise; paper caps; standard apparatus; toys.

In recent years, a great concern has been expressed for consumer protection and safety, especially for children. As an outgrowth of this concern, acoustical testing of potentially hazardous noise-producing toys has been carried out at the National Bureau of Standards for the
Bureau of Product Safety (FDA) under the authority of the Toy Safety Act of 1969. This paper discusses in detail the testing work carried out on commercial cap guns and caps, which culminated in the development of a standard firing apparatus for testing paper caps. Engineering drawings of the standard apparatus are given as well as a recommended procedure for using this apparatus to test paper caps.

TN795. Review of network management problems and issues, A. J. Neumann, Nat. Bur. Stand. (U.S.), Tech. Note 795, 77 pages (Oct. 1973)\$1.00, SD Catalog No. C13.46:795.

Key words: Academic computing; networks; network management; regional networks; research computing.

Computer networking is broadly considered including hardware, software, procedures and people. Networking encompasses many activities; such as, creation of network products, distribution processes, user activities, and supporting services like marketing, documentation, information services and maintenance. Network management covers both the establishment of networking operations and actual operation of the network facilities. It includes all management functions performed at such network nodes as computing centers, documentation facilities, and service distribution centers. In order to survey the problems facing development of network management, user requirements and system requirements are outlined in a qualitative manner. Examples of political, economic and legal constraints are summarized, such as the economic impact of extended networks on regional and local computing activities. Critical issues for networking management, and other areas of significant management concern are outlined. Organizational alternatives are conceived in terms of a four layer organization model. Conclusions deal with continuing problem areas, the need for a structural model for network management, critical experiments and tasks to be undertaken to further networking capabilities, and a suggestion to establish planning teams to initiate some of the initial steps required for further networking development.

TN796. FRAME: An on-line correction procedure for quantitative electron probe microanalysis, H. Yakowitz, R. L. Myklebust, and K. F. J. Heinrich, Nat. Bur. Stand. (U.S.), Tech. Note 796, 51 pages (Oct. 1973) 80 cents, SD Catalog No. C13.46:796.

Key words: Electron probe; mini-computer; on-line correction; quantitative microanalysis.

A procedure using a mini-computer for on-line correction of $\mathrm{x}$-ray data from electron microprobe analysis has been developed. This program, called FRAME, allows mass fractions to be computed online by the ZAF approach. Besides x-ray intensities, the only input data required are the atomic numbers of the elements present, the analytical line being used, and the operating voltage. Other required parameters such as atomic weights and $x$-ray mass attenuation coefficients are stored or calculated by the program. FRAME is in FORTRAN IV, and requires about $4 \mathrm{~K}$ of computer core. Results from FRAME are very close to those of COR2, which is considered to be the most accurate program available for quantitative electron probe microanalysis.

TN797. Static language analysis, G. Lyon, Nat. Bur. Stand. (U.S.), Tech. Note 797, 23 pages (Oct. 1973) 50 cents, SD Catalog No. C13.46:797.

Key words: Data archives; language use; programming aids; programming languages; source-statement analysis; syntax analysis.

Although many variants of programming languages exist, little information is available on how language features are actually used by programmers. Several data collection schemes are discussed here; 
each would provide empirical data on language use. Some internal details are given for analyzers for FORTRAN and COBOL. In addition, a suggestion is made for a special systems option which would allow a compiler to continuously record source statement characteristics or programs given to it.

CIS7. What About Metric?, L. E. Barbrow, Nat. Bur. Stand. (U.S.), Consum. Inf. Ser. 7, 16 pages (Oct. 1973) 80 cents, SD Catalog No. C13.53:7.

Key words: Metric system; SI; weights and measures.

The metric system of measurement, how it compares with our customary system, and how it will affect everyday life are described in everyday terms. Examples of computations of the type frequently encountered by the average citizen are included to illustrate the relative simplicity of the metric system. Although extensive use of the metric system in the United States is envisioned to be several years in the future, the reasons for at least becoming acquainted with the system now are discussed. The necessary acquaintanceship for everyday life involves the learning of fewer than ten metric units of measurement.

The following Bibliography Series are available by purchase from the National Technical Information Service (NTIS), Springfield, Va. 22151 .

COM-73-10281. Index and cumulative list of papers on radiation chemistry, Vol. V, Nos. 27-52, July through Dec. 1972, Radiation Chemistry Data Center, Radiation Laboratory, University of Notre Dame, Jan. 1973, $\$ 6.00$.

Key words: Biological systems; ESR; hot atom chemistry; luminescence; photochemistry; polymers; radiation chemistry; radiation chemistry theory.

The Radiation Chemistry Data Center, as part of its operations, collects, keywords, and stores literature of fundamental radiation chemistry and several related fields. Since 1968, references to this literature have been stored in computer files. These files have been used for retrospective researches and for the Weekly List of Papers on Radiation Chemistry which has been used as a current-awareness aid by radiation chemists since 1968. This index to and cumulation of entries in the Weekly List of Papers on Radiation Chemistry for the period July through December 1972 is intended as a guide to the recent literature and as a searching tool for those who would find a printed index valuable.

This column lists all outside publications by the NBS staff, as soon after issuance as practical. For completeness, earlier references not previously reported may be included from time to time.

Achenbach, P. R., Phillips, C. W., Performance characteristics of pressure-actuated water-regulating valves for refrigerant condensers, (Proc. XII Int. Congress of Refrigeration, Madrid, Spain, 1967), Paper in Progress in Refrigeration Science and Technology 2, 1107-1118 (Gráficas Reunidas, Madrid, Spain, 1969).

Key words: Performance characteristics; refrigeration accessories; valves; water-flow regulation.

Water-regulating valves are used on the condensers of watercooled refrigerating units to maintain a satisfactory refrigerant condensing pressure and to conserve water. Both pressure-actuated and temperature-actuated valves are used for this purpose. A study was made of three sizes of pressure-actuated water-regulating valves from each of three sources to determine their range of condenser pressure control, the change in condensing pressure required to move the valves from fully-closed to fully-open position, the hysteresis in the control mechanism, and the water-flow characteristics near the fullyclosed position. These and other performance characteristics related to water conservation and reliable operation of refrigerating units were investigated to provide guidance to the U.S. Army Natick Laboratories in writing performance specifications. The study revealed that the nominal pipe size of the valves was not a good indication of water-flow capacity, that the sensitivity of the various valves to change in condensing pressure differed widely, and that the difference between opening and closing pressure was in excess of $10 \mathrm{psi}$ $\left(0.7 \mathrm{~kg} / \mathrm{cm}^{2}\right)$ in some valves. Moreover, the condensing pressure at 90 percent maximum water flow rate ranged from 118 to 172 psig ( 8.3 to $12.1 \mathrm{~kg} / \mathrm{cm}^{2}$ ) for the several valves when the opening pressure was set at $80 \mathrm{psig}\left(5.6 \mathrm{~kg} / \mathrm{cm}^{2}\right)$.

Acquisita, N., Abramowitz, S., Vibrational spectrum of $\mathbf{M o F}_{5}, J$. Chem. Phys. 58, No. 12,5484-5488 (June 15, 1973).

Key words: Infrared; matrix isolation; $\mathrm{MoF}_{5}$; Raman spectroscopy.

The infrared spectrum of matrix isolated $\mathrm{MoF}_{5}$ as well as the Raman spectra of the liquid and polycrystalline species have been observed. The use of double boiler Knudsen cells has facilitated a vibrational assignment for monomeric $\mathrm{MoF}_{5}$ based on a trigonal bipyramid $\left(D_{3 h}\right)$ structure.

Albers, J., Deutch, J. M., On the rate equation description of spectral lines, Chem. Phys. 1, No. 2, 89-98 (Mar./Apr. 1973).

Key words: Correlation function; density expansion; kinetic equations; Langevin equation; rate equations; scattering theory.

We present a derivation of an exact, low-density equation of motion for the generating operator $G_{i j}(t)=\exp (\mathrm{i} L t)|j\rangle\langle i|$. For the case of foreign gas pressure broadening, the equation for $G_{i j}(t)$ may be used to obtain an exact rate equation for the line amplitude operator. Under certain well-defined approximations, this rate equation reduces to the form of an equation proposed by Gordon. The origin of the linear density term is considered. We discuss the implications of the use of only completed collisions to describe the spectrum.

Anderson, R. L., The high temperature stability of platinum resistance thermometers, (Proc. 5 th Symp. on Temperature, Its Measurement and Control in Science and Industry, Washington, D.C., June 21-24, 1971), Paper in Temperature, Its Measurement and Control in Science and Industry, H. H. Plumb, Editor-in-Chief, 4, Part 2, 927-934 (Instrument Society of America, Pittsburgh, Pa., 1972).

Key words: Chemical changes in platinum resistance thermometers; high temperature platinum resistance thermometers; physical changes in platinum resistance thermometers; stability of platinum resistance thermometers.

Some of the chemical and physical parameters that affect the stability of platinum resistance thermometers have been studied, particularly at temperatures near the gold point $\left(1064{ }^{\circ} \mathrm{C}\right)$. A simplified form of resistance thermometer sensor was designed to aid in these studies. The new design, designated as the "steeple," allowed the fabrication of some thermometers from single crystals. Measurements were made of the resistance at the triple point of water after the thermometers had been held above $1000{ }^{\circ} \mathrm{C}$ for extended periods. Further information on the aging of platinum wires at high temperatures was obtained with the scanning electron microscope. Some of the results are shown to be applicable to standard thermometers when used above $400^{\circ} \mathrm{C}$.

Aras, N. K., Zoller, W. H., Gordon, G. E., Lutz, G. J., Instrumental photon activation analysis of atmospheric particulate material, Anal. Chem. 45, No. 8, 1481-1489 (July 1973).

Key words: Air pollution; atmospheric particulate material; electron linac; photon activation analysis.

Concentrations of fourteen elements in atmospheric particulate matter have been measured by irradiation of the samples with 
bremsstrahlung from electrons of $35 \mathrm{MeV}$ from the NBS electron linac and observation of $\gamma$ rays from the reaction products with $\mathrm{Ge}(\mathrm{Li})$ detectors. The elements routinely observed by this nondestructive method are: $\mathrm{Na}, \mathrm{Cl}, \mathrm{Ca}, \mathrm{Ti}, \mathrm{Cr}, \mathrm{Ni}, \mathrm{Zn}, \mathrm{As}, \mathrm{Br}, \mathrm{Zr}, \mathrm{Sb}, \mathrm{I}, \mathrm{Ce}$, and $\mathrm{Pb}$. Several other elements such as $\mathrm{Fe}, \mathrm{Se}, \mathrm{Rb}$, and $\mathrm{Y}$ are marginally observable. Although, in general, instrumental photon activation analy sis (IPAA) is less sensitive than instrumental neutron activation analysis (INAA), with IPAA one can measure concentrations of several elements that are difficult or impossible to measure in urban particulates with INAA, especially $\mathrm{Ti}, \mathrm{Ni}, \mathrm{As}, \mathrm{I}$, and $\mathrm{Pb}$. Measurements of $\mathrm{Ni}, \mathrm{As}$, and $\mathrm{Pb}$ are quite important because of their known toxicities.

Armstrong, G. T., Calorimetric reference materials-status of the primary standard, Proc. Ist Int. Conf. on Calorimetry and Thermodynamics, W arsaw, Poland, Aug. 31-Sept. 4, 1969, pp. 261267 (Polish Scientific Publishers, Warsaw, Poland, 1971).

Key words: Benzoic acid; calorimetric reference materials.

Reference materials for reaction calorimetry are briefly reviewed. The value of $26434 \mathrm{Jg}^{-1}$ for the energy of combustion of the primary standard, benzoic acid, has been confirmed by three recent careful determinations, and give this value a very sound basis. Any future investigations leading to a possible change in this value will require extremely careful documentation of precision and accuracy of measurement. Possible sources of systematic error are discussed.

Arvidson, J. M., Durcholz, R. L., Reed, R. P., Compressive properties of polyurethane and polystyrene foams from 76 to 300 K, (Proc. 1972 Cryogenic Engineering Conf., Boulder, Colo., Aug. 9-11, 1972), Paper E-4 in Advances in Cryogenic Engineering 18, 194-201 (Plenum Press, New York, N.Y., 1973).

Key words: Compression; foams; temperature.

The compressive properties of 4 different polyurethane foams and 2 polystyrene foams have been measured at 300, 195 and $76 \mathrm{~K}$. Similar to tensile properties, the Young's modulus, yield strength, and compressive strength increased with decreasing temperature, while the elongation to fracture decreased. An approximate linear dependence on density was found for Young's modulus in compression and the proportional limit. Longitudinal specimens were usually stronger than transverse specimens. Specimens pulled in tension were considerably stronger than specimens loaded under compression, but these differences diminished at lower temperatures.

Atkinson, G. H., Laufer, A. H., Kurylo, M. J., Detection of free radicals by an intracavity dye laser technique, J. Chem. Phys. 59, No. 1, 350-354 (July 1, 1973).

Key words: Absorption; flash photolysis; free radicals; laser; spectra.

A new technique for the detection of free radicals inside the cavity of a dye laser is described. This intracavity absorption phenomenon has two important advantages: (1) It has the potential for quantitative detection suitable for kinetic studies of transient chemical species and (2) it has a high degree of sensitivity. In the present work, the technique is shown to be at least as sensitive as, and most probably several orders of magnitude more sensitive than, previous methods for the detection of transients. It is presently a powerful tool for obtaining high resolution spectra as well as obtaining precise information about the energy distribution of transient species produced photolytically or kinetically. Spectra for both $\mathrm{NH}_{2}$ and $\mathrm{HCO}$ (produced flash photolytically) are presented.

Barnes, I. L., Murphy, T. J., Gramlich, J. W., Shields, W. R., Lead separation by anodic deposition and isotope ratio mass spectrometry of microgram and smaller samples, Anal. Chem. 45, No. 11, 1881-1884 (Sept. 1973).

Key words: Anodic deposition; isotopic analysis; lead; mass spectrometry.
A method is reported for the separation by anodic deposition and subsequent analyses by isotope ratio mass spectrometry of small samples of lead from a variety of matrices. The combined procedure is applicable to samples containing from $10 \mu \mathrm{g}$ to less than $10 \mathrm{ng}$ of lead and the electrodeposition is more than $95 \%$ efficient at these levels. Only a few elements interfere with the deposition, most notably iron and cerium, and procedures for removing the interfering elements are given. The optimum conditions for the anodic deposition of lead as $\mathrm{PbO}_{2}$ were studied. The mass spectrometric procedure described permits a precision of $0.1 \%$ ( $95 \%$ limit of error) or better for the measured isotopic ratios.

Barnes, J. D., Neutron inelastic scattering study of the "rotator" phase transition in n-alkanes, (Proc. 5th Symp. on Neutron Inelastic Scattering, Grenoble, France, Mar. 6-10, 1972), Chapter in Neutron Inelastic Scattering, pp. 287-299 (International Atomic Energy Agency, Vienna, Austria, 1972).

Key words: n-Alkanes; n-nonadecane; neutron inelastic scattering; phase transition; rotational diffusion; rotator phase.

Many n-alkanes exhibit a solid-solid phase transition a few degrees below their melting points. Such characteristics of the phase transition as transition temperatures, volume change on transition, and heats of transition are very sensitive to chain length in these materials. To characterize the role which molecular motions play in this phase transition, inelastic neutron scattering experiments were carried out on the Fermi chopper time-of-flight spectrometer at the $\mathrm{Na}$ tional Bureau of Standards Reactor. Experiments were performed on $\mathrm{n}$-nonadecane at temperatures of 77, 291, 297,301 and $307 \mathrm{~K}$ and on n-eicosane at $301 \mathrm{~K}$. Momentum transfers ranged between $.42 \AA^{-1}$ and $3.3 \AA^{-1}$ for $2.467 \AA$ neutrons. The full width at half maximum of elastically scattered neutrons was found to be $1.58 \mathrm{ps}^{-1}$ from measurements of scattering from vanadium $(\Delta \lambda / \lambda=4.6 \%) .297 \mathrm{~K}$ and 301 $\mathrm{K}$ are above the temperature of the "rotator" phase transition for $\mathrm{n}$ nonadecane. The spectra taken under these conditions consist of a broadened elastic peak superimposed on a continuous spectrum arising from the vibrational modes of the system. The broadening of the elastic peak is found to depend on momentum transfer and is analysed in terms of models involving rotational diffusion of the molecule about the long axis of the chain. The data at $307 \mathrm{~K}$, where the material is molten, reveal a further increase in the quasi-elastic component of the scattering.

Bedford, R. E., Ma, C. K., Barber, C. R., Chandler, T. R., Quinn, T. J., Burns, G. W., Scroger, M., New reference tables for platinum 10\% rhodium/platinum and platinum 13\% rhodium/platinum thermocouples, (Proc. 5th Symp. on Temperature, Its Measurement and Control in Science and Industry, Washington, D.C., June 21-24, 1971), Paper in Temperature, Its Measurement and Control in Science and Industry, H. H. Plumb, Editor-in Chief, 4, Part 3, 1585-1602 (Instrument Society of America, Pittsburgh, Pa., 1972).

Key words: Blackbodies; calibrations; optical pyrometer; platinum resistance thermometer; platinum-rhodium vs platinum thermcouples; reference tables; thermometric fixed points.

New reference tables for platinum 10 percent rhodium/platinum and platinum 13 percent rhodium/platinum thermocouples have been prepared as a result of a cooperative program among the National $\mathrm{Bu}$ reau of Standards (USA), the National Physical Laboratory (UK), and the National Research Council (Canada). High purity platinum wires $\left(\alpha \geqslant 1.3924 \times 10^{-3}\right)$ and alloy wires of as closely as possible 10 percent and 13 percent rhodium composition, respectively, were supplied by seven American and British manufacturers, from which thirty-two $\mathrm{Pt} 10 \mathrm{Rh} / \mathrm{Pt}$ and thirty-six $\mathrm{Pt} 13 \mathrm{Rh} / \mathrm{Pt}$ thermocouples were constructed. Primary calibrations below $1064.43{ }^{\circ} \mathrm{C}$ were performed at NBS and NRC; primary calibrations above $1064.43{ }^{\circ} \mathrm{C}$ were done at 
NPL; thermocouple intercomparisons over the whole temperature range were done at NBS and NRC. The reference tables derive from polynomials fitted, by means of least squares orthogonal polynomial techniques, to a selected group of thermocouples of each type.

Birky, M. M., Calorimeter for laser energy measurements, Appl. Opt. 10, No. 1, 132-135 (Jan. 1971).

Key words: Calorimeter; energy; laser; neodymium; ruby.

A calorimeter enclosed in a constant temperature environment has been constructed to measure the output energy of a conventional mode ruby or neodymium laser. The calorimeter was designed according to the measurement theory and has an estimated uncertainty of $\pm 2 \%$ in the range $5 \mathrm{~J}$ to $100 \mathrm{~J}$. The time-temperature curves were analyzed according to the theory with the aid of a computer program.

Brower, W. S., Parker, H. S., Roth, R. S., Synthesis of mercury bismuth sulfide $\mathbf{H g B i}_{2} \mathbf{S}_{4}$, Mater. Res. Bull. 8, 859-862 (1973).

Key words: Bismuth; mercury; sulfides; synthesis.

The compound $\mathrm{HgBi}_{2} \mathrm{~S}_{4}$ was found to be the only phase present, other than the end members, in mixtures of $\mathrm{HgS}$ and $\mathrm{Bi}_{2} \mathrm{~S}_{3}$. The compound is apparently a new structure type with monoclinic symmetry, space group $\mathrm{C} 2, \mathrm{Cm}$ or $\mathrm{C} 2 / \mathrm{m} a=14.179, b=4.0555, c=13.986 \AA, \beta=$ $118^{\circ} 13.8^{\prime}$.

Brown, W. C., Buchanan, C. J., A study of the strength capabilities of children ages two through six, NBSIR 73-156, 56 pages, (Aug. 7, 1973). (Available as COM 73-11286 from the National Technical Information Service, Springfield, Va. 22151.)

Key words: Children; children's strength; pull; push; safety; strength; squeeze; test methods; toys; toy safety; twist.

The Child Strength Study was conducted to provide information which can be used to develop reliable and realistic standards and test methods for children's toys. The study was conducted on over 550 children in the Washington Metropolitan area, and included both black and white children with varying economic and social backgrounds.

Four test devices were used to measure the forces exerted by children when pushing, pulling, twisting, and squeezing. Quantitative relationships were found to exist between these four types of measurements. The study also provided quantitatively precise and useful information about the effects of age and sex on the strength capability of children two through six years old. The results of the study are exhibited in tables of averages, standard deviations, coefficients of variation, and 95th percentiles for each age and sex group tested. A number of graphs are also included for a quick appraisal of the test results.

Brown, W. E., Solubilities of phosphates and other sparingly soluble compounds, Chapter 10 in Environmental Phosphorus Handbook, E. J. Griffith, A. Beeton, J. M. Spencer and D. T. Mitchell, Eds., pp. 203-239 (John Wiley \& Sons, Inc., New York, N.Y., 1973).

Key words: Calcium carbonates; calcium phosphates; hydroxyapatite; limnetic phosphate; phase diagrams; phosphate pollution; solubility.

Solubilities of five calcium phosphates, $\mathrm{Ca}_{5}\left(\mathrm{PO}_{4}\right)_{3} \mathrm{OH}, \beta-$ $\left.\mathrm{Ca}_{3}\left(\mathrm{PO}_{4}\right)_{2}, \mathrm{Ca}_{8} \mathrm{H}_{2}\left(\mathrm{PO}_{4}\right)_{6}\right) 5 \mathrm{H}_{2} 0, \mathrm{CaHPO}_{4}$, and $\mathrm{CaHPO}_{4} \cdot \nless \mathrm{H}_{2} \mathrm{O}$ must be considered as factors that may limit the concentrations of calcium and orthophosphate ions in natural waters. In the three-dimensional plot $\mathrm{pH}$ vs $\left[\mathrm{Ca}(\mathrm{OH})_{2}\right]$ and $\left[\mathrm{H}_{3} \mathrm{PO}_{4}\right]$ for all solutions in the ternary system, $\mathrm{Ca}(\mathrm{OH})_{2}-\mathrm{H}_{3} \mathrm{PO}_{4}-\mathrm{H}_{2} \mathrm{O}$, one obtains a surface that (i) has an important bearing on the positions of the isotherms for the five calcium phosphates and the fact that the isotherms have negative slopes, and (ii) is a consequence of the fact that $\mathrm{H}_{3} \mathrm{PO}_{4}$ is a polybasic, weak acid.
The phase diagram for the ternary system can be expanded to approximate a four component system in which the effects of all other components are incorporated into a single variable which is a measure of their net basicity or acidity. This diagram should have considerable value in the interpretation of field data. Lines of constant $\mathrm{pH}$ on this diagram can be used to determine whether a solution is undersaturated or supersaturated with respect to the salt under consideration. Other lines on this diagram define compositions along which the chemical potentials of $\mathrm{Ca}(\mathrm{OH})_{2}, \mathrm{H}_{3} \mathrm{PO}_{4}$ and the various calcium phosphate salts are all constant.

Potential diagrams $\left(-\log\right.$ of the activity of $\mathrm{Ca}(\mathrm{OH})_{2}$ plotted vs that of $\mathrm{H}_{3} \mathrm{PO}_{4}$ ) are useful for establishing (i) the degree of saturation of a given solution with respect to anyone or all of the calcium phosphates, and (ii) the $\mathrm{Ca} / \mathrm{P}$ ratio of the saturating solid phase.

A variety of theoretical and experimental factors must be taken into account in the design of solubility measurements and in the interpretation of results. Their application to calcium phosphates and other sparingly soluble salts of polybasic acids is described.

Burns, G. W., Hurst, W. S., Studies of the performance of W-RE type thermocouples, (Proc. 5th Symp. on Temperature, Its Measurement and Control in Science and Industry, Washington, D.C., June 21-24, 1971), Paper in Temperature, Its Measurement and Control in Science and Industry, H. H. Plumb, Editor-in-Chief, 4, Part 3, 1751-1766 (Instrument Society of America, Pittsburgh, Pa., 1972).

Key words: Beryllium oxide; ductility; emf-temperature relationship; microstructure; thermocouple drift; W-Re alloys; WRe type thermocouples; W-Re thermoelements.

The effect of exposure of bare-wire and BeO-insulated commercial W-Re thermocouple materials to high temperatures in gaseous environments has been investigated. The temperature range of interest has been primarily 2000 to $2400 \mathrm{~K}$, and the investigations have been confined to thermocouple wires of $0.25 \mathrm{~mm}$ diameter. With high temperature exposure of the bare thermoelements, an initial shift in the emf-temperature relationship of the exposed thermoelements versus an unexposed "as received" thermoelement was exhibited, and thereafter no discernible drift occurred with exposure in environments of $\mathrm{Ar}, \mathrm{He}, \mathrm{H}_{2}$ or $\mathrm{N}_{2}$ for periods up to 1000 hours. Aging studies were performed to determine the time-temperature parameters of the shift. Thermoelements were examined for metallurgical structural changes and chemical changes by conventional methods. In the temperature range of interest, grain growth was inhibited in the chemically doped W-3 percent Re alloy, and excellent room temperature ductility was retained subsequent to the exposure. The compatibility of high purity (in excess of 99.8 percent), sintered $\mathrm{BeO}$ insulators with the thermoelements differed, depending upon whether the $\mathrm{BeO}$-insulated thermoelement assemblies were self-heated electrically or heated in a furnace; in tests in argon environments, highly reliable performance occurred when the assemblies were heated in a furnace. $\mathrm{BeO}$-insulated W-3 percent Re vs W-25 percent Re thermocouples, constructed with degassed and aged materials, exhibited drifts equivalent to about $3 \mathrm{mK} / \mathrm{h}$ during 1000 hours of exposure at $2073 \mathrm{~K}$ in argon while in the presence of tantalum.

Canfield, L. R., Johnston, R. G., Madden, R. P., NBS detector standards for the far ultraviolet, Appl. Opt. 12, No. 7, 1611-1617 (July 1973).

Key words: Detectors; far ultraviolet; ion chamber; photodiodes; radiometry; thermopile.

A program at NBS leading to the realization of practical, stable transfer detector standards for the far ultraviolet is reviewed. Three basic detector types, one covering the region of 584-1216 $\AA$ and the other two covering the region of 1164-2537 $\AA$, are described. Examples of these detectors have been calibrated at NBS and distributed 
to laboratories throughout the United States and Europe, where they are being used as primary radiometric calibration references in a variety of far-uv experiments.

\section{Cataland, G., Plumb, H. H., The realization of low temperature} fixed points on the NBS acoustical and the NBS-1955 temperature scales, (Proc. 5th Symp. on Temperature, Its Measurement and Control in Science and Industry, Washington, D.C., June 21-24, 1971), Paper in Temperature, Its Measurement and Control in Science and Industry, H. H. Plumb, Editor-in-Chief, 4, Part 1, 183-193 (Instrument Society of America, Pittsburgh, Pa., 1972).

Key words: Acoustical thermometry; e- $\mathrm{H}_{2} \mathrm{NBP}-\mathrm{e}-\mathrm{H}_{2}$ TP fixed points; neon NBP.

The normal boiling and triple points of equilibrium hydrogen have been realized and related to the NBS (1955) temperature scale. From isotherms that were determined with the NBS acoustical thermometer, values of $\mathrm{T}$ (acoustical) can be associated with the above fixed points and also with the normal boiling point.

Cezairliyan, A., A high-speed (millisecond) system for studies of phase transitions and thermophysical properties of electrical conductors above $2000 \mathrm{~K}$, Proc. Int. Conf. on Etude des Transformations Cristallines a Haute Température, Odeillo, France, Sept. 27-30, 1971, No. 205, 25-32 (Centre National de la Recherche Scientifique, Paris, France, 1972).

Key words: High-speed methods; high temperature; phase transitions; refractory metals; thermophysical properties.

A high-speed system is described for conducting studies on phase transitions, and for measuring selected thermophysical properties of electrical conductors at temperatures above $2000 \mathrm{~K}$. The system can measure specific heat electrical resistivity, hemispherical total emittance, and melting point in subsecond duration experiments. Temperature measurements are made with a millisecond resolution photoelectric pyrometer. Experimental quantities are recorded with a high-speed digital data acquisition system. The entire system has a time resolution of approximately 0.4 millisecond. An experiment simulating the conditions of phase transitions is described. Results of measurements on solid-liquid phase transitions in niobium, molybdenum, and tungsten are presented. High-speed measurements of selected thermophysical properties of niobium, molybdenum, tantalum, and tungsten are summarized. Sources and magnitudes of errors are discussed.

Cezairliyan, A., Measurement of the heat capacity of graphite in the range 1500 to $3000 \mathrm{~K}$ by a pulse heating method, (Proc. 6th Symp. on Thermophysical Properties, Palm Springs, Calif., Aug. 1973), Paper in Proceedings of the 6th Symposium on Thermophysical Properties, P. E. Liley, Ed., pp. 279-285 (American Society of Mechanical Engineers, New York, N.Y., 1973).

Key words: Graphite; heat capacity; high-speed measurements; specific heat; thermodynamics.

Measurement of the heat capacity of a grade of graphite (AXM-5Q, POCO) in the temperature range 1500 to $3000 \mathrm{~K}$ by a subsecond-duration, pulse-heating technique is described. The smoothed results for a single specimen corresponding to two different heating rates are in agreement within $0.1 \%$ on the average. The smoothed results for two different specimens are in agreement within $0.6 \%$. The heat capacity of graphite in the temperature range 1500 to $3000 \mathrm{~K}$ based on the present results is expressed by the following function (standard deviation $=0.5 \%$ :

$$
\mathrm{c}_{p}=19.12+4.236 \times 10^{-3} \mathrm{~T}-5.919 \times 10^{-\tau} \mathrm{T}^{2},
$$

where $\mathrm{T}$ is in $\mathrm{K}$ and $\mathrm{c}_{p}$ is in $\mathrm{J} \mathrm{mol}^{-1} \mathrm{~K}^{-1}$. The inaccuracy of the re ported results is estimated to be not more than $3 \%$.
Cezairliyan, A., Measuring transient high temperatures by optical pyrometry, (Proc. 5th Symp. on Temperature, Its Measurement and Control in Science and Industry, Washington, D.C., June 21-24, 1971), Paper in Temperature, Its Measurement and Control in Science and Industry, H. H. Plumb, Editor-in-Chief, 4, Part 1, 657-664 (Instrument Society of America, Pittsburgh, Pa., 1972).

Key words: High-speed measurements; high temperature; pyrometry; radiation; temperature measurement.

Various pyrometric (optical) methods, using photoelectric and photographic detectors, are described for measuring high tempera tures. Emphasis is placed on techniques of measuring transient temperature of solids above approximately $1500 \mathrm{~K}$ with subsecond (upper millisecond to upper microsecond) resolution. Advantages and limita tions of the various methods are discussed and estimates of uncer tainties are given. Examples of application of the high-speed temperature measurement methods to various fields of investigations, in cluding determination of thermophysical properties, is presented.

Churney, K. L., West, E. D., Armstrong, G. T., A cell model for isoperibol calorimeters, NBSIR 73-184, 100 pages (Apr. 1973). (Available as COM 73-11110 from the National Technical Information Service, Springfield, Va. 22151).

Key words: Calorimetry; energy equivalents; energy measure ment; heat transfer; internal energy measurement; isoperibol calorimeters; measurement theory.

A calorimeter can be modeled as a large number of volume elements or cells in each of which the temperature may be considered uniform, and each of which can store heat and exchange heat with other cells. Application of the first law of thermodynamics to this set of cells leads to representations of the usual calorimetric equations for internal energy change expressed in terms of measurable or esti matable heat capacities, heat transfer coefficients, temperatures, and work terms for the individual cells. Analysis of the results yields a framework within which most of the design and measurement problems of isoperibol calorimeters can be treated.

Cohen, J., Edelman, S., Vezzetti, C. F., Pyroelectricity and piezoelectricity in oriented films of polyvinyl fluoride and polyvinylidene fluoride, (Proc. Conf. on Electrets, Charge Storage and Transport in Dielectrics, Miami Beach, Fla., Oct. 8-13, 1972), Paper in Electrets, Charge Storage and Transport in Dielec. trics, Martin M. Perlman, Ed., pp. 505-516 (The Electrochemical Society, Inc., Princeton, N.J., 1973).

Key words: Piezoelectricity; poling; polyvinyl fluoride; polyvinylidene fluoride; pyroelectric coefficient; pyroelectricity.

Improved pyroelectric and piezoelectric activities have been produced in films of polyvinyl fluoride (PVF) and polyvinylidene fluoride $\left(\mathrm{PVF}_{2}\right)$. The phenomena are ascribed to orientation of dipoles normal to the plane of the film. Activity is developed or enhanced by applying intense electrical fields across the films at elevated temperatures and cooling to room temperature with the field still applied (poling). The $\mathrm{PVF}_{2}$ films are usually stretched before poling, and this is found to increase both pyroelectric and piezoelectric effects. Room temperature pyroelectric coefficients for these materials have been estimated from measurements of voltage responsivity, and pyroelec tric coefficients comparable to that of triglycine sulfate (TGS) have been obtained. Observations of the correlation between the thermal radiation effects and the piezoelectric activity suggest that the former are pyroelectric. A method has been developed to study the poling process.

Corliss, E. L. R., Remark on "Fixed-scale mechanism of absolute pitch," J. Acoust. Soc. Amer. Letters to Editor 53, No. 6 , 1737-1739 (June 1973). 
Key words: Absolute pitch sense; audition; auditory memory; hearing; musical acoustics; pitch recognition.

Several aspects of this author's subjective experiences concerned with perception of pitch are at variance with the experiences reported by Paul T. Brady, J. Acoust. Soc. Am. 48, 883-887 (1970). In particular, my recognition is not tied to a specific scale (though, of course, nomenclature must be); the precision of recognition shows little fluctuation, if any; and changes in tuning do not influence the recognition of pitch, although such changes may influence the performance of remembered music and the ease of transposition. Tonal memory overrides motor memory for the performance of music learned on instruments tuned to initially different keys.

Craw, A. R., A comparison of several methods for forecasting U.S. traffic fatalities, NBSIR 73-189, 45 pages (May 1973). (Available as COM 73-11173 from the National Technical Information Service, Springfield, Va. 22151.)

Key words: Exponential smoothing; forecasting; time-series; traffic fatalities.

This is a second report to the Mathematical Analysis Division of the National Highway Traffic Safety Administration (NHTSA) on the subject of forecasting annual highway fatalities. This report concerns a comparison of several time series analysis programs based on exponential smoothing and nondecompositional methods currently employed by NHTSA for projecting the annual traffic fatalities for the entire U.S. Several methods of data aggregation are studied.

It is found that there is some advantage in using lumped (pooled) data for each region aggregated either quarterly or half yearly, and using the Sum of Regional estimates to estimate the national value.

Also, there does not appear to be any great difference in the results obtained using the nondecompositional methods and those obtained by time-series analysis programs based on exponential smoothing methods.

Estimates for the 1972 and 1973 national traffic fatalities by a variety of methods were made. For 1973 the estimates ranged from a low of 54186 to a high of 55994 , with a mean of 55055 .

Craw, A. R., Analyses for decision in the office of flammable fabrics: the level of the standard, NBSIR 73-182, 90 pages, (Apr. 1973). (Available as COM 73-11284 from the National Technical Information Service, Springfield, Va. 22151.)

Key words: Children's sleepwear; decision analysis; flammable fabrics; probability assessment; standards; utility theory.

The fundamentals of a single-stage decision problem are discussed and illustrated in the problem: The Level of the Standard for Children's Sleepwear, originally discussed by M. Tribus. Outcomes are identified, and various potential measures of disutility are discussed.

Given a particular alternative is in effect one must assign the conditional probabilities of arriving at each outcome. This process is aided by introducing intermediate events (extending the conversation). For the children's sleepwear problem this is done by considering for each of two age groups and three income levels the probability tree with branches: alternatives (a), technology (T), nightwear $(\mathrm{N})$, additional cost to the consumer $(\mathrm{C})$, Use (U) or non-use (u), existence of a hazard $(\mathrm{H})$, exposure $(\mathrm{E})$, ignition (I), burn (B) and burn-severity $\left(\mathrm{B}_{i}\right)$, survival (S) or death (D) and body image $\left(\mathbf{I}_{d}\right)$.

Attention is given to the preliminary assignment of each of the conditional probabilities needed. Suggestions are made as to sources of information. Much of the needed information is not available, especially that dealing with the social and behavioral aspects of the problem. The concept of exposure to an ignition hazard, for which an operational definition does not exist, is discussed.
Craw, A. R., Ku, R., The sensitivity of certain indices associated with two-vehicle accidents, Accident Anal. Prev. 5, 137-146 (1973).

Key words: Highway traffic accidents; indices; sensitivity analysis.

This study describes in mathematical terms a procedure employed by the National Highway Traffic Safety Administration of the Department of Transportation for the analysis of two-vehicle accidents. The procedure contains an Assignment Rule in which one of the involved driver-vehicle combinations is assigned to the class of active involvement and the other driver-vehicle combination is assigned to the class of passive involvement. Once case of interest is the Random Assignment Rule, and this is contrasted with the results of a Fixed Assignment Rule. Results are derived that show the effect on specific indices of (1) errors in assignment and (2) a Composite Assignment Rule (a mixture of Fixed and Random Rules).

Cruz, J. E., Rogers, E. H., Hiester, A. E., Continuous liquid level measurements with time-domain reflectometry, (Proc. 1972 Cryogenic Engineering Conf., Boulder, Colo., Aug. 9-11, 1972), Paper H-4 in Advances in Cryogenic Engineering 18, 323-327 (Plenum Press, New York, N.Y., 1973).

Key words: Coaxial probe; emptying rate; fill rate; liquid level; time domain reflectometer.

A time domain reflectometer is considered a closed-loop, one dimensional radar system. Applying the principle of time domain reflectometry to the detection of cryogenic liquid levels, measurements on the order of $\pm 0.3 \%$ of total liquid level probe length are possible.

The time domain reflectometer liquid level measurement is independent of liquid density variations and is simple to calibrate and operate. Construction of the liquid level sensing probe is described.

Daney, D. E., McConnell, P. M., Strobridge, T. R., Low-temperature nitrogen ejector performance, (Proc. 1972 Cryogenic Engineering Conf., Boulder, Colo., Aug. 9-11, 1972), Paper L-4 in Advances in Cryogenic Engineering 18, 476-485 (Plenum Press, New York, N.Y., 1973).

Key words: Cryogenic ejector; ejector; ejector pump; jet pump; low temperature refrigeration; refrigeration.

The primary objective of the test program reported here was to obtain a nitrogen ejector to replace the Joule-Thomson valve in a JouleThomson refrigerator. The desired primary nozzle inlet conditions were $200 \mathrm{~atm}$ and $161 \mathrm{~K}$ with a flow rate of $16.6 \mathrm{~g} / \mathrm{s}$, and the required entrainment ratio was 0.145 . In an attempt to find a near optimum ejector for the above conditions, and in order to obtain a more general knowledge of low temperature nitrogen ejector performance, the tests were run over a range of operating conditions. The primary nozzle supply pressure ranged from 35 to $200 \mathrm{~atm}$ with a temperature near $161 \mathrm{~K}$. The discharge pressure varied from 1.2 to $1.6 \mathrm{~atm}$, and the entrainment ratio varied from 0.0 to 0.5 . Combinations of three primary nozzles with three mixing sections resulted in a range of 118 to 365 for the ratio of the mixing tube area to the primary nozzle throat area. For the design conditions given above, a suction pressure of $0.27 \mathrm{~atm}$ was obtained. This corresponds to a liquid nitrogen saturation temperature of $67.7 \mathrm{~K}$.

Dhez, P., Ederer, D. L. Photoionization resonance profile parameters of the $3 \mathbf{s} 3 \mathbf{p}{ }^{1} P_{1}$ two-electron excitation in $\mathrm{He} \mathrm{I}$, J. Phys. B: At. Mol. Phys. Letter to Editor 6, L59-L64 (Apr. 1973).

Key words: Autoionization; cross section; Fano parameters; helium; photoionization; resonance profile.

The cross section profile of the $3 \mathrm{~s} 3 \mathrm{p}^{1} \mathrm{P}_{1}$ two-electron excitation has been measured in He I. The cross section was assumed to have the form 


$$
\sigma(E)=C(E)+\frac{\left(E-E_{0}\right) \frac{1}{2} \Gamma a+\left(\frac{1}{2} \Gamma\right)^{2} b}{\left(E-E_{0}\right)^{2}+\left(\frac{1}{2} \Gamma\right)^{2}}
$$

where the adjustable parameters $a, b, 1 / 2 \Gamma$ and $E_{0}$ were determined by a least squares fitting process. The parameter values obtained in the experiment were: $a=0.86 \pm 0.16 \mathrm{~cm}^{-1}, b=0.27 \pm 0.13 \mathrm{~cm}^{-1}$, $1 / 2 \Gamma=65.9 \pm 7.0 \mathrm{meV}, E_{0}=69.919 \pm 0.007 \mathrm{eV}$. The Fano parameters $q$ and $\sigma_{a}$ were determined from $a$ and $b$ and had the values $1.36 \pm 0.20$ and $0.32 \pm 0.08 \mathrm{~cm}^{-1}$ respectively.

Edelsack, E. A., Kropschot, R. H., Olien, N. A., Olsen, J. L., A Directory of European Low Temperature Research, Cryogenics 13, No. 3, 132-133 (Mar. 1973).

Key words: Cryogenics; European low temperature research.

The publication of a Directory of Low Temperature Research in seventeen European countries is described. The Directory contains the names of some three hundred researchers, their addresses, telephone numbers, and brief descriptions of their research interests. Information for obtaining free copies of the Directory is included.

Eisen, H., Rosenstein, M., Silverman, J., Electron dosimetry using Chalkley-MeLaughlin dye-cyanide thin films, (Proc. Int. Symp. on Dosimetry in Agriculture, Industry, Biology and Medicine, Vienna, Austria, April 1972), Paper in Dosimetry in Agriculture, Industry, Biology and Medicine, pp. 615-625 (International Atomic Energy Agency, Vienna, Austria, 1973).

Key words: Calorimetry; depth dose; dose distributions; dye films; electron beams; interface; Monte Carlo transport; stopping power; thin films.

The purpose of this work was to measure electron energy deposition profiles in a variety of absorbing materials and to evaluate the Chalkley-McLaughlin radiochromic dye-cyanide film dosimeter. Information of this type is useful for effective utilization of electron beams in industry and medicine where adjustments in sample thickness, electron beam energy, angle of electron beam incidence, and backing materials may provide more advantageous beam utilization. Experimental depth-dose distributions were determined for broad beams of $2.00 \mathrm{MeV}$ electrons incident on polystyrene, aluminium, copper, tin, gold, and several two-layer slab absorbers. Data were obtained for both semi-infinite and finite homogeneous absorbers at incident beam angles ranging from 0 (normal incidence) to 75 degrees. Radiochromic dye-cyanide films were used as solid-state cavity dosimeters, with an experimental reproducibility of $\pm 6 \%(2 \sigma)$. The stopping power ratio necessary to convert from film dose to absorber dose was evaluated several ways. Depth-dependent stopping power ratios, obtained by accounting for the changing electron energy spectrum with absorber depth by two methods, were compared with a constant stopping power ratio for each material. The difference between the constant ratio and a depth-dependent ratio was $1 \%$ to $2 \%$ for aluminium, $3 \%$ to $5 \%$ for copper, $3 \%$ to $7 \%$ for tin, and $3 \%$ to $8 \%$ for gold. The data demonstrate the decrease in the depthdose distribution and the total absorbed dose in finite slabs as compared to equivalent layers in semi-infinite slabs. The effect of the atomic number of the absorber and the angle of beam incidence on the shape of the energy deposition profile is also demonstrated. The data for the two-component slab absorbers illustrate the modification of the depth-dose profile in a finite slab of material if a different material is placed adjacent to it. From the dose received by a film placed at the interface, the surface doses at that position were estimated using the material-to-film stopping-power ratio appropriate for each material. The data are compared to theoretical depth-dose profiles obtained using Monte Carlo transport codes. The agreement is generally between $5 \%$ to $10 \%$ for homogeneous cases and in most cases better than $10 \%$ for the two-component cases.
Eisenhower, E. H., Safety recommendations in ANSI documents, (Proc. Symp. on Radiation Safety and Protection in Indus. trial Applications, Washington, D.C., Aug. 16-18, 1972), DHEW Pub. No. (FDA) 73-8012, H. F. Klein, Ed., pp. 240-252 (U.S. Depart ment of Health, Education, and Welfare, Public Health Service, Food and Drug Administration, Bureau of Radiological Health. Rockville, Md., Oct. 1972).

Key words: Radiation safety; radiography; voluntary standards; $\mathrm{x}$ rays.

This paper discusses American National Standards relating to safety in industrial applications of ionizing radiation. It includes methods by which voluntary standards are produced, and outlines approval procedures required for designation as an American National Standard. The structure and relevant activities of Standards Committee N43, of the American National Standards Institute (ANSI) are described. Maximum permissible dose equivalent values recommended by the National Council on Radiation Protection and Measurements are presented as the basis for requirements in ANSI standards. Existing and future standards of interest to radiation safety in industrial applications are outlined.

Ely, J. F., Hanley, H. J. M., Straty, G. C., Analysis of the pressure virials and Clausius-Mossotti function for polyatomic gases, J. Chem. Phys. 59, No. 2, 842-848 (July 15, 1973).

Key words: Clausius-Mossotti function; dielectric virial coefficients; m-6-8 potential; polarizability; polyatomic gases; pressure second virial coefficients; quadrupole moment; statistical mechanics.

Statistical mechanical equations for the second pressure virial coefficient and the second and third dielectric virial coefficients for quadrupolar molecules are evaluated using the $m-6-8$ potential function. The results are compared with experimental data for nitrogen and fluorine. An approximate value for the quadrupole moment of fluorine is estimated. Agreement between theory and experiment is generally good.

Evans, J. P., High temperature platinum resistance thermometry, (Proc. 5th Symp. on Temperature, Its Measurement and Control in Science and Industry, Washington, D.C., June 2124, 1971), Paper in Temperature, Its Measurement and Control in Science and Industry, H. H. Plumb, Editor-in-Chief, 4, Part 2, 899. 906 (Instrument Society of America, Pittsburgh, Pa., 1972).

Key words: Freezing point; gold point; high temperature; platinum resistance thermometer; standard thermocouple; temperature scale.

During the past decade a number of investigators have worked on various aspects of high temperature platinum resistance thermometry with the aim of developing thermometers suitable for use as interpolating instruments on a practical temperature scale up to the gold point. Long-time stability studies have been made of thermometers employing several designs and a variety of insulating and protecting materials; factors affecting the use of thermometers for temperature measurement have been investigated; new electrical instruments, using both direct and alternating current, have been developed to facilitate the measurement of thermometer resistance; and the investigation of metal freezing points as fixed points for calibrating thermometers has been extended to higher temperatures. An intercomparison of standard thermocouples and high temperature platinum resistance thermometers has shown that a practical temperature scale based on resistance thermometry can be realized at least an order of magnitude more precisely than a scale based on thermocouples, and several workers have suggested interpolation schemes for resistance thermometer scales. This paper reviews recent developments in high temperature platinum resistance thermometry, its current status, and some of the problem areas that need further attention. 
Feldman, A., Horowitz, D., Waxler, R. M., Laser damage in materials, NBSIR 73-119, 52 pages (Feb. 1973). (Available as AD 757789 from the National Technical Information Service, Springfield, Va. 22151.)

Key words: Absorption coefficient; damage threshold; electrostrictive self-focusing; electrostriction; Kerr effect; laser damage; nonlinear index of refraction; self-focusing; thermal self-focusing.

The relative contributions of the Kerr, electrostrictive, and thermal effects to the self-focusing thresholds of borosilicate crown glass, fused silica, and dense flint glass have been estimated from an analysis of damage threshold data for linearly polarized and circularly polarized radiation. The measurements were made with a $\mathrm{Nd}$ :glass laser operating in the TEM ${ }_{o o}$ mode with a temporal pulse width of 25 ns. The Kerr effect appears to be the largest effect. The thermal effect is also significant. The electrostrictive effect is smallest. Reasonable values of absorption coefficient are calculated from the thermal contribution. The results are in qualitative agreement with the work of others. Self-focusing data obtained with linearly polarized and circularly polarized radiation are presented for yttrium aluminum garnet (YAG) and five commercial Nd:doped laser glasses. The YAG data agree with the theory of self-focusing. Near the threshold the laser glass data appear to indicate intrinsic damage rather than selffocusing. Differences between the various laser glasses are small. Self-focusing data obtained in dense flint glass with a longer focal length lens are also presented. An electro-optic shutter actuated by a laser triggered spark gap is discussed.

Ferguson, J. B., Summary of flame spread and smoke generation tests conducted for operation BREAKTHROUGH, NBSIR 73-228, 27 pages (July 1973). (Available as PB 222425 from the National Technical Information Service, Springfield, Va. 22151.)

Key words: Carpets; flame spread; kitchen cabinets; Operation BREAKTHROUGH; smoke generation; wall and ceiling.

This document is a listing of the flame spread and smoke generation results of a range of materials that were tested under the Operation BREAKTHROUGH housing evaluation program. The test results reported here were obtained under differing conditions and should not be considered the results of a comprehensive and unified research program for evaluation of interior finish materials. Tables of test results and a brief discussion of the results are presented for walls, ceilings, kitchen cabinets and floor coverings.

Fickett, F. R., Properties of nonsuperconducting technical solids at low temperatures, Proc. 4th Int. Conf. on Magnet Technology, Brookhaven National Laboratory, Upton, N.Y., Sept. 19-22, 1972, pp. 498-516 (Atomic Energy Commission, Washington, D.C., 1972).

Key words: Composite materials; electrical properties; mechanical properties; metals; plastics; review; thermal properties.

A number of physical and mechanical properties of materials used in low temperature applications are described with references to both theory and compiled data. These properties, which fall into three main groups, thermal, electrical, and mechanical, are given for pure metals, alloys, and a few nonmetals. In essence, this paper is a review of concepts and available data for low temperature engineering applications of nonsuperconductors.

Finkel, P. W., Rowen, J. W., Clinical laboratory performance analysis using proficiency test statistics, NBSIR 73-197, 61 pages (June 1973). (Available as COM 73-11253 from the National Technical Information Service, Springfield, Va. 22151.)

Key words: Accuracy; CLIA '67; clinical chemistry; hematology; microbiology; precision; proficiency testing.
The proficiency testing aspects of the Clinical Laboratory Improvement Act of 1967 program were assessed. The overall ability of licensed or volunteer laboratories to accurately determine mean values for any of the 13 constituents was not significantly altered during the first two years of program operation. However, the variability of the laboratories has decreased over the two-year period. It appears that the program has increased consistency of laboratory performance.

The general level of laboratory capability seemed to be independent of involvement in state-supported or voluntary proficiency testing programs other than the CDC program and of whether the working supervisor had a B.S., M.S., Ph.D., or M.D. degree. Choice of analytical method did significantly affect performance. Although insufficient evidence was available to make a definitive statement, the data do not appear to support arguments favoring establishment of method-dependent reference group target values.

Finally, it appears that consideration should be given to alternative sampling methods, such as reduced or skip-lot sampling, for those constituents which appear to present no analytical challenge to the licensed and volunteer laboratories. Greater emphasis might then be placed on those constituents which give the laboratories the most difficulty (cholesterol and creatinine, for example).

Flynn, D. R., Inter-Noise 72 Panel: Noise measurement-problems, perils and pitfalls, Noise/News 2 , No. 1, 7-9 (Jan.-Feb. 1973).

Key words: Acoustics; noise measurements; sound levels.

This short paper discusses some of the problems involved in noise measurements. It is pointed out that noise measurement standards should specify environmental and operational constraints in addition to precise, accurate measurement and operational procedures. A few examples are given of sources of significant measurement errors. The Measurement Assurance Programs of NBS are briefly described as a means that has been used in other disciplines to improve measurements in a total system context.

Fraker, A. C., Ruff, A. W., The effect of solution pH on the saline water corrosion of titanium alloys, (Proc. $2 \mathrm{~d}$ Int. Conf. on Titanium, Boston, Mass., May 2-5, 1972), Paper in Titanium Science and Technology, R. I. Jaffee and H. M. Burte, Eds., 4, 2655-2663 (Plenum Publishing Corp., New York, N.Y., 1973).

Key words: Corrosion; electron microscopy; pressure; salt water; titanium.

The initial stages of corrosion attack on several titanium alloys in saline water solutions have been studied. Transmission electron microscopy and electron diffraction were used to study the corrosion films formed on the exposed surfaces of thin foil specimens and to determine their degree of crystallinity and composition. The corrosion sensitivity of each material to $\mathrm{pH}$ variation was studied. Six different alloys were examined over the range $100-200{ }^{\circ} \mathrm{C}$ in a Hastelloy$\mathrm{C}$ pressure vessel containing the 3.5 wt. pct. $\mathrm{NaCl}$ solution. Sulfuric acid, hydrochloric acid and sodium hydroxide were added singly to the saline solution for individual tests with $\mathrm{pH}$ values ranging from 1.8 to 12.5 . We find that the surface oxide composition changes with different solution $\mathrm{pH}$ values. The oxide covering the surface after exposing in neutral and acid solutions does not occur in alkaline solutions. Examples of local pitting attack were found to occur at both high and low $\mathrm{pH}$ values but were more frequent when specimens were corroded in the alkaline solutions.

Fraker, A. C., Ruff, A. W., Yeager, M. P., Corrosion of titanium alloys in physiological solutions, (Proc. 2d Int. Conf. on Titanium, Boston, Mass., May 2-5, 1972), Paper in Titanium Science and Technology, R. I. Jaffee and H. M. Burte, Eds., 4, 2447-2457 (Plenum Publishing Corp., New York, N.Y., 1973). 
Key words: Alloys; biological; corrosion; electron microscopy; implant; saline solution; titanium.

This study intends to determine corrosive effects of saline and organic solutions on several titanium alloys for potential use as biological implant materials. Experimental techniques included electrochemical measurements and thin foil transmission electron microscopy and diffraction. The effects of varying alloy composition, method of specimen preparation, and different organic and salt solutions were studied. Thin foil transmission electron microscopy was used to examine surfaces of specimens exposed to salt solutions containing albumin, cystine, alanine and uric acid.

Franzen, D. L., Continuous laser-sustained plasmas, J. Appl. Phys. 44, No. 4, 1727-1732 (Apr. 1973).

Key words: Gas breakdown; laser; plasma.

Continuous plasmas sustained by a focused high-power $\mathrm{CO}_{2}$ laser are described. The power required for maintaining a cw plasma following preionization has been determined for $\mathrm{Xe}, \mathrm{Kr}$, and $\mathrm{Ar}$, and attempted for $\mathrm{Ne}$ and $\mathrm{He}$. Measurements indicate the noble gases with the lowest ionization potentials have the lowest sustaining thresholds. Radiative properties of some of the plasmas were studied with calorimetric techniques. Under certain conditions, more than half of the incident laser radiation can either be scattered or absorbed by the plasma. A major loss mechanism for the plasma is shown to be radiation in the visible and ultraviolet. Spectra of low-pressure Xe plasmas indicate the presence of ultraviolet transitions with a high contrast over the continuum.

Frenkiel, F. N., Klebanoff, P. S., Probability distributions and correlations in a turbulent boundary layer, Phys. Fluids $\mathbf{1 6}$, No. 6, 725-737 (June 1973).

Key words: Boundary layer; correlations; higher-order moments; high-speed computing; hot-wire anemometry; probability distributions.

One-dimensional and joint probability density distributions for longitudinal components of turbulent velocities as well as higher-order correlations are measured in a turbulent boundary layer on a flat plate using hot-wire anemometry and high-speed computing methods. The effect of the nonlinear response of the hot-wire is taken into account. Data pertaining to the general nature of the turbulent boundary layer are presented and comparison is made between the measured correlations and those corresponding to a Gaussian probability distribution of turbulent velocities as well as to non-Gaussian distributions of the Gram-Charlier type. Similar comparisons are made of the measured one-dimensional and joint probability distributions. Probability distributions in the boundary layer are also compared to those measured downstream of a grid. The closure of the tails of the probability distribution and its effect on the accuracy of the measurements of higher-order moments is considered.

Fröhlich, C., Geist, J., Kendall, J., Sr., Marchgraber, R. M., The Third International Comparisons of Pyrheliometers and a comparison of radiometric scales, Sol. Energy 14, 157-166 (1973).

Key words: International Pyrheliometric Scale; irradiance; pyrheliometer; World Meteorological Organization.

The Third International Comparisons of Pyrheliometers organized by the World Meteorological Organization and the Davos Observatory were held in September 1970 at Davos and Locarno. For this purpose the intensity of solar radiation was measured simultaneously by the standard radiometers (Ångström compensation and silver-disc pyrheliometers) from all over the world. For meteorological use the intensity values refer to the International Pyrheliometric Scale 1956 represented by the reference instruments of the Davos Observatory and of the Swedish Meteorological and Hydrological Institute at
Stockholm. At the same time measurements were performed by two instruments rendering an absolute value of high accuracy. These sophisticated instruments have been constructed by Kendall and Geist respectively.

A fully-automatic data acquisition system together with a computer was used to compare simultaneously the 22 Angström Pyrheliometers and to monitor the auxiliary measurements necessary for defining the state of the atmospheric conditions specified by a turbidity coefficient of $0^{\prime} 03<\mathrm{m} \beta<0^{\prime} 3$. The intensity values covered a range of $55-100 \mathrm{~mW} / \mathrm{cm}^{2}$. The results show a significant difference between the two radiometeric scales. The intensity value deduced from the absolute measurement is about 2 percent higher than the value based on the International Pyrheliometric Scale.

Fromhold, A. T., Jr., Kruger, J., Space-charge and concentration-gradient effects on anodic oxide film formation, J. Electrochem. Soc. 120, No. 6, 722-729 (June 1973).

Key words: Anodization; corrosion; oxidation.

Numerical computations illustrate the effects of space charge and a concentration gradient on the steady-state mobile-defect concentration profile and the kinetics of anodic film formation. The position-dependence of the concentration of mobile defects producing growth is shown to vary with current density and film thickness. Of especial interest is a series of curves illustrating the total electrostatic potential developed across the oxide as a function of thickness for growth under constant current conditions. Space charge is shown to have the capability of being a critical factor in retarding the growth rate of the anodic film.

Furukawa, G. T., Bigge, W. R., Riddle, J. L., Triple point of argon, (Proc. 5th Symp. on Temperature, Its Measurement and Control in Science and Industry, Washington, D.C., June 21-24, 1971), Paper in Temperature, Its Measurement and Control in Science and Industry, H. H. Plumb, Editor-in-Chief, 4, Part 1C, 231-243 (Instrument Society of America, Pittsburgh, Pa., 1972).

Key words: Argon; fixed point; triple point; temperature scale.

The average triple-point (TP) temperature of two argon cells was determined to be $83.7997_{7} \mathrm{~K}$, the two cells being within $0.38 \mathrm{mK}$ of each other and the estimated uncertainty of the value being $\pm 0.5 \mathrm{mK}$. (The uncertainty includes imprecision of the measurements and possible systematic errors.) The temperature value is based on thermometers calibrated in terms of the NBS-1955 temperature scale adjusted to the International Practical Temperature Scale of 1968 (IPTS-68). The value of temperature obtained by extrapolating the deviation function, $\Delta \mathrm{W}_{4}(\mathrm{~T})$, specified for the temperature interval $90.188 \mathrm{~K}$ to $273.15 \mathrm{~K}$ by the IPTS-68, is about $0.3 \mathrm{mK}$ lower. The argon $\mathrm{TP}$ is recommended as a defining fixed point to replace the oxygen normal boiling point.

Furukawa, G. T., Riddle, J. L., Bigge, W. R., Investigation of freezing temperatures of National Bureau of Standards tin standards, (Proc. 5th Symp. on Temperature, Its Measurement and Control in Science and Industry, Washington, D.C., June 2124, 1971), Paper in Temperature, Its Measurement and Control in Science and Industry, H. H. Plumb, Editor-in-Chief, 4, Part 1D, 247-263 (Instrument Society of America, Pittsburgh, Pa., 1972).

Key words: Fixed point; freezing point; standards; tin; tin point.

The intercomparison of freezing points was made on selected samples of tin from two series of standards that are nominally 99.9999 $(6 \mathrm{~N})$ and $99.999(5 \mathrm{~N})$ percent pure. The freezing point of each tinpoint cell prepared from the samples is reproducible within $0.05 \mathrm{mK}$ from freeze to freeze; the freezing points of the cells from each series agree with each other within $\pm 0.1 \mathrm{mK}$. The freezing points of the $5 \mathrm{~N}$ standard are on the average $0.5 \mathrm{mK}$ lower than those of the $6 \mathrm{~N}$ standard. On the basis of the chemical purity information on the samples, 
the freezing-point of the $6 \mathrm{~N}$ samples is expected to be within less than $\pm 0.7 \mathrm{mK}$ of the freezing point of 100 percent pure tin.

Furukawa, G. T., Vapor pressures of ${ }^{20} \mathrm{Ne}$ and ${ }^{22} \mathrm{Ne}$, (Proc. 5 th Symp. on Temperature, Its Measurement and Control in Science and Industry, Washington, D.C., June 21-24, 1971), Paper in Temperature, Its Measurement and Control in Science and Industry, H. H. Plumb, Editor-in-Chief, 4, Part 1B, 127-135 (Instrument Society of America, Pittsburgh, Pa., 1972).

Key words: Fixed point; ${ }^{n a t} \mathrm{Ne} ;{ }^{20} \mathrm{Ne} ;{ }^{22} \mathrm{Ne}$; neon; vapor pressure.

The results of the vapor-pressure measurements with pure neon isotopes ${ }^{20} \mathrm{Ne}$ and ${ }^{22} \mathrm{Ne}$ are described. The measurement precision is \pm 0.1 to $\pm 0.2 \mathrm{mK}$. The vapor pressures of ${ }^{n a t} \mathrm{Ne}$ calculated from the law for ideal solutions and the data on the pure neon isotopes are in agreement with the observed values on ${ }^{n a t} \mathrm{Ne}$ within about $\pm 0.5 \mathrm{mK}$. A table of normal boiling point temperatures as a function of composition of " $n a t \mathrm{Ne}$ " is given.

Gadzuk, J. W., Lucas, A. A., Field-emission tails and tunneling lifetimes, Phys. Rev. B 7, No. 11, 4770-4775 (June 1, 1973).

Key words: Field emission; surfaces; tunneling.

Recent observations of high- and low-energy tails in field-emission energy distributions can be interpreted in terms of quasi-stationarystate single-particle tunneling. This imposes a restriction on the observable range of energies in such studies. The tails result from the predicted breakdown of the transfer Hamiltonian theory of tunneling when fourth-order terms in the perturbation expansion of the tunneling matrix element become large. The tunneling lifetimes $\sim 10^{-12} \mathrm{sec}$ required to fit the experimental data are consistent with both the $R C$ time constant discussed by Thornber, McGill, and Mead and also a simple intuitive picture. Alternate theories of tunneling lifetimes are critically evaluated.

Garvin, D., Chemical kinetics data survey IV. Preliminary tables of chemical data for modelling of the stratosphere, NBSIR-203, 95 pages, (May 1973). (Available as COM 73-11288 from the National Technical Information Service, Springfield, Va. 22151.)

Key words: Atmospheric chemistry; chemical kinetics; data evaluation; energy transfer; gas phase; high temperature air chemistry; ion-molecule reactions; optical absorption cross sections; photochemistry; quantum yield; rate constants.

Chemical kinetic and photochemical data for gas phase reactions pertinent to the chemistry of the stratosphere are presented in four tables. These tables give recommended values and also cite recent experimental work. They give data in the following subject areas: chemical reactions and photochemistry of neutral species, energy transfer reactions, high temperature air reactions, and ion-molecule reactions.

Garvin, D., Chemical kinetics data survey V. Sixty-six contributed rate and photochemical data evaluations on ninety-four reactions, NBSIR 73-206, 121 pages, (May 1973). (Available as COM 73-11262 from the National Technical Information Service, Springfield, Va. 22151.)

Key words: Atmospheric chemistry; chemical kinetics; data evaluation; gas phase reactions; optical absorption cross sections; photochemistry; quantum yields; rate constants.

This report records the data evaluations contributed to the Climatic Impact Assessment Program chemical kinetics survey during the period Nov. 1972-Apr. 1973 by various kineticists and photochemists. Data are included on reactions of $\mathrm{O}\left({ }^{1} \mathrm{D}\right), \mathrm{O}\left({ }^{1} \mathrm{~S}\right), \mathrm{O}_{2}\left({ }^{1} \Delta\right)$, $\mathrm{CH}_{3} \mathrm{ONO}, \mathrm{CH}_{3} \mathrm{O}, \mathrm{CH}_{3} \mathrm{O}_{2}, \mathrm{H}_{2} \mathrm{O}_{2}, \mathrm{HO}_{2}, \mathrm{SO}, \mathrm{SO}_{2}$ and the $\mathrm{H}_{2}-\mathrm{N}_{2}-\mathrm{O}_{2}$ system.
Garvin, D., Hampson, R. F., Evaluated rate and photochemical data for modeling of the stratosphere, (Proc. $2 \mathrm{~d}$ Conf. on Climatic Impact Assessment Program, Cambridge, Mass., Nov. 14-17, 1972), DOT Report No. TSC-OST-73-4, 12 pages (Transportation Systems Center, Department of Transportation, Cambridge, Mass., 1972).

Key words: Atmospheric chemistry; chemical kinetics; data evaluation; nitrogen oxides; ozone; photochemistry; stratosphere; water.

Three important types of input data for studies of the chemistry of the stratosphere are rate constants, absorption coefficients, and quantum yields for elementary processes. About 135 of these data items are needed for studies that will define the chemistry of the stratosphere. These data are being obtained both by experiment and by review and evaluation of existing measurements.

The data-evaluation program has two parts: evaluation by a group at NBS, and a cooperative survey by a large number of gas kineticists. The evaluated data now available are summarized in a table. The possible interactions among 42 species that may be present in the stratosphere are displayed on a reaction grid. Where possible the importance of a reaction and the status of its data are indicated.

Pollutants introduced into the stratosphere will interact with the existing complex $\mathrm{O}_{3} / \mathrm{O}_{2} / \mathrm{NO}_{x} / \mathrm{HO}_{x}$ photolytic system. Laboratory studies of the $\mathrm{O}_{3} / \mathrm{O}_{2}$ and $\mathrm{O}_{3} / \mathrm{H}_{2} \mathrm{O}_{2}$ photolytic systems and rate measurements in an $\mathrm{O} / \mathrm{O}_{3} / \mathrm{NO}_{x}$ system illustrate the types and magnitudes of effects to be expected.

Garvin, D., Progress in rate evaluations, (Proc. 7th Thermochemistry Working Group, Interagency Chemical Rocket Propulsion Group, Cleveland, Ohio, Apr. 9-11, 1969), CPIA Pub. 189, I, 109-118 (Chemical Propulsion Information Agency, Johns Hopkins University, Applied Physics Laboratory, Silver Spring, Md., Aug. 1969).

Key words: Art of evaluation; chemical reactions; quality control measures; rate constants; rate evaluations.

A survey is given of recent activities in the area of evaluation of rates of chemical reactions. The problem of quality control is discussed. A recent evaluation of rates of reactions of oxygen is used to illustrate the uses of evaluated data and conclusions that can be drawn from them. A plan for expanding evaluation efforts is offered.

Geist, J., New NBS scale of irradiance, Appl. Opt. 12, No. 4, 907 908 (Apr. 1973).

Key words: Electrically calibrated detectors; irradiance; total irradiance.

This letter presents a short report on the new NBS scale of total irradiance that was recently realized with an electrically calibrated detector. The results of intercomparisons of two such detectors as well as a comparison of the new scale with the old scale as maintained at NBS are presented.

Geist, J., Theoretical analysis of laboratory blackbodies. 1: A generalized integral equation, Appl. Opt. 12, No. 6, 1325-1330 (June 1973).

Key words: Blackbody; holrahm radiation; radiometry; thermal radiative transfer.

The integral equations describing radiative equilibrium in a blackbody cavity are presented. Solving these equations in terms of the power sources in the furnace surrounding the cavity is not practical. However, if provisions are made for measuring the temperature over some surface between the power sources and the cavity interior, the analysis is feasible. This restriction and some realistic assumptions lead to a single, linear, inhomogeneous integral equation that approximately describes the interaction of the cavity geometry, the 
thermal radiative properties of the cavity wall, and the temperature gradients within the cavity in reducing the quality of the blackbody. The formulation is general enough to accomodate realistic reflectance and temperature distributions for high quality blackbodies, and the accuracy of calculations based upon it will probably not be limited by approximations involved in its derivation, but by the present state of the art in the knowledge of the thermal radiative properties of materials.

Geltman, S., Free-free radiation in electron-neutral atom collisions, J. Quant. Spectrosc. Radiat. Transfer 13, 601-613 (June 1973).

Key words: Bremsstrahlung; elastic scattering; free-free radiation.

Free-free absorption coefficients are calculated for the electronneutral atom systems involving $\mathrm{He}, \mathrm{C}, \mathrm{N}, \mathrm{O}, \mathrm{Ne}, \mathrm{Ar}, \mathrm{Kr}$, and $\mathrm{Xe}$. The calculations are based upon model atomic potentials which have been adjusted to fit experimental scattering cross sections or electron affinities. Some angular distributions are presented and thermal averages are evaluated in the ranges $\lambda=0.5-20 \mu \mathrm{m}$ and $T=500-$ $20,000 \mathrm{~K}$

Ginnings, D. C., Reilly, M. L., Calorimetric measurement of thermodynamic temperatures above $0{ }^{\circ} \mathrm{C}$ using total blackbody radiation, (Proc. 5 th Symp. on Temperature, Its Measurement and Control in Science and Industry, Washington, D.C., June 21-24, 1971), Paper in Temperature, Its Measurement and Control in Science and Industry, H. H. Plumb, Editor-in-Chief, 4, Part 1, 339-348 (Instrument Society of America, Pittsburgh, Pa., 1972).

Key words: Blackbody; calorimeter; ice point; steam point; Stefan-Boltzmann law; thermodynamic temperature scale.

Using the Stefan-Boltzmann law, a thermodynamic temperature can be determined by measuring the ratio of blackbody radiation at the unknown temperature to that at the triple point of water. This measurement requires no knowledge either of radiation constants or of geometry. For the above measurements, there has been developed a heat-flow calorimeter operating at liquid helium temperatures in which extremely small powers can be accurately measured. The radiant power absorbed by the calorimeter is measured by substituting known electrical power; if these powers are equal the substitution results in no change in the temperature of the calorimeter.

The calorimeter was originally intended for measuring the thermodynamic temperature of the melting point of gold, but as a check on its performance, measurements are being made of the ratio of radiation at $100{ }^{\circ} \mathrm{C}$ to that of $0{ }^{\circ} \mathrm{C}$ (IPTS-68). Performance tests show the calorimeter to be sensitive to a change of about $0.002{ }^{\circ} \mathrm{C}$ in the temperature of the radiator with the chosen aperture system. There is now in progress an investigation of possible errors of the measurements, including any effect of diffraction.

Gonano, R., Isothermal comparisons of $\mathrm{He}^{3}$ and $\mathrm{He}^{4}$ vapor pressures, (Proc. 5th Symp. on Temperature, Its Measurement and Control in Science and Industry, Washington, D.C., June 2124, 1971), Paper in Temperature, Its Measurement and Control in Science and Industry, H. H. Plumb, Editor-in-Chief, 4, Part 1, 121126 (Instrument Society of America, Pittsburgh, Pa., 1972).

Key words: Helium; pressure measurement; temperature scale; vapor pressure.

Isothermal measurements of $\mathrm{He}^{3}$ and $\mathrm{He}^{4}$ vapor pressures are being made in order to compare proposed vapor pressure scales in the region 0.90 to $3.32 \mathrm{~K}$. Preliminary results in the range 1.40 to 3.25 $\mathrm{K}$ show that the currently accepted scales, $\mathrm{T}_{62}$ and $\mathrm{T}_{58}$, are in close agreement with each other as was intended during the construction of $\mathrm{T}_{62}$. Observed differences are less than $0.6 \mathrm{mK}(\mathrm{rms}$ deviation $=$
$0.22 \mathrm{mK}$ ), which is within the experimental uncertainty of the present comparison. No systematic pattern is detectable in the deviations. A comparison of germanium resistance thermometers calibrated on the NBS Provisional Scale 2-20 (1965) with the vapor pressure scales shows that $\mathrm{T}_{2-20}-\mathrm{T}_{v p}$ ranges from $6 \mathrm{mK}$ at $2.3 \mathrm{~K}$ to $10 \mathrm{mK}$ at $4.2 \mathrm{~K}$, in agreement with other published values. We also discuss the techniques used to reduce or eliminate the effects on vapor pressure measurements of the aerostatic and thermomolecular pressure gradients and of the heat load due to superfluid film flow.

Grabner, L., Wong, E. Y., Zeeman effect of no-phonon ${ }^{4} \mathbf{A}_{2 g}-{ }^{4} \mathbf{T}_{2 g}$ transition of $\mathbf{C r}^{3+}$ in $\mathbf{T i O}_{2}$, Phys. Rev. B 8, No. 3, 1032-1037 (Aug. 1, 1973).

Key words: $\mathrm{Cr}^{3+}$ in $\mathrm{TiO}_{2}$; identification of excited state; ${ }^{4} \mathrm{~A}_{2 g}$. ${ }^{4} \mathrm{~T}_{2 g}$ transition; Zeeman effect.

The site symmetry of $\mathrm{Cr}^{3+}$ in $\mathrm{TiO}_{2}$ is $D_{2 h}$ which splits the cubic $\left(O_{h}\right)$ ${ }^{4} T_{2 g}$ state into ${ }^{4} B_{1 g},{ }^{4} B_{2 g}$, and ${ }^{4} B_{3 g}$. Spin-orbit interaction further splits these states into six Kramers doublets all of symmetry $\Gamma_{5}{ }^{+}$. Previous optical work on $\mathrm{TiO}_{2}: \mathrm{Cr}^{3+}$ established the lowest-lying sharp lines at 12685 and $12732 \mathrm{~cm}^{-1}$ as no-phonon lines of magnetic dipole character. It proposed these lines as due to transitions between the ${ }^{4} A_{2 g}$ ground state and two of the above six states. The present report extends this work by a Zeeman study, in emission, at $4 \mathrm{~K}$ of the line at $12685 \mathrm{~cm}^{-1}$. The results are: The Zeeman splitting of this line identifies the excited state of this transition as the $M_{s}= \pm 3 / 2$ spinorbit component of an orbital state consisting of $77 \%{ }^{4} \mathrm{~B}_{2 g}, 17 \%{ }^{4} \mathrm{~B}_{1 g}$, and $6 \%{ }^{4} B_{3 g}$ with an effective $g=1.73$. Furthermore, the line at 12732 $\mathrm{cm}^{-1}$ is identified as the $M_{s}= \pm 1 / 2$ spin-orbit component by its effect in second order in the magnetic field on the Zeeman pattern of the line at $12685 \mathrm{~cm}^{-1}$. For the excited state the spin is quantized along the $x$ direction of the magnetic axes while for the ground state it is quantized along the $z$ direction. The reason for spin quantization along the $x$ axis is discussed.

Guildner, L. A., Anderson, R. L., Edsinger, R. E., Effects of sorption on the realization of the thermodynamic scale, (Proc. 5th Symp. on Temperature, Its Measurement and Control in Science and Industry, Washington, D.C., June 21-24, 1971), Paper in Temperature, Its Measurement and Control in Science and Indus. try, H. H. Plumb, Editor-in-Chief, 4, Part 1E, 313-322 (Instrument Society of America, Pittsburgh, Pa., 1972).

Key words: Gas thermometer; sorption; steam point; thermodynamic temperature scale.

The NBS Gas Thermometer is of the constant volume type. It has a $450 \mathrm{~cm}^{3}$ platinum- $20 \%$ rhodium bulb connected by a $0.9 \mathrm{~mm}$ internal diameter tube to a diaphragm at room temperature. The measured quantities contribute an estimated uncertainty of 5 parts per million. The gas thermometer has such stability that, upon return to the fiducial temperature, the pressure is reproduced within one or two parts per million for periods of a week or more. This stability is attributed to a marked reduction of sorption effects achieved by the following: (1) The thermometer bulb is subjected to prolonged pumping at high temperatures prior to measurements. (2) With most of the contaminants removed by this procedure, and the use of very pure helium as a thermometric fluid, there is too little active gas left to produce erratic results from sorption. The value of the temperature at the steam point on the thermodynamic Celsius scale has been determined as $99.973{ }^{\circ} \mathrm{C}$. A final certainty is not assigned.

Hall, J. L., Bordé, C., Measurement of methane hyperfine structure using laser saturated absorption, Phys. Rev. Lett. 30, No. 22, 1101-1104 (May 28, 1973).

Key words: Hyperfine spectrum; laser stabilization; methane; spectoscopy.

With optical resolution above $10^{10}$, we study hyperfine structure in the methane vibration-rotation line at $3.39 \mu \mathrm{m}$. Doppler-generated 
crossing resonances were observed in addition to the resolved $\Delta F=0$ and -1 lines. Splittings in both ground and excited states were determined. Differential saturation of such hyperfine structure will lead to an intensity-dependent shift in many molecularly stabilized lasers.

Hamilton, C. A., Analog-computer studies of mixing and parametric effects in Josephson junctions, J. Appl. Phys. 44, No. 5, 2371-2377 (May 1973).

Key words: Analog; Josephson junction; mixing; parametric.

Analog-computer studies are made on a variety of mixing and parametric effects in Josephson junctions. The predictions of the constant-voltage model are compared with the more general behavior of a junction in a resistive circuit. A simple approximate method is developed for calculating frequency conversion efficiency and the matching condition for a junction operating in the oscillator mixer mode. A similar calculation is made for the second mode of operation, in which an external local oscillator is used. In either of these modes, frequency conversion gain is possible even in a purely resistive circuit. The conditions for parametric amplification without frequency conversion are also studied and it is found that gain occurs only when the self-oscillation frequency is near the signal frequency.

Hastie, J. W., Mass spectrometric studies of flame inhibition: Analysis of antimony trihalides in flames, Combust. Flame 21, 49-54 (1973).

Key words: Antimony trihalides; flame inhibition; flames; mass spectrometry.

The chemistry of $\mathrm{SbBr}_{3}$ and $\mathrm{SbCl}_{3}$ in 1 atm premixed fuel rich $\mathrm{CH}_{4-}$ $\mathrm{O}_{2}$ and $\mathrm{CH}_{4}-\mathrm{O}_{2}-\mathrm{N}_{2}$ flames has been studied. Using line-of-sight mass spectrometric techniques, concentration profiles were obtained for the major species $\mathrm{SbX}_{3}, \mathrm{HX}, \mathrm{CH}_{3} \mathrm{X}, \mathrm{X}, \mathrm{Sb}$, and $\mathrm{SbO}$, where $\mathrm{X}=\mathrm{Br}$ or Cl. Reaction mechanisms are indicated and their relation to flame inhibition discussed. Evidence for a negligible perturbation of the flame kinetics by the sampling procedure is given.

Hauge, R. H., Margrave, J. L., Hastie, J. W., Infrared spectra of matrix isolated $\mathbf{Z r F}_{2}, \mathbf{Z r F}_{3}$, and $\mathbf{Z r F}_{4}$, High Temp. Sci. 5, 89-96 (1973).

Key words: Entropy; geometry; infrared spectra; matrix isolation; stability; $\mathrm{ZrF}_{2}, \mathrm{ZrF}_{3}, \mathrm{ZrF}_{4}, \mathrm{CaF}_{2}$.

By using the multiple Knudsen cell technique the equilibrium species $\mathrm{ZrF}_{2}, \mathrm{ZrF}_{3}$, and $\mathrm{ZrF}_{4}$ have been produced and isolated in rare gas solid matrices. From infrared spectra, the antisymmetric stretch frequencies have been assigned for each species. Isotope shift measurements indicate a $120^{\circ} \pm 4^{\circ}$ bond angle for the $\mathrm{C}_{2 v}-\mathrm{ZrF}_{2}$ species, the symmetry being verified by the observation of the symmetric stretch frequency. The results are compared with those of the Ti-F and similar systems. The measured frequencies and bond angle of $\mathrm{ZrF}_{2}$ were used to determine the entropy and $\mathrm{FEF}$ data for $\mathrm{ZrF}_{2}$ at various temperatures.

Heinrich, K. F. J., Errors in electron probe microanalysis, Proc. of the Seminar on Quantitative Analysis with Electron Microprobes and Secondary Ion Mass Spectrometry, Jülich, Germany, Oct. 1820, 1972, pp. 68-79 (Mar. 1973).

Key words: Data reduction; electron probe; errors; microanalysis; $\mathrm{x}$-ray measurement.

Errors in quantitative electron probe microanalysis are due to errors in the measurement of relative characteristic $x$-ray intensities and in the interpretation of the experimental measurements. The random errors in the $x$-ray measurement include those due to Poisson's statistics, but other sources must not be excluded from consideration. Systematic errors may be committed in the estimation of coincidence losses (dead-time) and background. Those arising in the evaluation of the data may be due to the theoretical models, or to the parameters and constants which enter the calculation. Satisfactory models require adjustment to empirical measurements, and improvement in the accuracy of electron probe microanalysis requires the performing of critical experiments which can lead to further adjustment of the models. It is also important to adjust the conditions of measurement so as to minimize the effects of uncertainties and errors in models and parameters.

Heinrich, K. F. J., The application of Monte-Carlo calculations in electron probe microanalysis, Proc. of the Seminar on Quantitative Analysis with Electron Microprobes and Secondary Ion Mass Spectrometry, Jülich, Germany, Oct. 18-20, 1972, pp. 149155 (Mar. 1973).

Key words: Data reduction; electron probe; Monte-Carlo calculations; thin layers.

The simulation of electron trajectories by means of the MonteCarlo calculations offers an attractive alternative to the conventiona data reduction procedures in electron probe microanalysis. It is particularly flexible with regard to specimen geometry, and should be very useful for the analysis of thin films and similar materials. How ever, as in the conventional procedures, approximations and empirical adjustments are necessary for the development of a useful model. The experiences derived from such a model can in turn be used to improve the conventional algebraic correction schemes.

Hessel, M. M., Lucatorto, T. B., The rotating heat-pipe oven; a universal device for the containment of atomic and molecular vapors, Rev. Sci. Instrum. 44, No. 5, 561-563 (May 1973).

Key words: Heat pipe; indium iodide; laser application; sodium; spectroscopic application.

A new type of heat-pipe oven has been developed that uses centrifugal force as a return mechanism for the condensed vapors in con trast to capillary return forces for the conventional heat-pipe oven. Since this new oven is no longer limited to materials that wet wicks, it can be used to contain any material that does not react with the walls of the containing vessel. We describe the operation of this oven with sodium and InI even when the InI is solid. Spectroscopic and laser applications of the "rotating" heat-pipe oven are discussed.

Hsieh, C., Thomson, R., Lattice theory of fracture and crack creep, J. Appl. Phys. 44, No. 5, 2051-2063 (May 1973).

Key words: Creep of crack; fracture; lattice theory.

A quasianalytic solution for the atomic displacements of a discrete two-dimensional lattice containing a crack is obtained. We assume that the force laws are linear up to a critical displacement when the bond snaps, which is the basic assumption of the lattice static approximation. When compared to the classic Griffith continuum description, new results are: (i) a predicted and observable lattice trapping of the crack, (ii) difficulties with the interpretations of the crystal surface energy in a cleavage experiment, and (iii) a predicted characteristic crack creep phenomenon under external constant stress. The present theory shows how two separate "surface energies" are inferred from the stress to open and to close a crack, and on our model these energies differ from one another by a large factor of 5.7. The thermodynamic "surface energy" is not related to either of these quantities. Experimental verification of the lattice trapping of cracks is thought to be most readily and directly obtained by observations of the creep of a crack under high vacuum conditions.

Hudson, R. P., Pfeiffer, E. R., Temperature scale for cerous magnesium nitrate, (Proc. 5th Symp. on Temperature, Its Measurement and Control in Science and Industry, Washington, D.C., June 21-24, 1971), Paper in Temperature, Its Measurement and Con- 
trol in Science and Industry, H. H. Plumb, Editor-in-Chief, 4, Part 2, 1279-1285 (Instrument Society of America, Pittsburgh, Pa., 1972).

Key words: Cerous magnesium nitrate; low temperature; magnetic temperature; temperature scale; thermometry.

Below $1 \mathrm{~K}$, cerous magnesium nitrate $(\mathrm{CMN})$ should obey the Curie Law over a wide temperature range and show deviations only in consequence of the dipolar coupling between ions. The susceptibility deviation should be accounted for by a very small Curie-Weiss $\theta$ (theoretical value, $0.27 \mathrm{mK}$ ) and the entropy should vary as $\ln 2-$ $\mathrm{AT}^{-2}+\mathrm{BT}^{-3}-\mathrm{CT}^{-4}+\ldots$, with theoretical values now available for A, B and-somewhat less firmly based -C. These show that representation of $S(T)$ by the term in $A$ alone is justifiable only above $0.1 \mathrm{~K}$. We present experimental values for A, B, and C arising from recent measurements together with new results for the magnetic temperature, $T^{*}$, scale derived from $\gamma$-ray heating calorimetry.

Huggett, C., Carpet flammability and the NBS corridor fire program, ASTM Stand. News 1, No. 5, 16-20 (May 1973).

Key words: Carpets; corridor fires; fire test; flammability; floor coverings.

The NBS corridor fire program was designed to study the effects of configuration, fuel loading and distribution, ventilation, and other design parameters on the spread of fire through corridors in multiple occupancy buildings. A fully instrumented $8 \mathrm{ft} \times 8 \mathrm{ft} \times 30 \mathrm{ft}$ corridor is used to carry out full-scale experiments. Fires are started in a connecting $8 \mathrm{ft} \times 8 \mathrm{ft} \times 9 \mathrm{ft}$ fire room and the rate and intensity of fire spread in the corridor is observed.

Floor coverings have received special attention during the initial phase of the program. With a sufficiently intense room fire source, fire can spread rapidly over the surface of a carpet in the corridor, even with noncombustible wall and ceiling surfaces. Radiative energy transfer to the carpet surface appears to be the controlling mechanism. When the carpet starts to burn, additional energy feedback causes an accelerated propagation down the corridor. The fire spread is characterized in terms of critical energy input necessary to cause propagation, rate of fire spread, and energy contribution of the carpet to the fire.

Results of typical experiments are described. Preliminary experiments relating to the development of a test method to assess the hazard potential of floor coverings in building, based on a critical energy concept, are described.

Hust, J. G., Clark, A. F., A survey of compatibility of materials with high pressure oxygen service, Cryogenics 13, No. 6, 325336 (June 1973).

Key words: Compatibility data; high pressure; oxygen; safety; survey.

The literature on high pressure oxygen compatibility has been surveyed in order to present the existing state of knowledge. Searches have been conducted of NASA and NBS data retrieval systems. In addition, many individuals, active in the field, were contacted in order to retrieve useful unpublished information. Compatibility data, such as mechanical impact, pneumatic impact, ignition temperature, and flash-and-fire point, were compiled for pressures above 200 bar $\left(2 \times 10^{7} \mathrm{Nm}^{-2}\right)$. Lower pressure data were included if they were useful for extrapolation to pressures above 200 bar. These data, too numerous to be given here, are available from the authors. Brief descriptions of the trends of these data are given. Recommendations for additional high pressure studies are included.

Hust, J. G., Powell, R. L., Sparks, L. L., Methods for cryogenic thermocouple thermometry, (Proc. 5th Symp. on Temperature, Its Measurement and Control in Science and Industry,
Washington, D.C., June 21-24, 1971), Paper in Temperature, Its Measurement and Control in Science and Industry, H. H. Plumb, Editor-in-Chief, 4, Part 3, 1525-1535 (Instrument Society of America, Pittsburgh, Pa., 1972).

Key words: Cryogenics; thermocouples; thermometry.

Accurate cryogenic thermocouple thermometry is only possible if care is taken in material selection, general experimental design, thermocouple calibration and assembly, and measurement techniques. After several years' research on both calibration and usage of thermocouples, we have developed procedures and tests that minimize experimental temperature errors and give realistic estimates of the inaccuracies.

Some material selection criteria are listed and recommendations are given for a few common experimental conditions. Simple experimental systems are described that may be used for tests to determine static or dynamic short range inhomogeneities, variability and interchangeability of different lots, and deviations from standard values. Methods for adding corrections to the standard tables are also given.

Good design criteria and methods of thermocouple assembly can lead to significant improvement in accuracies. Specific topics of discussion include reference junction placement, thermal tempering, heat conduction and radiation shielding, electrical connections, and electrical shielding.

Jacox, M. E., Milligan, D. E., Matrix isolation study of the vacuum-ultraviolet photolysis of methanol. The infrared spectrum of the $\mathrm{CH}_{2} \mathrm{OH}$ free radical, J. Mol. Spectrosc. 47, No. 1, 148-162 (July 1973).

Key words: $\mathrm{CH}_{2} \mathrm{OH}$; force constants; infrared spectrum; matrix isolation; methanol; vacuum-ultraviolet photolysis.

Infrared studies of the products of the $1470 \AA$ photolysis of normal and isotopically substituted methanol isolated in argon and nitrogen matrices at $14{ }^{\circ} \mathrm{K}$ have provided evidence for the stabilization of a significant yield of $\mathrm{CH}_{2} \mathrm{OH}$. Assuming a slightly nonplanar structure for the molecule, it has been possible to obtain an approximate valenceforce potential field which provides a reasonable fit to virtually all of the data. The $\mathrm{C}-\mathrm{O}$ bond of $\mathrm{CH}_{2} \mathrm{OH}$ is slightly stronger than that of methanol, and the torsional barrier is significantly greater, in accord with previous electron spin resonance observations. There is no evidence for the production or stabilization of $\mathrm{CH}_{3} \mathrm{O}$ in the matrix. $\mathrm{CH}_{2} \mathrm{OH}$ undergoes photodecomposition upon exposure to radiation in the 2300-2800 $\AA$ spectral region, leading to a growth in the HCO absorptions.

Jones, F. E., Air density and helicopter lift, Joint Army-Navy Aircraft Instrumentation Research, JANAIR Report No. 721201, 54 pages (Available as AD 754420 from the National Technical Information Service, Springfield, Va. 22151, Jan. 1973).

Key words: Air density; helicopter lift; ideal gas law.

An analysis has been made of ideal and real gas equations as they apply to the calculation of air density in the region of interest for helicopter flight. The uncertainties in calculated air density due to uncertainties in measurements of temperature, pressure and humidity have been investigated and estimates have been made of measurement accuracies which would be required to enable calculation of air density with a desired relative uncertainty. A reference system has been assembled to provide measurements of temperature, pressure and dew-point temperature aboard a helicopter. This system is to be used in making calculations of reference air density for flight tests of a system for computing hover lift margin and several devices for measuring air density. The effects on hover lift margin, defined by a simple equation, of relative uncertainties in air density and power have been investigated. Nuclear statistics as they apply to "direct" mea- 
surements of air density by application of nuclear radiation are discussed.

Kamper, R. A., Simmonds, M. B., Adair, R. T., Hoer, C. A., Quantum mechanical measurement of rf attenuation, Proc. 1972 Applied Superconductivity Conf., Annapolis, Md., May 1-3, 1972, pp. 696-700 (IEEE, Inc., New York, N.Y., 1972).

Key words: Josephson effect; quantum interference; rf attenuation; rf measurements; superconductivity.

We have used a broadband Superconducting QUantum Interference Device (SQUID), operating at a frequency of $9 \mathrm{GHz}$, as a sensor of current at lower radio frequencies. The periodic nature of the response of the SQUID enabled us to measure variations in rf attenuation directly. The results of such a measurement were in agreement with the NBS Calibration Service to within $\pm 0.004 \mathrm{~dB}$ over a dynamic range of $40 \mathrm{~dB}$. We also discuss other applications of this SQUID to rf measurements.

Kamper, R. A., Survey of noise thermometry, (Proc. 5th Symp. on Temperature, Its Measurement and Control in Science and Industry, Washington, D.C., June 21-24, 1971), Paper in Temperature, Its Measurement and Control in Science and Industry, $\mathrm{H} . \mathrm{H}$. Plumb, Editor-in-Chief, 4, Part 1, 349-354 (Instrument Society of America, Pittsburgh, Pa., 1972).

Key words: Absolute temperature; thermal noise; thermometry.

This survey covers various techniques which have been developed to estimate relative or absolute temperatures by measuring various parts of the spectrum of thermal noise at frequencies in the microwave range and below. It includes a report of the author's own work on absolute noise thermometry in the millikelvin range of temperature.

Keplinger, M. S., The case for invisible copies, Proc. 33d Annual Meeting of the American Society for Information Science, Philadelphia, Pa., Oct. 11-15, 1970, 7, 241-243 (1970).

Key words: Computers; copyright; information storage and retrieval; infringement; input; intellectual property; proprietary rights.

The problem of control of the use of copyrighted works in computerized information storage and retrieval systems is discussed. It is concluded that such input may be considered copyright infringement under the current Copyright Revision Bill as interpreted through the teachings of recent court decisions, as well as being an infringement under the current copyright statute.

Kirchhoff, W. H., Microwave spectroscopy, Chem. Eng. News 47, 88-98 (Mar. 24, 1969).

Key words: Dipole moment; microwave spectroscopy; molecular rotation; molecular structure; qualitative analysis; quantitative analysis.

A review of microwave spectroscopy is presented with special emphasis on its applications to problems of chemical interest. The fundamental concepts of molecular rotation are discussed using classical mechanics, and the relationship of molecular structure and forces with the molecular rotation is presented. The quantum mechanical model is then presented with sufficient detail to understand the nature of rotational spectroscopy. The Stark effect and its dependence on the molecular dipole moment is briefly described. Recent instrumental advances as well as the application of microwave spectroscopy to quantitative and qualitative analysis are mentioned.

Koonce, C. S., Enhancement effects: Theory, (Proc. of a Summer Course on The Science and Technology of superconductivity, held at Georgetown University, Washington, D.C., Aug. 13-26, 1971),
Paper in The Science and Technology of Superconductivity, W. D. Gregory, W. N. Mathews, Jr., and E. A. Edelsack, Eds., 1, 389-403 (Plenum Press, New York, N.Y., 1973).

Key words: Dielectric function; superconductor; transition metal; transition temperature.

A discussion of which modifications of normal state properties such as phonon frequencies and electronic density of states as a function of energy are likely to enhance the superconducting transition temperature will be given. A discussion of the methods of modification of the material properties such as alloying, doping applying pressure and forming thin films will also be given.

Koonce, C. S., Theory of superconducting semiconductors, (Proc. of a Summer Course on The Science and Technology of Superconductivity, held at Georgetown University, Washington, D.C., Aug. 13-26, 1971), Paper in The Science and Technology of Superconductivity, W. D. Gregory, W. N. Mathews, Jr., and E. A. Edelsack, Eds., 1, 373-387 (Plenum Press, New York, N.Y., 1973).

Key words: Energy gap equation; semiconductors; superconductor; transition temperature.

The BCS theory of superconductivity will be applied to degenerate semiconductors. Methods of calculating superconducting properties of degenerate semi-conductors will be compared with methods used to calculate superconducting properties of metals. The normal state properties of degenerate semiconductors which are important in determining the superconducting properties will be discussed.

Kruger, J., Application of ellipsometry to electrochemistry, Chapter in Advances in Electrochemistry and Electrochemical Engineering, R. H. Muller, Ed., 9, 227-280 (John Wiley \& Sons, Inc., New York, N.Y. 1973).

Key words: Corrosion; electrochemistry; electropolishing; ellipsometry; electrodeposition.

A review of the application of ellipsometry to electrochemistry is given which considers the electrochemical phenomena of passivation and corrosion, electroadsorption, electrodeposition and electropolishing. The ellipsometry of bare surfaces and gaseous adsorption as related to electrochemistry is discussed. Both the advantages and limitations of the techniques are considered. Over a hundred references are cited.

Kuriyama, M., Dynamical diffraction equations for imperfect crystals, $Z$. Naturforsch. 28a, No. 5, 622-626 (1973).

Key words: Canonical transformation; dynamical diffraction; imperfect crystal.

The ray theory of Kato and Kambe for imperfect crystals is derived in a formal way from a general dynamical theory of diffraction. This development together with the results from a previous paper concerning Takagi's equation (the wave theory) helps to clarify the meaning and limits of various phenomenological theories that have been extended to an imperfect crystal from the dynamical diffraction theory for a perfect crystal.

LaFleur, P. D., Retention of mercury when freeze-drying biological materials, Anal. Chem. 45, No. 8, 1534-1536 (July 1973).

Key words: Freeze-drying; lyophilization; mercury; mercury loss; methylmercury; nuclear activation analysis; phenylmercuric acetate.

The retention on freeze-drying of three compounds of mercury tagged with mercury-203 and fed to experimental animals, has been measured. The compounds employed in the investigation were methylmercuric chloride, phenylmercuric acetate and mercuric nitrate. The retention of mercury was determined radiometrically on 
individual tissues and on blood and feces. The effect of prefreezing the samples, prior to the lyophilization cycle, was also studied.

\section{LaVilla, R. E., $\mathbf{M}_{2,3}$-Region $x$-ray emission spectrum from gase- ous krypton, Phys. Rev. A. 8, No. 2, 1143-1145 (Aug. 1973).}

Key words: Double electron single vacancy process; final state configuration interaction; krypton; $\mathrm{M}_{2,3}$ x-ray emission; single electron double vacancy process.

The $\boldsymbol{M}_{2,3}$ x-ray emission spectrum of gaseous krypton excited by direct electron bombardment has been recorded with a scanning single-flat crystal spectrometer. The most prominent spectral features are two peaks at 187 and $203 \mathrm{eV}$, with the $187-\mathrm{eV}$ peak having an extended low-energy tail. This low-energy tail is attributed to doubleelectron single-vacancy transitions owing to the strong mixing of the final-state configuration $4 s 4 p^{6}{ }^{2} S$ with the even levels $4 s^{2} 4 p^{4} n s^{2} S$ and $4 s^{2} 4 p^{4} n d{ }^{2} S$. The $203-\mathrm{eV}$ peak is identified as probably the single-electron double-vacancy $M_{2,3} M_{2,3} \rightarrow M_{2,3} N_{1}$ multiplet complex.

Leasure, W. A., Jr., Rubin, A. I., Fath, J. M., Fisher, R. L., Flynn, D. R., Fundamentals of noise: Measurement, rating schemes, and standards, Environmental Protection Agency Report No. NTID300.15, 163 pages (Available as PB 206727 from the National Technical Information Service, Springfield, Va. 22151, Dec. 31, 1971).

Key words: Acoustics; environmental pollution; noise; sound.

This report is intended to serve as an introduction to noise, including the inter-relationship between physical measures and psychological responses. The basic principles of sound generation and propagation are discussed as well as the measurement of both the physical attributes of noise and the effects of noise on people. The suitability and effectiveness of various noise exposure rating schemes, used to estimate or predict the effects of noise on man, are discussed and critiqued. Included are sample calculations of sound level, loudness level, and perceived noise level for five selected spectra. The need is stressed for inclusion of well-defined environmental and operational requirements into measurement procedures for those devices where the noise produced is dependent on the surroundings and the operation of the device. Also presented are a glossary of pertinent acoustic terminology and a compilation of existing standards related to noise, including a brief description of the intent and scope of each.

Lee, R. D., Kostkowski, H. J., Quinn, T. J., Chandler, P. R., Jones, T. P., Tapping, J., Kunz, H., Intercomparison of the IPTS 68 above $1064{ }^{\circ} \mathrm{C}$ by four national laboratories, (Proc. 5th Symp. on Temperature, Its Measurement and Control in Science and Industry, Washington, D.C., June 21-24, 1971), Paper in Temperature, Its Measurement and Control in Science and Industry, H. H. Plumb, Editor-in-Chief, 4, Part 1, 377-393 (Instrument Society of America, Pittsburgh, Pa., 1972).

Key words: International temperature scale; pyrometry; standards; temperature.

The International Practical Temperature Scale above the melting point of gold, as realized and maintained with high precision photoelectric pyrometers at NBS, NPL, NSL and PTB, has been intercompared. Six specially selected tungsten strip lamps, four vacuum and two gas, were used in the intercomparison. Determinations were made at a number of brightness temperatures from 1064 to $1700{ }^{\circ} \mathrm{C}$ and at $2200{ }^{\circ} \mathrm{C}$ with the laboratories agreeing to within a few tenths of a degree up to $1700{ }^{\circ} \mathrm{C}$ and $2.0^{\circ} \mathrm{C}$ at $2200{ }^{\circ} \mathrm{C}$.

Lee, T. G., Huggett, C., Interlaboratory evaluation of the tunnel test (ASTM E 84) applied to floor coverings, NBSIR 73125, 56 pages, (Mar. 1973). (Available as COM 73-11189 from the National Technical Information Service, Springfield, Va. 22151.)

Key words: ASTM E 84; building materials; carpets; fire tests; flame spread tests; interlaboratory evaluation; round robin; statistical analysis; test method standard.

Results of an interlaboratory evaluation of the ASTM E 84 tunnel test method involving eleven laboratories and nine materials, including four carpets, are reported. Data on flame spread, smoke, and fuel contribution are analyzed statistically. Selected physical characteristics of each tunnel are tabulated and compared relative to specifications in the test method. The between-laboratory coefficient of variation (reproducibility) in flame spread classification (FSC) was found to range from 7 to $29 \%$ for the four carpets and from 18 to $43 \%$ for the other materials tested. The between-laboratory coefficients of variation for smoke developed and fuel contribution ranged from 34 to $85 \%$ and from 22 to $117 \%$ respectively for all materials tested. The causes of higher variability in smoke and fuel contribution measurement between laboratories is not definitely known but may reasonably be attributed to variations in tunnel construction, maintenance, and operation, in the location of photometers, and in the mounting of thermocouples in different laboratories. Some variability of results may possibly be due to variation in test specimens. Variation in construction and measurement techniques among tunnels may be minimized by updating the test method standard.

Le Neindre, B., Tufeu, R., Bury, P., Sengers, J. V., Thermal conductivity of carbon dioxide and steam in the supercritical region, Ber. Bunsenges. Physik. Chem. 77, No. 4, 262-275 (1973).

Key words: Carbon dioxide; critical phenomena; steam; thermal conductivity; transport properties.

The thermal conductivity of carbon dioxide and steam has been measured as a function of temperature and density using a concentric cylinder method. Earlier measurements of the thermal conductivity of $\mathrm{CO}_{2}$, obtained with a parallel plate method, covered a range of temperatures from 25 to $75^{\circ} \mathrm{C}$ and revealed the existence of an anomalous thermal conductivity in the critical region. In this paper the experimental temperature range for the thermal conductivity of $\mathrm{CO}_{2}$ is extended to $700{ }^{\circ} \mathrm{C}$. The high temperature data enable us to determine a "background" thermal conductivity needed for a quantitative analysis of the anomalous thermal conductivity in the critical region. In addition, we provide experimental evidence that the thermal conductivity of steam exhibits an anomalous increase in the critical region similar to the behavior observed for the thermal conductivity of $\mathrm{CO}_{2}$.

Lew, H. S., The effect of impact loadings on the performance of wood joist subflooring systems, NBSIR 73-187, 49 pages (May 1973). (Available as PB 221188 from the National Technical Information Service, Springfield, Va. 22151.)

Key words: Concentrated loads; deflection; floor hardboard; housing; impact energy; Operation BREAKTHROUGH; plywood; subfloors; underlayment; wood; wood joists.

This report presents the results of an experimental study of woodjoist subflooring systems subjected to impact load. Six different types of subflooring systems were tested following the test method described in the ASTM Standard Methods (ASTM Designation E-72). The magnitude of impact load was varied by dropping a $60-\mathrm{lb}$ bag from different heights.

A concentrated static load of $400 \mathrm{lb}$ was applied to the subfloor after it was exposed to impact load. It is suggested that the deflection under this concentrated load be used as a measure of the impact resistance of the subfloor.

Liebman, J. F., On the electron affinity of perfluorocycloalkanes and perfluoroalkanes, J. Fluorine Chem. 3, 27-33 (1973/74).

Key words: Electron affinity; fluorocarbons; orbital; perfluoroalkanes; perfluorocycloalkanes. 
There is an increasing body of evidence showing that perfluorocycloalkanes have a higher electron affinity than their open chain analogs, the perfluoroalkanes. A new molecular orbital model is presented to explain these results and compared with the electrostatic model of Mittal and Libby. Explicit experiments are suggested which would allow comparison of the two models.

Linsky, J. L., A recalibration of the quiet sun millimeter spectrum based on the moon as an ubsolute radiometric standard, Solar Phys. 28, No. 2, 409-418 (Feb. 1973).

Key words: Millimeter absolute radiometry; millimeter solar continuum; solar chromosphere.

The solar millimeter continuum between 1 and $20 \mathrm{~mm}$ is recalibrated using observations of the average lunar brightness temperature at the center of lunar disk and new Moon brightness temperatures. The solar data are placed on a common scale according to the average lunar brightness temperature distribution proposed by Linsky. A least-squares parabolic regression curve is proposed for the solar millimeter continuum. A small departure from this regression curve near $8 \mathrm{~mm}$ may indicate the existence of an absorption feature.

Lozier, D. W., Maximon, L. C., Sadowski, W. L., A bit comparison program for algorithm testing, Comput. J. 16, No. 2, 111-117 (May 1973).

Key words: Algorithm testing; bit comparison testing; computer algorithm; mathematical function subroutines.

In view of the increasingly important role of the computer in scientific calculations, the development of computer algorithms for elementary and special functions has been given a great deal of attention. The development of algorithms cannot be divorced from their evaluation, for a computer algorithm is judged solely on the basis of its performance characteristics. These include storage requirements, speed and accuracy. The present paper will deal only with the accuracy aspect of algorithm testing. The other two aspects must be evaluated in the context in which the algorithm is used. In this paper by an algorithm we mean a computer algorithm, i.e., an implementation of a mathematical algorithm in a specific environment. The environment is taken to include factors that may affect the algorithm, e.g., the operating system under which the program is run and hardware algorithms for arithmetic operations. Whereas in some instances mathematical algorithms have been successfully used to locate hardware malfunctions that were not traceable by normal trouble shooting tests, any malfunctions of the software or hardware will not be considered here to be part of the environment.

Maienthal, E. J., Determination of trace elements in metals by differential cathode ray polarography, Amer. Lab., pp. 25-33 (1972).

Key words: Alloys; analyses; cast irons; differential cathode ray polarography; high purity materials; metals; steels; trace elements.

Some of the recent applications of cathode ray polarography at NBS to the determination of a number of trace elements in different metal matrices will be discussed. Some of the elements could be determined directly with no separations. The elements determined included aluminum, antimony, copper, cadmium, iron, lead, bismuth, and tellurium in matrices such as steels, high temperature alloys, white cast irons, brasses, bronzes, and high purity metals. The results will be compared with those obtained by other techniques.

Maki, A. G., Sams, R. L., Olson, W. B., Infrared determination of $\mathrm{C}_{0}$ for phosphine via perturbation-allowed $\Delta|\mathbf{k}-l|= \pm 3$ transitions in the $\mathbf{3} \boldsymbol{\nu}_{2}$ band, J. Chem. Phys. 58, No. 10, 4502 . 4512 (May 15, 1973).
Key words: Forbidden transitions; ground state splitting; infrared spectrum; perturbation allowed transitions; phosphine; rotational constants.

The $3 \nu_{2}\left(A_{1}\right)$ and $4 \nu_{2}-\nu_{2}\left(A_{1}\right)$ infrared bands of $\mathrm{PH}_{3}$ have been measured with high resolution. In the $\nu_{2}=3$ state an interaction between the $K$ and $K \pm 3$ levels gives rise to perturbation allowed $\Delta K=3$ transitions through a weak high order interaction. Since only one component of the $K=3$ levels is of the proper symmetry to interact with the $K=0$ levels there is a splitting of the $K=3$ levels. Also detectable is the splitting of the $K=3$ levels of the ground vibrational state. The measurements have been combined with microwave measurements to give accurate values for the ground state rotational constants $B_{0}, C_{0}, D_{0}{ }^{J}, D_{0}{ }^{J K}, D_{0}{ }^{K}, H_{0}{ }^{J}, H_{0}{ }^{J J K}$, and $H_{0}{ }^{J K K}$. The absence of observable inversion effects sets an upper limit of about $0.02 \mathrm{~cm}^{-1}$ for the inversion splitting of the $4 \nu_{2}$ level.

Martin, W. C., Some aspects of the energy-level structures of lanthanide atoms and ions, Opt. Pura Apl. 5, No. 3, 181-191 (1972).

Key words: Atomic spectra; energy levels; rare earths.

The development of our understanding of some main features of these structures is reviewed, and the present degree of completeness of the analyses and theoretical interpretations of the spectra is indicated. Energy differences of the type $4 f^{N-1} n l\left(6 s^{M}\right)-4 f^{N}\left(6 s^{M}\right)$ (with each configuration represented by its lowest level) are of special importance, both for the analyses of a number of the spectra and for the interpretation of certain basic data for metals and compounds of these elements. The general behavior of such differences as a function of $\mathrm{N}$ is understood, and the resulting graphs are very similar to the d-shell energy-difference graphs studied by Catalán, Rohrlich, and Shenstone, and by Racah. The data confirm striking regularities among the f-shell graphs, first used by Racah, that yield predictions of unknown system differences and, for third and higher spectra, of inonization energies $(M=0, n=\infty)$.

McCamy, C. S., Pope, C. I., Redox blemishes - their cause and prevention, (Proc. National Microfilm Association, Boston, Mass., May 7, 1969), J. Microgr. 3, No. 4, 165-170 (June 1970).

Key words: Archival records; microfilm; redox blemishes.

A type of small spots and character-associated defects on some microfilm were investigated by a variety of techniques. The blemishes result from the displacement of image silver by an oxidation-reduction reaction caused by peroxides and other gaseous products of degradation of the paper cartons in which the films are stored. A method of producing blemishes for test purposes was developed. Recommendations cover the materials, processes, and storage conditions for microfilm preservation of records of permanent value.

McCamy, C. S., Pope, C. I., The stability of silver-gelatin images, (Proc. 2d Int. Congress on Reprography, Cologne, Germany, Oct. 25-31, 1967), Paper A3-1 in Section A3 of Reprographie II, 112-115 (Verlag Dr. Othmar Helwich, Darmstadt, Germany und Wien, Austria, 1969).

Key words: Aging blemishes; blemishes, microfilm; film storage; microfilm; microfilm image stability.

Though microfilm has been in commercial use in the United States for 40 years, recent observations of blemishes on film have occasioned a re-evaluation of factors affecting long-term stability. Six types of blemishes appear to be the result of oxidation-reduction reactions initiated by gaseous reactants. These reactants are traceable to the cardboard containers in which reels of film have been stored. Statistical analysis of data gathered by 100 film inspectors supports this conclusion. Laboratory experiments ruled out biological causes. Experiments prove the existence of oxidizing and reducing 
agents, formaldehyde, and formic acid in the atmosphere within cardboard containers. Appropriate films, properly processed and stored in inert containers, at a relative humidity under 40 percent and temperature under $21^{\circ} \mathrm{C}$, should be as durable as the best record paper.

McCamy, C. S., Properties of photographic films related to information recovery, SPIE Seminar Proc. on Image Information Recovery, Philadelphia, Pa., Oct. 24-25, 1968, 16, 11-19 (Society of Photo-Optical Instrumentation Engineers, Redondo Beach, Calif., 1969).

Key words: Image processing; photographic films; photographic information.

New concepts, terminology, and symbolic notation simplify the precise treatment of optical density, which is the fundamental quantity in information recovery. The resolving power of optical and photographic systems may be treated as discrete or statistical, visual or instrumental and may be a guide to information capacity. The photographic spread function is the key to understanding image formation. The ambiguity of the modulation transfer function requires recourse to more rigorous analytic methods. Granularity, spatial effects of processing, temporal effects, and dimensional stability are important considerations in information recovery.

\section{McCamy, C. S., The evaluation and manipulation of photo-} graphic images, Chapter in Picture Processing and Psychopictorics, A. Rosenfeld and B. S. Lipkin, Eds., 57-74 (Academic Press, Inc., New York, N.Y., 1970).

Key words: Image evaluation; image manipulation; image optics; photography.

The scientific use of photography in the study of the psychophysics of images requires a knowledge of the techniques employed in specifying the characteristics of optical and photographic systems and the available techniques for manipulating photographic images. The primary measure of the photographic effect is optical density, a quantity which depends on the method of measurement in a complex way. The photographic process is quantitatively characterized by sensitometry. Image structure is characterized by resolving power, spread function, modulation transfer function, pupil function, acutance, and granularity. Photographic images may be manipulated by various forms of dodging, masking, and special processing.

McClenon, R., General purpose scientific document code operations under Exec 8, NBSIR 73-198, 21 pages, (May 1973). (Available as COM 73-11289 from the National Technical Information Service, Springfield, Va. 22151.)

Key words: Character codes for scientific text; computerized text processing; NBS computer system; scientific text; users manual.

Operating procedures for the use of the General Purpose Scientific Document Code text handling system are described. These apply to the use of the system on the NBS 1108 computer under control of the Exec 8 supervisor. Control cards, file definition and handling, compilation of routines and execution of programs are described. Examples of typical runs are given. The report is a manual for users of the system.

McLaughlin, W. L., Bjergbakke, E., Electrochemical dosimetry using ferric-fluoride ion complex formation, (Proc. Int. Symp. on Dosimetry in Agriculture, Industry, Biology and Medicine, Vienna, Austria, Apr. 1972), Paper in Dosimetry in Agriculture, Industry, Biology and Medicine, pp. 383-396 (International Atomic Energy Agency, Vienna, Austria, 1973).

Key words: Dosimetry; electrochemistry; ferric-fluoride complex; ferrous sulfate solutions; fluorides; Fricke dosimeter; ion selective electrodes; lanthanum fluoride; potentiometry.
Irradiated aqueous ferrous sulphate solutions containing fluoride ions can be analysed for ferric ion yield by means of electrochemical potentiometry. For certain applications this approach has advantages over the usual method of spectrophotometric determination of ferric ion concentration, which also varies linearly with absorbed dose up to about $40 \mathrm{krad}$ : (1) Small dosimeter volumes down to 10 microlitres are functional; (2) Solid gels may be used, thus allowing for thin-film geometries; (3) The potentiometric method permits real-time (current readings) or integrated (EMF readings) measurement of radiation dose. The electrochemical analysis of ion-complex yield is fairly simple. A fluoride ion electrode of the solid-state type serves as an ionselective sensor. The electrochemical potential (or its rate of change in some instances) between the fluoride ion electrode and the reference electrode is then read on a $\mathrm{pH}$-meter. Since the $\mathrm{Fe}^{3+}$ cation complex with $\mathrm{F}^{-}$is not passed by the lanthanum fluoride crystal membrane at the end of the electrode probe, and since the free $\mathrm{F}^{-}$ion concentration diminishes linearly with dose up to about $40 \mathrm{krad}$ (corresponding to approximately $0.4 \mathrm{~m} M \mathrm{Fe}^{3+}$ ion concentration at $\mathrm{pH}$ $2.7)$, the dose or dose rate can be determined from readings of linear change in millivoltage or rate of change of millivoltage. For cobalt-60 gamma-ray irradiation of a $1.00 \mathrm{~m} M$ solution of $\mathrm{Fe}^{2+}$ and $\mathrm{F}^{-}$made to $\mathrm{pH} 2.7$ with $\mathrm{H}_{2} \mathrm{SO}_{4}$, the $\mathrm{G}$-value of $\mathrm{Fe}^{3+}{ }_{-} \mathrm{F}^{-}$complex formation is 13.7 \pm 0.3 per $100 \mathrm{eV}$ energy absorbed. This $\mathrm{G}$-value is in good agreement with the initial $\mathrm{G}$-value 13.75 of the Fricke dosimeter at $\mathrm{pH} 2.74$.

McLaughlin, W. L., Hjortenberg, P. E., Radak, B. B., Absorbeddose measurements with thin films, (Proc. Int. Symp. on Doismetry in Agriculture, Industry, Biology and Medicine, Vienna, Austria, April 1972), Paper in Dosimetry in Agriculture, Industry, Biology and Medicine, pp. 577-597 (International Atomic Energy Agency, Vienna, Austria, 1973).

Key words: Absorbed dose; calorimetry; cavity theory; depth dose; dosimetry; dye dosimeters; electron beams; gamma rays; plastic dosimeters; radiochromic dyes; thin films.

Thin films of plastic, coatings, papers, ceramics, emulsions, cleaved crystals, microtomed gel sections, and metal foils have all been used with advantage to measure large radiation absorbed doses. The three most successful methods of relating the radiation effects in the film to the dose are: Calorimetry, which measures temperature rise; photometry, which measures changes in light emission, transmission or reflection; and electrometry, which measures electrical changes such as variations in resistivity, e.m.f., current, etc. The chief problems in making good measurements of radiation dose or dose rate with thin films are: (1) quality control of the dosimeter itself; (2) discontinuity problems, that is, how the energy imparted to a thin probe is related to energy imparted to surrounding matter; (3) meaning of the calibration, that is, how the radiation effect in the film material is related to the absorbed energy as a function of spectrum dose rate, temperature, etc. The first of these can be dealt with effectively by control of film thickness, chemical composition and environmental influences. The second is often more complicated, especially if the thin probe differs appreciably in absolute density and atomic number from its surroundings, since proper application of cavity theory may be difficult for some geometrical arrangements. The third problem is usually the most difficult of all, because the radiation effect in a thin material used as a dosimeter often depends on many variables leading to systematic errors in dose interpretations. In this work, methods are given for calibrating in electron beams the radiation response of thin-film dosimeters calorimetrically, accounting for the sources of error cited above. The calibration procedures include the use of appropriate cavity-theory correction factors needed to relate the response of the thin probe of one material held in another medium. Finally, a suitable film dosimeter material is described. It consists of radiochromic dye films, which can measure doses from about $10^{4}$ to $10^{8}$ rad in various media under different irradiation conditions. 
McLaughlin, W. L., Kosanić, M., Draganić, I. G., Extending the response of the pararosaniline dye system, (Proc. Int. Symp. on Dosimetry in Agriculture, Industry, Biology and Medicine, Vienna, Austria, Apr. 1972), Paper in Dosimetry in Agriculture, Industry, Biology and Medicine, pp. 362-366 (International Atomic Energy Agency, Vienna, Austria, 1973).

Key words: Dosimetry; dyes; gamma rays; nitrobenzene; oxidation; pararosaniline cyanide; radiochromic dyes; triphenylmethane dyes.

Organic solutions of triphenylmethane dye precursors, particularly pararosaniline cyanide $\left(4,4^{\prime}, 4^{\prime \prime}\right.$-triamino-triphenylacetonitrile) and hexa (hydroxyethyl) pararosaniline cyanide $\left(4,4^{\prime}, 4^{\prime \prime}\right.$-tris- (di- $\beta$ hydroxyethylamino) triphenylacetonitrile, have been used successfully in measuring gamma-ray absorbed doses in the range from 1 to $100 \mathrm{krad}$. With conventional slightly acidified and aerated ether alcohol solutions of the dye precursors, the optical density read at the absorption maximum in the visible portion of the spectrum increases linearly with dose up to about 100 krad. Saturation and bleaching of the solutions at doses between 100 and $200 \mathrm{krad}$ limit the usefulness of these liquid systems. A recent study has been performed at the Boris Kidric Institute of Nuclear Sciences and the Danish Atomic Energy Commission, Research Establishment Ris $\varnothing$, for the purpose of making chemical adjustments in the solutions so that higher absorbed doses may be measured with a linear optical density-versusdose response.

Meijer, P. H. E., Calculations on the specific heat and the susceptibility of interacting spin systems, (Proc. 5th Symp. on Temperature, Its Measurement and Control in Science and Industry, Washington, D.C., June 21-24, 1971), Paper in Temperature, Its Measurement and Control in Science and Industry, $\mathrm{H} . \mathrm{H}$. Plumb, Editor-in-Chief, 4, Part 1, 1267-1278 (Instrument Society of America, Pittsburgh, Pa., 1972).

Key words: Dipole-dipole interactions; low temperature salts; specific heat; susceptibility.

The corrections on the specific heat and susceptibility due to dipole-dipole interactions in a number of low temperature compounds are calculated. A general description of the method is given, followed by a short discussion of the properties of the most used low temperature compounds. Eight representative salts were chosen and the deviations from the ideal specific heat and susceptibility in second and third order were determined.

Milligan, D. E., Jacox, M. E., Infrared spectroscopic evidence for the stabilization of $\mathrm{HAr}_{n}{ }^{+}$in solid argon at $14 \mathrm{~K}, \mathrm{~J}$. Mol. Spectrosc. 46, No. 3, 460-469 (June 1973).

Key words: Argon reactions; $\mathrm{H}\left(2^{2} \mathrm{~S}\right)$ reaction with $\mathrm{Ar}: \mathrm{HAr}_{n}{ }^{+}$; infrared spectrum; interstitial $\mathrm{H}$ atom spectrum; matrix isolation; proton affinity; vacuum ultraviolet photolysis.

Absorptions which have been observed at 905 and at $644 \mathrm{~cm}^{-1}$ upon 1216- $\AA$ photolysis of hydrogen- and deuterium-containing compounds, respectively, in an argon matrix correspond well with similar absorptions reported in studies of the trapped products of a glow discharge through Ar: $\mathrm{H}_{2}$ and Ar: $\mathrm{D}_{2}$ mixtures. Evidence is presented supporting the assignment of these two absorptions to $\mathrm{HAr}_{n}{ }^{+}$and to $\mathrm{DAr}_{n}{ }^{+}$rather than to interstitial $\mathrm{H}$ and $\mathrm{D}$ atoms trapped in octahedral sites in the argon lattice.

Mitchell, R. A., Woolley, R. M., Chwirut, D. J., Composite-overlay reinforcement of cutouts and cracks in metal sheet, NBSIR 73-201, 96 pages, (Feb. 1973). (Available as COM 73-11121 from the National Technical Information Service, Springfield, Va. 22151.)

Key words: Adhesively bonded joints; composite materials; composite-overlay reinforcement; contour plotting; cracks, reinforcement of; cutouts, reinforcement of; debond analysis, progressive; finite element analysis; joints, adhesively bonded; nonlinear analysis, shear; reinforcement, composite overlay; reinforcement, cutouts and cracks; shear analysis, nonlinear.

Finite element computer programs were developed for the planform analysis and the longitudinal cross-section analysis of metal sheet reinforced by adhesively bonded overlays of composite material. The analyses articulate the separate responses of the metal sheet, the composite overlays, and the adhesive layers. All materials are assumed to be orthotropic and linear elastic, with the provision that nonlinear interlaminar shear deformation can be approximated by a series of stepwise-linear solutions. The computer programs were developed specifically for the study of three general configurations: (1) a sheet with a reinforced cutout; (2) a sheet with a reinforced cutout with two symmetrical transverse cracks, within the sheet, radiating away from the cutout edge; and (3) a sheet with a reinforced transverse crack. The programs are also suitable for the study of bonded lap joints. The principal output of the computer programs is a set of contour plots of stress and strain fields throughout the sheet, the overlays, and the adhesive layers. A series of laboratory tests was conducted to demonstrate the validity of the analyses. Strains measured on the surfaces of specimens representing the general configurations studied were, for the most part, in good agreement with strains predicted by the finite element analyses. Significant correlations between certain failure modes and the stresses computed by the finite element analyses were apparent. Similarities between the modes of failure under static and fatigue loading were also evident.

Mittag, K., Kapitza conductance and thermal conductivity of copper niobium and aluminum in the range from 1.3 to 2.1 K, Cryogenics 13, No. 2, 94-99 (Feb. 1973).

Key words: Aluminum; copper; heat transfer; Kapitza conductance; niobium; superfluid helium; thermal conductivity.

The Kapitza conductance and thermal conductivity of ofhc-copper, niobium, ultra high purity aluminium, and of the aluminium alloy $6061 \mathrm{Al}$ have been measured in the temperature range from 1.3 to 2.1 $\mathrm{K}$, yielding both quantities in the same steady state experiment. The temperature dependence of the Kapitza conductance, $h_{0}$, was between $\mathrm{T}^{3.3}$ and $\mathrm{T}^{4.6}$ for the different samples, which is higher than the most frequently observed $\mathrm{T}^{3}$ dependence. The magnitude of $\mathrm{h}_{0}$ for both ofhc-copper and aluminium agrees well at $1.9 \mathrm{~K}$ with an empirical prediction, but for niobium it is a factor of two to four lower than the value predicted. At $1.9 \mathrm{~K}, \mathrm{~h}_{0}$ is higher by a factor of two for an annealed and chemically polished niobium sample than for an untreated sample. The thermal conductivity measured from ofhc-copper and $6061 \mathrm{Al}$ as in good agreement with the value calculated from the resistivity of these materials and the Wiedemann-Franz law. The measured thermal conductivity obtained for an annealed niobium sample is a factor of 2.8 higher than the highest published value.

Molino, J., Perceiving the range of a sound source when the direction is known, J. Acoust. Soc. Amer. 53, No. 5, 1301-1304 (May 1973).

Key words: Audition and ranging; physiological and psychological acoustics; psychophysics; space perception.

A modification is proposed in Hirsch's equation for determining the range of a sound source of unknown strength $[H$. R. Hirsch, J. Acoust. Soc. Am. 43, 373-374 (1968)]. The modified formula applies to the case where the direction of the sound source is known. Greene's comments on Hirsch's letter are investigated for their ability to predict the limitations on the resolution obtainable in human auditory ranging [D. C. Greene, J. Acoust. Soc. Am. 44, 634 (1968)]. In a brief experiment, two subjects were unable to make distance judgments for sustained pure-tone sources over ranges of 3 to $48 \mathrm{ft}$.

Moore, R. T., Penetration tests on J-SIIDS barriers, NBSIR 73223, 86 pages, (June 4, 1973). (Available as COM 73-11120 from the National Technical Information Service, Springfield, Va. 22151.) 
Key words: Barrier penetration; intrusion resistance; physical security.

A series of penetration tests were made on three simulated arms rooms which incorporated a variety of structural barriers which were intended to be representative of the broad range of construction likely to be encountered in existing arms rooms.

The observed penetration times varied from 1.3 minutes for a double-planked wooden wall, 11.31 minutes for an eight-inch thick, reinforced concrete wall and up to 18.27 minutes for a GSA Class 6 vault door. All penetrations were made with portable readily available tooling and produced acoustical or vibrational or both types of disturbances which are readily detectable.

The test results provide a basis for estimating the time in which response to an intrusion alarm must occur in order to adequately safeguard an arms room, a computer room or any other sensitive area.

Moriarty, J. E., City I: Player's Manual, NBSIR 73-110, 149 pages (Mar. 1973). (Available as COM 73-11191 from the National Techni cal Information Service, Springfield, Va. 22151.)

Key words: City; computer; directors; economic; games; government; metropolitan; players; sectors; simulation; social; urban.

City $\mathbf{I}$ is an operational simulation game in which participants make economic, government, and social decisions affecting a hypothetical metropolitan area. Through the use of a computer, the simulated urban system responds to the participant's decisions as any real city would. Each player in City $\mathrm{I}$ is assigned to a team which shares an economic and governmental role. This manual describes the player details for the economic and government sectors along with general information required for game play. It is one of three manuals necessary for game play. (Player's Manual, Director's Manual, Computer Operator's Manual). Each of these manuals are designed to be used for reference and by themselves will not describe enough details for a complete game play.

Negas, T., The SrMnO ${ }_{3-x}-\mathbf{M n}_{3} \mathbf{O}_{4}$ system, J. Solid State Chem. 7, 85-88 (1973).

Key words: Nonstoichiometry; phase equilibria; $\mathrm{SrMnO}_{3-x^{-}}$ $\mathrm{Mn}_{3} \mathrm{O}_{4}$ system; $\mathrm{SrMn}_{3} \mathrm{O}_{6-x}$

Phase relations were determined in the $\mathrm{SrMnO}_{3-x}-\mathrm{Mn}_{3} \mathrm{O}_{4}$ system at elevated temperatures in air using quenching, gravimetric, and $\mathrm{x}$ ray diffraction techniques. The system contains one intermediate compound, $\mathrm{SrMn}_{3} \mathrm{O}_{6-x}\left(0 \leqslant x \leqslant 0.10\right.$ between $\left.900-1200{ }^{\circ} \mathrm{C}\right)$, which decomposes to $\mathrm{SrMnO}_{3-x}$ plus $\mathrm{Mn}_{3} \mathrm{O}_{4}$ near $1215{ }^{\circ} \mathrm{C}$. The existence of an oxygen deficient $\mathrm{SrMnO}_{3-x}$ having the hexagonal 4-layer structure was confirmed. Crystals of perovskite-like $\mathrm{SrMnO}_{3-x}(x<0.25)$ were grown from its primary field located in the system.

Okabe, H., Splitstone, P. L., Ball, J. J., Ambient and source $\mathrm{SO}_{2}$ detector based on a fluorescence method, J. Air Pollut. Contr. Ass. 23, No. 6, 514-516 (June 1973).

Key words: Air pollutant; detector, fluorescence; $\mathrm{SO}_{2}$.

The principle of this detector is based on the measurement of the intensity of the ultraviolet fluorescence of $\mathrm{SO}_{2}$ produced by absorption of the $\mathrm{Zn} 2138 \AA$ or $\mathrm{Cd} 2288 \AA$ line. The fluorescence intensity was found to be linear from 0.1 to $500 \mathrm{ppm}$ of $\mathrm{SO}_{2}$ in air with the $\mathrm{Zn}$ lamp and from 0.1 to $1600 \mathrm{ppm}$ with the Cd lamp. The detection limit at present is about $20 \mathrm{ppb}$. There is no detectable interference from $\mathrm{O}_{3}, \mathrm{H}_{2} \mathrm{~S}, \mathrm{NO}_{2}, \mathrm{CO}_{2}, \mathrm{CO}$, or $\mathrm{H}_{2}$, although the presence of a large concentration of $\mathrm{CS}_{2}\left(500\right.$ times as much as $\left.\mathrm{SO}_{2}\right) \mathrm{NO}\left(500\right.$ times) or $\mathrm{C}_{2} \mathrm{H}_{4}$ (4000 times) interferes with the measurement. The presence of 2 percent $\mathrm{H}_{2} \mathrm{O}$ reduces the signal by 25 percent, while up to 1 percent $\mathrm{CH}_{4}$ has almost no effect.
Olien, N. A., Sarkes, L. A., Keeping up with LNG-a new literary awareness service helps to do the job, Amer. Gas Ass. Mon. 55, No. 7-8, 29 and 31 (July-Aug. 1973).

Key words: Current awareness services; information retrieval; information systems; Liquefied Natural Gas; methane; methane mixtures.

A description is given of the methods used by the Cryogenic Data Center in covering the current published and patent literature. The services provided to the Cryogenic industry are also discussed. The Liquefied Natural Gas Quarterly which has been published since 1970 is covered in detail. It is noted that nearly 2,000 articles, papers, reports, and patents dealing with LNG have been listed in the twelve issues of the quarterly published to date. A series of comprehensive bibliographies on LNG, methane, and methane mixtures is also described.

Omont, A., Smith, E. W., Cooper, J., Redistribution of resonance radiation. I. The effect of collisions, Astrophys. J. 175, No. 1, Part 1, 185-199 (July 1972).

Key words: Collisional depolarization; level degeneracy; redistribution functions; resonance radiation.

The techniques of modern line-broadening theory are used to investigate the scattering of polarized radiation in the rest frame of an atom undergoing collisions. The formulation explicity includes both elastic and inelastic (quenching) collisions. When the lower state has zero width, a form for the redistribution function similar to that of Zanstra is obtained, but with the redistribution in the neighborhood of the resonance line being caused solely by elastic collisions. In the limit of no collisions, but with both levels of finite lifetime, the result of Weisskopf and Woolley is obtained. The effect of level-degeneracy is also explicitly included; in this case the results are a function of the polarization of the light and the different relaxation rates for the multipolar components of the atomic states.

Omont, A., Smith, E. W., Cooper, J., Redistribution of resonance radiation. II. The effect of magnetic fields, Astrophys. J. 182, No. 1, Part 1, 283-300 (May 15, 1973).

Key words: Irreducible tensor formalism; magnetic fields; resonance radiation.

Previously obtained results for scattering of radiation in the presence of collisions are restated in a density matrix formalism which employs an irreducible-tensor description of the radiation field. This formalism is particularly useful for problems associated with radiative transfer theory. The redistribution is then extended to include the effect of a weak magnetic field. By averaging over a finite bandwith which is on the order of the Doppler width, simplified expressions of physical significance for the scattering in the Doppler core and the Lorentz wings are obtained. Expressions are also obtained for the corresponding source function of radiative transfer theory.

Orcutt, R. H., Interlot density variation of a siloxane manometer fluid, J. Vac. Sci. Technol. 10, No. 4, p. 506 (July-Aug. 1973).

Key words: Diffusion pump fluid; micromanometry; silicone.

The mean value of density for six samples of a siloxane manometer fluid is $1.06311 \mathrm{~g} / \mathrm{cm}^{3}$ with an estimated standard deviation of $11 \times$ $10^{-5} \mathrm{~g} / \mathrm{cm}^{3}$ for the lot-to-lot variation in density of this fluid. From this result it is concluded that for use of this material in manometry to the $0.01 \%$ level the density of the actual fluid used must be determined.

Peiser, H. S., Corruccini, R. J., Newman, S. B., Standardization and measurement services in Turkey, NBSIR 73-172, 90 pages (Oct. 14-28, 1972). (Available as COM 73-11175 from the National Technical Information Service, Springfield, Va. 22151.) 
Key words: AID; assistance; economics; LDC's (less developed countries); measurement services; standardization; survey; Turkey.

The survey of standardization and measurement services for developing industries in Turkey has been carried out by NBS with funding by AID, with participation by representatives of Ecuador and Korea, and under the guidance of the Turkish Standards Institute. The Survey Team spent two weeks in Turkey where it inspected representative laboratories and plants, and had discussions with leaders of Government, the USAID Mission, principal universities and industry. The Report describes the preparation for the Survey, a summary of the economy of the country soon to be a full member of the European Common Market, notes on Turkish science and technology and the independent Turkish Standards Institute recog. nized by law as the national standards body. Issues addressed are 1) Standards Development, 2) Test Methodology, 3) Product Certification, 4) Product Testing, 5) Calibration, 6) Weights and Measures Control, 7) Export Control, 8) Quality Control, 9) Consumer Protection, 10) Industrial Extension, 11) Building Codes, 12) International Contacts, and 13) Publications. The principal conclusion is that the Turkish economy would benefit from a strengthening of standardization and measurement services. Appropriate recommendations are offered.

Peiser, H. S., Coyle, T. D., Eby, R. K., A report on a survey in Korea on standardization and measurement services in support of industrialization goals of Korea. NBSIR 73-185, 41 pages, (June 19-30, 1972). (Available as COM 73-11287 from the National Technical Information Service, Springfield, Va. 22151.)

Key words: AID; assistance; economics; LDC's (less developed countries); measurement services; standardization; survey; Korea.

The survey of standardization and measurement services for developing industries in Korea has been carried out by NBS with funding by AID, participation by representatives of Ecuador and Turkey, and under the guidance of the Korean Ministers for Commerce and Industry, and for Science and Technology. The Korean Director of the Survey was backed by six Korean Survey Team members and seven senior staff. The Survey Team spent two weeks in Korea where it inspected representative laboratories and plants, and had discussions with leaders of government, the USAID Mission, principal universities and industry. The report describes the preparation for the Survey, a summary of the economy of the country, notes on Korean science and technology, and relevant Korean institutions and laws. Nineteen problems were identified as of concern to national capability for standardization and measurement services. A summary description is given of the various existing and needed functions that Korean government should provide. The idea is endorsed to create a single agency to address all these functions.

Peterson, R. L., Kinks in the magnetophonon oscillations of semiconductors, Phys. Rev. B 7, No. 12, 5405-5408 (June 15, 1973).

Key words: Magnetophonon effect; semiconductors; transport theory.

Exact expressions for the discontinuities in the magnetic field derivative of the longitudinal drift mobility at the magnetophonon resonance and pseudoresonance fields are given for nonpolar semiconductors with combined optic- and acoustic-phonon scattering of carriers. The reasons for the discontinuities are discussed in physical terms.

Pierce, E. T., Kelly, K. L., McPherson, M. A., Howett, G. L., Booker, R. L., Emergency vehicle warning devices: Interim review of the state-of-the-art relative to performance standards, LESP-RPT-0501-00, 73 pages. Available as PB 211938 fror the $\mathrm{Na}$ - tional Technical Information Service, Springfield, Va. 22151, (U.S. Department of Justice, Law Enforcement Assistance Administration, National Institute of Law Enforcement and Criminal Justice, Washington, D.C., May 1972).

Key words: Action; communication; conspicuity; controlled environment; effectiveness; flashing lights; guidelines; information; laboratory testing; people; response; sirens; standards.

This interim progress report describes the activities carried out, from the initiation of the program through July 1971, concerning the preparation of performance standards for emergency vehicle warning devices (lights and sirens). A partial survey of present standards and specifications indicated that there now are very few meaningful performance standards for emergency warning lights and essentially none for sirens. Brief descriptions of those standards which were found are included. Manufacturer's literature on available warning devices rarely includes meaningful quantitative data on the physical performance characteristics of either lights or sirens. The program strategy described in this report includes (a) quantitative physical characterization of the spectral content, directionality, level, and time duration of the signals from a representative sampling of emergency vehicle warning equipment; (b) literature and laboratory study of the effectiveness of representative signals in alerting drivers to an emergency situation requiring appropriate reactions; and (c) development of draft standards. In conjunction with the physical characterization of lights and sirens, examples are given of the type of data which will be taken and detailed descriptions are given of the facilities which will be used for these measurements. A discussion is given of the various factors which influence the effectiveness of warning signals. It is proposed to study both the time elapsing between the occurrence of a signal and the completion of the required response (complex reaction time) and the distance at which an observer first notices and correctly interprets a signal (recognition distance). Performance standards can then be prepared which are clearly related to the appropriate human responses.

Pike, R. G., Hay, R. E., Clifton, J. R., Beeghly, H. F., Mathey, R. G., Nonmetallic coatings for concrete reinforcing bars, Public Roads 37, No. 5, 185-197 (June 1973).

Key words: Chlorides; concrete; corrosion; epoxy coatings; organic coating; steel reinforcing bars.

The study reported here was conducted to determine the feasibility of using organic coatings, especially epoxies, to protect steel reinforcing bars embedded in concrete from corrosion accelerated by chloride ions.

Coatings were evaluated on the basis of their chemical and physical durabilities as well as their protective qualities. In this study, attention was also directed to the application methods and surface preparation of the steel reinforcing bars. Four different materials appear to be suitable for such coatings.

Powell, C. J., Contrasting valence-band Auger-electron spectra for silver and aluminum, Phys. Rev. Lett. 30, No. 23, 1179 . 1182 (June 4, 1973).

Key words: Aluminum; Auger electron transitions; electronic density of states; final state effects; silver; transition probabilities.

Measurements of the $L_{2,} V V$ ( $V=$ valence) Auger spectrum of aluminum and the $M_{4,4} V V$ Auger spectrum of silver cannot be simply related to the valence-band density of states. The data for $\mathrm{Al}$ indicate a strong energy variation of the transition probability. For silver, the position and shape of the Auger spectrum are associated with multiplet splitting of localized double-d-hole final states.

Powell, C. J., High-resolution measurements of Auger-electron and photoelectron structure in the secondary-elec- 
tron energy distributions of aluminum, nickel and copper, (Proc. Int. Conf. on Inner Shell Ionization Phenomena and Future Applications, Atlanta, Ga., Apr. 17-22, 1972), Paper in Proceedings of the International Conference on Inner Shell Ionization Phenomena and Future Applications, R. W. Fink, S. T. Manson, J. M. Palms and P. V. Rao, Eds., CONF-720404, 1, 743-756 (U.S. Atomic Energy Commission, Technical Information Center, Oak Ridge, Tenn., Jan. 1973).

Key words: Aluminum; Auger-transitions; copper; electronic density of states; nickel; photoelectron energy distribution; secondary-electron energy distribution; $x$-ray photoemission.

Measurements are reported of selected structure in the secondary electron energy distributions of evaporated aluminum, nickel and copper. The specimens were bombarded with $3 \mathrm{keV}$ electrons and the secondary structure was measured with a resolution of $0.1 \mathrm{eV}$. For each metal, attention was given primarily to data that could give information on the valence-band density of states.

Attempts were made to observe the $\mathrm{AlKL}_{2,3} \mathrm{M}$ Auger-electron energy distribution expected at about $1470 \mathrm{eV}$. Structure was, however, observed with a high-energy edge of $1485.9 \pm 0.5 \mathrm{eV}$ and a breadth of 8-9 eV. This structure was interpreted as being due to photoemission of valence electrons by internally generated $\mathrm{K} \alpha$-rays and was similar to uv photoelectron distributions and to the calculated density of states. Inelastic scattering of the photoelectrons obscures the expected $\mathrm{AlKL}_{2,3} \mathrm{M}$ structure.

Auger electron peaks in the ranges $730-800 \mathrm{eV}$ and 820 to $865 \mathrm{eV}$ were measured in the energy spectra for nickel and copper, respectively. Structure was observed in the $\mathrm{L}_{3} \mathrm{M}_{2,3} \mathrm{M}_{4,5}$ transition which could be associated in part with solid-state effects and in part with the final atomic states of each element. Density-of-states data could not be derived from the Auger spectra without more detailed knowledge of the final states expected after the Auger transition of interest.

Powell, R. L., Hall, W. J., Hust, J. G., The fitting of resistance thermometer data by orthogonal functions, (Proc. 5 th Symp. on Temperature, Its Measurement and Control in Science and Industry, Washington, D.C., June 21-24, 1971), Paper in Temperature, Its Measurement and Control in Science and Industry, $\mathrm{H} . \mathrm{H}$. Plumb, Editor-in-Chief, 4, Part 2, 1423-1431 (Instrument Society of America, Pittsburgh, Pa., 1972).

Key words: Numerical analysis; orthogonal functions; resistance thermometer.

Analyses of highly accurate thermal data require sophisticated fitting methods so that expensively obtained experimental precision will not be negated by inadequate mathematical techniques. This article describes fitting methods using orthogonal functions that have been used for several years to fit many types of data, including germanium resistance curves. The method is a generalization and extension of ideas suggested earlier by Lanczos for fitting noisy data. The method usually cleanly separates noise from the fundamental signal in a straightforward manner, allowing one to avoid either an oscillating overfit or an inaccurate underfit. The procedure consists of five parts: (1) transformation of variables so that the curve is as linear as possible in the transformed variables; (2) weighting of data to satisfy the Gauss-Markoff conditions with the weighting function inversely proportional to the experimental variance; (3) orthogonal function generation and coefficient determination using Gram-Schmidt type algorithms developed by Bjorck; (4) separation of noise coefficients from the fundamental signal coefficients based on their different dependence on the number of terms; and (5) calculation of smoothed data using the proper number of coefficients.

Powell, R. L., Revision of the standard reference data for thermocouples, (Proc. 5th Symp. on Temperature, Its Measurement and Control in Science and Industry, Washington, D.C., June 2124, 1971), Paper in Temperature, Its Measurement and Control in Science and Industry, H. H. Plumb, Editor-in-Chief, 4, Part 3, 1579-1584 (Instrument Society of America, Pittsburgh, Pa., 1972).

Key words: Standard Reference Data; thermocouples.

Revision of the International Practical Temperature Scale requires that there be changes for all accurately tabulated thermophysical values. Revised reference data for thermocouples have been generated in a cooperative program between groups of the National Bureau of Standards in Boulder and Gaithersburg. The new reference data reflect not only revisions in the temperature scale, but also slight changes in the materials themselves and improvements in data fitting methods. A new NBS monograph that contains tables, analytic expressions, various approximations, and explanatory text has been prepared. A general discussion of the project and some specific examples will be given.

Quinn, T. J., Lee, R. D., Vacuum tungsten strip lamps with improved stability as radiance temperature standards, (Proc. 5th Symp. on Temperature, Its Measurement and Control in Science and Industry, Washington, D.C., June 21-24, 1971), Paper in Temperature, Its Measurement and Control in Science and Industry, H. H. Plumb, Editor-in-Chief, 4, Part 1, 395-411 (Instrument Society of America, Pittsburgh, Pa., 1972).

Key words: Pyrometry; source; temperature; tungsten.

This paper describes the changes which take place in a piece of tungsten strip as it is outgassed and aged during the processing of a vacuum tungsten strip lamp. It is shown that by paying sufficient attention to the cleaning of the tungsten and the glass bulb, and to the outgassing and aging of the tungsten, a very stable strip lamp can be produced. Results are given of a series of stability tests from 1064 to $1500{ }^{\circ} \mathrm{C}$ of a group of lamps made in this way at NBS.

Reader, J., Comment on: How to mount a Pellin-Broca prism for laser work, Appl. Opt. 12, No. 7, 1405 (July 1973).

Key words: Pellin-Broca prism; spectroscope.

It is shown that a recently published mounting for constant deviation prisms is equivalent to one published in 1917. An example of the use of this mounting for a plane grating spectrograph at NBS is given.

Reed, R. P., Arvidson, J. M., Durcholz, R. L., Tensile properties of polyurethane and polystyrene foams from 76 to $300 \mathrm{~K}$, (Proc. 1972 Cryogenic Engineering Conf., Boulder, Colo., Aug. 9. 11, 1972), Paper E-3 in Advances in Cryogenic Engineering 18, 184193 (Plenum Press, New York, N.Y., 1973).

Key words: Foams; low temperature; tensile properties.

The tensile properties of 17 different polyurethane foams and 2 polystyrene foams have been measured at 300, 195 and $76 \mathrm{~K}$. The Young's modulus, yield strength and tensile strength increased with decreasing temperature, while the elongation decreased. Strength and Young's modulus were found to be approximately linearly dependent on temperature; however, at low temperatures the density dependence was greater. Specimens whose long axis was cut parallel to the cell rise direction were stronger than those whose long axis was cut normal to the cell rise direction. Comparisons between foam tensile and compressive properties are presented in the accompanying paper.

Reichard, T. W., Greene, W. E., Jr., Cattaneo, L. E., Masters, L. W., Structural tests on housing components of glass fiber reinforced polyester laminate, NBSIR 73-188, 98 pages (Apr. 1973). (Available as PB 221183 from the National Technical Information Service, Springfield, Va. 22151.)

Key words: Adhesive bond; aging; composites; compression; flexure; glass fiber; housing system; innovations; laminate; 
Operation BREAKTHROUGH; racking; reinforced plastics; reinforced polyester; sustained loading; tensile shear.

This report describes a series of structural evaluation tests performed on housing components made with a glass fiber reinforced polyester (FRP) laminate. The components tested were: (1) the FRP laminate used for the facings and the corrugated core of the basic panel; (2) the adhesive bond between the facing and core; (3) typical wall panels; and (4) typical roof panels. Test data include: (1) the effect of temperature and moisture on the tensile and compressive strength of the FRP laminate; (2) the effect of temperature, accelerated aging and sustained loads on the tensile shear strength of the facing-to-core polyester adhesive bond; (3) the short-term strength of the wall panels under compressive and in-plane shear loading; (4) the long-term strength of the wall panels under sustained compressive loading; and (5) the short-term and long-term performance of the roof panels under flexural loading.

Reno, R. C., Swartzendruber, L. J., Origin of Mössbauer linewidth in stainless steel, (Proc. 18th AIP Conf. on Magnetism and Magnetic Materials, Denver, Colo., Nov. 28-Dec. 1, 1972), Paper in Magnetism and Magnetic Materials, C. D. Graham, Jr., and J. J. Rhyne, Eds., No. 10, 1350-1353 (American Institute of Physics, New York, N.Y., 1973).

Key words: Hyperfine fields; perturbed angular correlation, Mössbauer effect; stainless steel.

The hyperfine interactions which broaden the Mössbauer effect (ME) spectrum in austenitic stainless steel have been investigated with the aid of ${ }^{57} \mathrm{Fe}$ time-differential perturbed angular correlations (TDPAC). The TDPAC measurements reveal a distribution of electric field gradients at the ${ }^{57} \mathrm{Fe}$ nuclei with a mean value corresponding to a Mössbauer splitting of $0.14 \mathrm{~mm} / \mathrm{s}$. This splitting is not sufficient to explain the total line width and isomer shifts are invoked to account for the remaining width.

Robertson, A. F., Rappaport, M. W., Fire extinguishment in oxygen enriched atmospheres, NASA CR-121150, 60 pages $(\mathrm{Na}-$ tional Aeronautics and Space Administration, Washington, D.C., Feb. 1973).

Key words: Controlled atmospheres; extinguishing; fire extinguishers; fires; halons; oxygen; spacecraft cabin atmospheres; water.

Current state-of-the-art of fire suppression and extinguishment technique in oxygen enriched atmosphere is reviewed. Four classes of extinguishment action are considered: cooling, separation of reactants, dilution or removal of fuel, and use of chemically reactive agents. Current practice seems to show preference for very fast acting water spray applications to all interior surfaces of earth-based chambers. In space, reliance has been placed on fire prevention methods through the removal of ignition sources and use of nonflammable materials. Recommendations are made for further work related to fire suppression and extinguishment in oxygen enriched atmospheres, and an extensive bibliography is appended.

Roder, H. M., A new phase transition in solid hydrogen?, Cryogenics Letter to Editors 13, No. 7, 439-440 (July 1973).

Key words: Hydrogen; phase transition.

Available but often discordant data on PVT, dielectric constant, specific heat, velocity of sound, and melting pressures are interpreted to indicate the possibility of a transition in solid hydrogen. This structural change, suggested by others previously, has not yet been investigated as thoroughly as the corresponding transition in solid helium.

Rosenstock, H. M., Larkins, J. T., Walker, J. A., Interpretation of photoionization thresholds: Quasiequilibrium theory and the fragmentation of benzene, Int. J. Mass Spectrom. Ion Phys. 1 1, 309-328 (1973).

Key words: Appearance potential; benzene; photoionization; quasiequilibrium theory.

Quasiequilibrium theory has been applied to the parent ion fragmentation of benzene. Assuming uniform excitation energy transfer in the fragmentation threshold region and applicability of the stepfunction photoionization threshold law, it is possible to calculate fragment photoionization threshold curves in good agreement with experiment. It is concluded that the unimolecular decomposition occurs via two independent pairs of competing reactions. One pair of reactions leads to the formation of $\mathrm{C}_{6} \mathrm{H}_{5}{ }^{+}$and $\mathrm{C}_{6} \mathrm{H}_{4}{ }^{+}$, and involves the benzene ion ground state. The other pair of reactions, leading to $\mathrm{C}_{4} \mathrm{H}_{4}{ }^{+}$and $\mathrm{C}_{3} \mathrm{H}_{3}{ }^{+}$involves the first excited state of $\mathrm{C}_{6} \mathrm{H}_{6}{ }^{+}$lying 2.25 $\mathrm{eV}$ above the ground state, or an open chain isomer having a similar heat of formation. At threshold the $\mathrm{C}_{6} \mathrm{H}_{5}{ }^{+}$ion has a phenyl ion structure, the $\mathrm{C}_{3} \mathrm{H}_{3}{ }^{+}$ion a cyclopropenyl ion structure and the $\mathrm{C}_{4} \mathrm{H}_{4}{ }^{+}$ion may have a cyclobutene ion structure. A heat of formation of $\sim 100$ $\mathrm{kcal} / \mathrm{mol}$ is derived for the benzyne molecule, in good agreement with semi-empirical estimates. Kinetic shift effects on the fragmentation thresholds are found to be important. Some difficulties are encountered in the comparison of relative abundances of parent ion metastable transitions to the relative abundances of the daughter ions near threshold. The calculated energy dependence of the unimolecular rate of formation of $\mathrm{C}_{4} \mathrm{H}_{4}{ }^{+}$ion is in good agreement with experiment. However, the weak energy dependence of the rate of formation of $\mathrm{C}_{6} \mathrm{H}_{5}{ }^{+}$found experimentally cannot be explained. Suggestions for further work are outlined.

Roth, R. S., Parker, H. S., Brower, W. S., Waring, J. L., Phase equilibria, crystal chemistry and crystal growth of alkali oxide-metal oxide systems, (Proc. NATO sponsored Advanced Study Institute, Belgirate, Italy, Sept. 1972), Paper in Fast Ion Transport in Solids, pp. 217-232 (North-Holland Publ. Co., Amsterdam, The Netherlands, 1973).

Key words: Alkali oxides; crystal chemistry; crystal growth; phase equilibria; system $\mathrm{LiTaO}_{3}-\mathrm{Ta}_{2} \mathrm{O}_{5}$; system $\mathrm{NaTaO}_{3}-\mathrm{Ta}_{2} \mathrm{O}_{5}$; system $\mathrm{KTaO}_{3}-\mathrm{Ta}_{2} \mathrm{O}_{5}$.

In view of the recently discovered properties of the sodium ion in $\beta$-alumina, it is of some scientific and practical importance to review the chemistry of alkali ions in oxide systems in general. From a practical point of view, however, the number of systems of interest will necessarily be severely limited. For commercial utilization of ionic conductivity it is necessary to limit systems to those which will contain little or no electronic conductivity and therefore do not contain an element which is easily reduced during the synthesis. For fast ion transport it is probably advantageous to have an alkalai ion in a "nonstoichiometric" crystallographic position. Attention will be concentrated on methods of study of alkali oxide-tantalum oxide systems as applied to the search for new crystallographic phases which may be of interest.

New results are presented of phase equilibria studies in the systems $\mathrm{Li}_{2} \mathrm{O}, \mathrm{Na}_{2} \mathrm{O}$ and $\mathrm{K}_{2} \mathrm{O}$ with $\mathrm{Ta}_{2} \mathrm{O}_{5}$ and $\mathrm{Li}_{2} \mathrm{O}$ with $\mathrm{Nb}_{2} \mathrm{O}_{5}$. In addition preliminary results will be discussed of the ternary systems involving the binaries with $\mathrm{MoO}_{3}$. These ternary systems have been utilized for flux-growth of single crystals of many of the new phases in the binary systems. Each of the $\mathrm{Ta}_{2} \mathrm{O}_{5}$ systems has at least one interesting non-stoichiometric phase which deserves further study for conductivity properties. A phase in the $\mathrm{Li}_{2} \mathrm{O}-\mathrm{Ta}_{2} \mathrm{O}_{5}$ system has the structure of the low-temperature form of $\mathrm{Ta}_{2} \mathrm{O}_{5}$, the $\mathrm{Na}_{2} \mathrm{O}-\mathrm{Ta}_{2} \mathrm{O}_{5}$ system contains a phase with a "tetragonal-bronze"-like structure and the $\mathrm{K}_{2} \mathrm{O}-\mathrm{Ta}_{2} \mathrm{O}_{5}$ system has both "tetragonal-" and "hexagonalbronze"-like phases. In the sub-system $\mathrm{Ta}_{2} \mathrm{O}_{5}-\mathrm{KTaO}_{3}$ eleven distinct phases have been found where only two were previously known. 
Roszman, L. J., Hooper, C. F., Jr., Distribution of the time-dependent microfield in a plasma, Phys. Rev. A 7, No. 6, 21212130 (June 1973).

Key words: Distribution; Holtsmark; ion dynamics; microfield; plasma; time-average.

The theory of the distribution of the time average of the time-dependent microfield in a quantum plasma taken over a finite time interval is introduced and developed. The short- and long-time limits are derived. The Wigner phase-space representation is employed to derive the correct distribution for a classical plasma and to establish a formalism which can be used for low-order quantum corrections. Numerical results are presented for a classical gas of charged noninteracting particles. It is found that for time-averaging intervals, which are larger than the time it takes a particle traveling with the average thermal velocity to cross the ion-sphere radius, the distribution deviates from the corresponding Holtsmark distribution for the quasistatic model.

Rubin, A. I., The social impact of noise: A survey of medical, psychological, and social consequences, Environmental Protection Agency Report No. NTID300.11, 25 pages (Available as PB 206724 from the National Technical Information Service, Springfield, Va. 22151, Dec. 1971)

Key words: Noise; noise sources; social impact.

Noise is an environmental pollutant which shares many characteristics with other pollutants-its levels are increasing, more and more people are being affected; its consequences are medical, psychological and social. Man has been successful in producing labor-saving devices used during work and play as well as to provide many forms of transportation. However, an associated by-product is increasingly in evidence as the machines have become more powerful, namely Noise. Whereas only midcity areas, heavy industries and communities near airports were formerly recognized as being "special" problems because of the noise levels associated with them; this is no longer true. Intrusive noise pervades the home, industry and most recreation areas now since, where man has moved, he has taken his machines with him. This pervasiveness of noise has led to actions by individuals, groups, and many levels of government to "do something about the problem." Among the methods attempted have been regional planning, zoning ordinances, government standards and regulations, and individual law suits. Thus far these approaches have not been successful. The number of people exposed to hazardous noise levels is increasing, the quality of our auditory environment is being degraded, and the social impact of noise may substantially contribute to other problems in our society.

Rupp, N. W., Intermediary base and cementation, Chapter 5 in Operative Dentistry, L. Baum, Ed., pp. 59-72 (W. B. Saunders Co., Philadelphia, Pa., 1973).

Key words: Cementation; intermediary base; pulp protection; retention; temporary cementation.

This is a literature review of the dental cements currently being used for intermediary bases and cementation. Clinical applications of the various cements are discussed relative to physical properties and biological response of tooth tissues. Some recently introduced materials are included.

Schneider, S. J., Levin, E. M., Polymorphism of $\mathbf{K}_{2} \mathbf{C O}_{3}$, J. Amer. Ceram. Soc. -Discussions and Notes 56, No. 4, 218-219 (1973).

Key words: DSC; DTA; high temperature x-ray; $\mathrm{K}_{2} \mathrm{CO}_{3}$; phase transformation; polymorphs.

The polymorphism of $\mathrm{K}_{2} \mathrm{CO}_{3}$ was investigated by differential thermal analysis, differential scanning calorimetry and high temperature $\mathrm{x}$-ray diffraction techniques. The data indicate that $\mathrm{K}_{2} \mathrm{CO}_{3}$ is dimorphic with a 2 nd order transformation from a monoclinic form to a hexagonal modification occurring at $420 \pm 5{ }^{\circ} \mathrm{C}$. Unit cell dimensions as a function of temperature and a representative $\mathbf{x}$-ray powder pattern of hexagonal $\mathrm{K}_{2} \mathrm{CO}_{3}$ are given.

Schooley, J. F., Enhancement effects, (Proc. Summer Course on The Science and Technology of Superconductivity, held at Georgetown University, Washington, D.C., Aug. 13-26, 1971), Paper in The Science and Technology of Superconductivity, W. D. Gregory, W. N. Mathews, Jr., and E. A. Edelsack, Eds., 1, 405-428 (Plenum Press, New York, N.Y., 1973).

Key words: High transition temperature; pressure effects; proximity effect; superconductive alloys; superconductive compounds; superconductivity.

Superconductivity research has had as one of its continuing aims the production of high-transition-temperature materials. This situation arises from the realization that superconductivity can be applied to transportation, communication, power transmission, and instrumentation on a wider and more efficient basis, the higher the transition temperature. Many of these applications will be discussed during this course by several of the lecturers.

In this lecture, I will discuss various ways in which experimenters have attempted to generate high transition temperatures.

Schooley, J. F., Soulen, R. J., Jr., The use of superconductors to provide fixed points on a cryogenic temperature scale, (Proc. 5th Symp. on Temperature, Its Measurement and Control in Science and Industry, Washington, D.C., June 21-24, 1971), Paper in Temperature, Its Measurement and Control in Science and Industry, H. H. Plumb, Editor-in-Chief, 4, Part 1, 169-174 (Instrument Society of America, Pittsburgh, Pa., 1972).

Key words: Fixed points; OSRM; superconductive devices; superconductive transition temperature; superconductivity; temperature scale.

It is suggested that reproducible superconductive transition temperatures be used as fixed points for temperature scales below $10 \mathrm{~K}$. The superconductive transitions of lead, indium, aluminum, zinc, and cadmium have been found to be as narrow as one millikelvin and reproducible to less than one millikelvin. It is planned that devices incorporating these elements will be made available through the NBS Office of Standard Reference Materials.

Schooley, J. F., Superconductors in Thermometry, (Proc. Summer Course on The Science and Technology of Superconductivity held at Georgetown University, Washington, D.C., Aug. 1326, 1971), Paper in Science and Technology of Superconductivity, W. D. Gregory, W. N. Mathews, Jr., and E. A. Edelsack, Eds., 2, 625-630 (Plenum Press, New York, N.Y., 1973).

Key words: Critical magnetic field; heat capacity; Josephson junctions; noise thermometry; superconductive fixed points; superconductivity; thermometry.

Various properties of superconductors show monotonic temperature dependences, so that in principle they may be used as thermometric parameters. Other properties can be utilized in devices which find convenient application in thermometry. Of the many possible examples, we will examine several which have found some actual use either as thermometers or detectors in thermometry.

\section{Schroder, I. G., Emission of long-range $\alpha$-particles in the subthermal-, thermal- and resonance-neutron fission of ${ }^{239} \mathbf{P u}$, Nucl. Phys. A195, 257-268 (1972).}

Key words: Alpha-particle; emission; fission; neutron; reactor; ${ }^{239} \mathrm{Pu}$.

An investigation has been made of the possible dependence of the binary-to-ternary fission ratio as well as of the energy distribution of the long-range $\alpha$-particles emitted in the low-energy fission of ${ }^{239} \mathrm{Pu}$ 
on the energy of the incident neutron. To this effect a number of rela tive measurements have been made using three neutron filters covering, respectively, the subthermal-, thermal- and resonance-neutron regions. Furthermore, a measurement of the binary-to-ternary fission ratio has been performed for a reactor beam. The results obtained show no variation in the binary-to-ternary fission ratio or in the energy of the long-range $\alpha$-particles for the energy intervals considered to within the precision of these measurements. The measurement with the reactor beam yielded a value of the binary-to-ternary fission ratio of $412 \pm 11$.

Siu, C. I., Ellis, W. M., Kusuda, T., Test of a polyester composite wall panel for moisture accumulation and potential removal of moist ure through venting, NBSIR 73-220, 18 pages (May 1973). (Available as PB 222437 from the National Technical Information Service, Springfield, Va. 22151.)

Key words: Composite wall panel; condensation; humidity; moisture; pressure; temperature.

A polyester composite exterior wall panel was exposed to accelerated winter temperature and humidity conditions for the purpose of determining performance with respect to moisture accumulation and release as a result of pressure and temperature differences. No moisture condensation within the wall system was detected from visual examinations made at various times of the testing period; no significant increase in gross weight of the wall was found from the direct weighings of the wall system. Results also indicate that a wet insulation in such a wall system is unlikely to be dried out by natural thermal action and convective motion.

Slattery, W. J., Standards information for your company, Stand. Eng. 25, No. 3, p. 22, (June 1973).

Key words: Company; information; standardization; standards.

The Standards Information Services Section of the National Bureau of Standards (NBS-SIS) maintains the largest reference collection of engineering and related standards, specifications, test methods, codes and recommended practices in the United States. From its original holdings of several thousand standards, NBS-SIS now maintains an extensive reference collection of over $122.000 \mathrm{stan}$ dards issued by U.S. industry associations, federal and state governmental organizations, and foreign national and international standardizing bodies. NBS-SIS serves primarily as a referral activity by identifying sources of standards, and directing inquirers to the respective standards-issuing organizations to obtain copies of standards. By means of a computer-produced Key-Word-In-Context (KWIC) Index, more than 4,000 inquiries are answered a year. Although the majority of these requests have to date come from agencies of the U.S. Federal Government, the staff is particularly interested in receiving an increase in the number of inquiries from the corporate sector. NBS-SIS also compiles computer-produced indexes designed to assist companies and other industry groups, government organizations and anyone interested in information on standards. Requests for information may be made by personal visit, telephone or letter.

Smith, R. L., Phelan, R. J., Jr., Limitations of the use of vacuum photodiodes in instruments for the measurement of laser power and energy, Appl. Opt. 12, No. 4, 795-798 (Apr. 1973).

Key words: Biplanar vacuum photodiodes; lasers; laser energy measurements; laser power measurements; vacuum photodiodes.

The effect of the variation in the area sensitivity upon the calibration of instruments incorporating biplanar vacuum photodiodes for the measurement of laser power and energy is discussed. A technique for the measurement of the area sensitivity is described, and the experimental results for several tubes are given. At the present time it would appear to be difficult to use biplanar vacuum photodiodes in devices to measure laser energy or power.
Somes, N. F., Abnormal loading on buildings and progressive collapse, NBSIR 73-221, 76 pages (May 1973). (Available as PB 220849 from the National Technical Information Service, Springfield, Va. 22151.)

Key words: Abnormal loading; building; codes; design criteria; multistory; progressive collapse; risk; stability; standards; strength; United States.

The document is an interim report of ongoing studies at the $\mathrm{Na}$ tional Bureau of Standards. It defines the several aspects of abnormal loading on buildings and the problem of progressive collapse. It documents the extent to which present U.S. Codes and Standards address the problem.

Abnormal loadings are identified, classified and discussed with regard to their characteristics and frequencies of occurrence. The report reviews the state of international knowledge of the characteristics of abnormal loadings and the response of buildings and building elements to these loadings. The latter includes discussion of several incidents in which multistory buildings have collapsed progressively.

Using currently available statistics an estimate is made of the combined frequency of abnormal loadings on residential buildings in the U.S. For buildings susceptible to progressive collapse, the corresponding risk of fatality is compared with the levels of risk that society will generally accept. The risk is further compared with the risk of mortality associated with fire in residential buildings, an area of considerable public concern and expenditure.

It is concluded that U.S. standards-writing bodies should adopt appropriate rational criteria as soon as possible to reduce the risks of progressive collapse. There are several areas in which criteria might be introduced to reduce the risk of progressive collapse. These are discussed; particular attention is given to the philosophies behind the structural criteria implemented in the USA and other countries.

Soulen, R. J., Jr., Schooley, J. F., Superconducting transition widths and reproducibilities, (Proc. XIIIth Int. Congress of Refrigeration, Washington, D.C., Aug. 27-Sept. 3, 1971), Paper in Progress in Refrigeration Science and Technology 1, 399-4.03 (Avi Publ. Co., Inc., Westport, Conn., 1973).

Key words: Superconductivity; thermometry, transition temperature.

As part of a program to investigate the possibility of utilizing superconductive transitions as reference points on a cryogenic temperature scale, we are examining the transitions of samples with different purities and with various metallurgical histories. In our initial efforts, we examined the transition widths of $\mathrm{Pb}, \mathrm{Sn}, \mathrm{In}, \mathrm{Al}, \mathrm{Ga}, \mathrm{Zn}$ and $\mathrm{Cd}$ wires using short mutual inductance coils to avoid end effects. As we reported at the XII Int. Conf. on Low Temperature Physics, all but the $\mathrm{Sn}$ and $\mathrm{Cd}$ samples showed transition widths of $10^{-3} \mathrm{~K}$ or less, and repeated examination of the widths over an extended period of temperature cycling showed no drift or broadening of the five narrow transitions larger than $10^{-3} \mathrm{~K}$.

We are now preparing samples of $\mathrm{Pb}, \mathrm{In}, \mathrm{Al}, \mathrm{Zn}$ and $\mathrm{Cd}$ with various impurities and with various forming and annealing procedures in order to determine the practical boundary conditions for obtaining a given transition temperature and transition width. We are attempting to extend this study to low temperature $\left(\mathrm{Ir}, \mathrm{T}_{c} \approx 0.1 \mathrm{~K}\right)$ and high-temperature $\left(\mathrm{Nb}_{3} \mathrm{X}, \mathrm{V}_{3} \mathrm{Si}, \mathrm{T}_{c}=15-20 \mathrm{~K}\right)$ materials, although intitial experiments show transition widths of $0.1-0.3 \mathrm{~K}$ for the latter.

Smith, R. L., Honda, T., Impulse rise and fall times of biplanar vacuum photodiodes, Appl. Opt. 12, No. 7, 1606-1610 (July 1973).

Key words: Biplanar vacuum photodiodes; impulse fall time; impulse rise time; laser pulses. 
The impulse rise and fall times of biplanar vacuum photodiodes are experimentally investigated by the use of a single ultrashort laser pulse from a train of mode-locked pulses. It was confirmed that the impulse rise time is a function of the photoelectrons' transit time from photocathode to anode, and that the impulse fall time is 2.2 times the capacitance of the photodiode and the resistive component of the load.

Straty, G. C., Younglove, B. A., Velocity of sound in saturated and compressed fluid oxygen, J. Chem. Thermodyn. 5, No. 3, 305-312 (May 1973).

Key words: Compressed liquid; compressibility; saturated liquid; sound velocity oxygen; specific heat ratio.

In a continuing effort to generate accurate thermodynamic and transport properties of cryogenic fluids, we have measured the velocity of sound in saturated liquid oxygen from 58 to $150 \mathrm{~K}$ and in compressed fluid oxygen along isotherms from 70 to $300 \mathrm{~K}$ at pressures to $34 \mathrm{MPa}$. The results have been used along with previously measured $p, p, T$ results to obtain the isentropic compressibility and the heat capacity ratio, and to examine the quality of the $p, p, T$ data by comparison of the measured velocities with velocities calculated from these data.

Sugar, J., Ionization energies of the neutral actinides, J. Chem. Phys. 59, No. 2, 788-791 (July 15, 1973).

Key words: Actinium; americium; berkelium; californium; curium; einsteinium; fermium; ionization energy; mendelevium; neptunium; nobelium; plutonium; protactinium; thorium; uranium.

Values for the ionization energies of the neutral actinides have been derived by utilizing interpolated spectral properties of these atoms. The results in electron volts are Ac: 5.17(12); Th: 6.08(12); Pa: 5.89(12); U: 6.05(7); Np: 6.20(12); $\mathrm{Pu}$ : 6.06(2); Am: 5.993(10); Cm: 6.09(2); Bk: 6.30(9); Cf: 6.41(10); Es: 6.52(10); Fm: 6.64(11); Md: 6.74(12); No: 6.84(12).

Sullivan, D. B., Precise electrical measurements at low temperature, Proc. 1972 Applied Superconductivity Conf., Annapolis, Md., May 1-3, 1972, pp. 631-639 (IEEE, Inc., New York, N.Y., 1972).

Key words: Fundamental constants; Josephson effect; precise electrical measurements; superconductivity.

The application of low temperature phenomena to electrical metrology is reviewed. The review includes a number of recent developments which involve measurement systems based on the quantum of magnetic flux as well as adaptations of classical concepts to low temperature devices. Quantities considered include radio frequency current, infrared frequency, and direct current and voltage. Concepts for secondary emf standards are also discussed.

Swartzendruber, L. J., Evans, B. J., Local interactions and spin transfer mechanisms in the Heusler-type alloys $\mathbf{P d}_{1+x} \mathrm{MnSb}$ and $\mathbf{P d}_{2} \mathbf{M n S b}_{0.9} \mathbf{S n}_{0.1}$, (Proc. 18th AIP Conf. on Magnetism and Magnetic Materials, Denver, Colo., Nov. 28-Dec. 1, 1972), Paper in Magnetism and Magnetic Materials, C. D. Graham, Jr., and J. J. Rhyne, Eds., No. 10, 1369-1373 (American Institute of Physics, New York, N.Y., 1973).

Key words: Alloys; antimony; hyperfine fields; manganese; Mössbauer effect; palladium, tin.

The magnetic hyperfine fields at ${ }^{121} \mathrm{Sb}, \mathrm{H}_{\text {eff }}(\mathrm{Sb})$, in the Heusler-type alloys $\mathrm{Pd}_{1+x} \mathrm{MnSb}$ are found to be strongly dependent on $\mathrm{x}$, varying from about $600 \mathrm{kG}$ for $\mathrm{x}=1$ to about $300 \mathrm{kG}$ for $\mathrm{x}=0$. As $\mathrm{x}$ is decreased from unity, the single unique value observed in $\mathrm{Pd}_{2} \mathrm{MnSb}$ is replaced by a distribution in $\mathrm{H}_{\text {eff }}(\mathrm{Sb})$, with an average value which decreases in a regular manner with the number of $\mathrm{Pd}$ vacancies. In
$\mathrm{Pd}_{2} \mathrm{MnSb}_{0.9} \mathrm{Sn}_{0.1}, \mathrm{H}_{\text {eff }}(\mathrm{Sn})$ is found to be similar in magnitude to $\mathrm{H}_{\text {eff }}(\mathrm{Sn})$ in $\mathrm{Pd}_{2} \mathrm{MnSn}$. Both these results indicate that local spin transfer mechanisms are important in determining the magnitude and sign of $\mathrm{H}_{\text {eff }}$ at the $\mathrm{Sb}$ site in Heusler-type alloys.

Tilford, C. R., A fringe counting laser interferometer manometer, Rev. Sci. Instrum. 44, No. 2, 180-182 (Feb. 1973).

Key words: Fringe counting; laser interferometer; manometer.

A prototype standard mercury manometer using a fringe counting laser interferometer to measure the differential height of the mercury columns has been built and successfully operated. The $10.6 \mu$ wavelength radiation from a $\mathrm{CO}_{2}$ laser and specially treated manometer tubes have been used to reduce the effect of disturbances on the mercury surface so that reliable operation of the manometer is possible.

Tsai, D. H., MacDonald, R. A., Second sound in a solid under shock compression, J. Phys. C: Solid State Phys. Letter to Editor 6, L171-L175 (1973).

Key words: Crystalline solid; iron; molecular dynamics; second sound; shockwave; thermal relaxation; three dimensions.

The propagation of a strong shock wave in a perfect, three-dimensional crystalline lattice is studied by means of molecular-dynamical calculations. The results show that behind the shock front there is a region of thermal relaxation which increases with time. The thermally relaxed region, therefore, propagates with a velocity lower than that of the shock front. It is believed that the wave-like propagation of this thermally equilibrated region is a natural extension of second sound from the conventional low-temperature, low-pressure régime to the high-temperature, high-pressure régime. The implication of this phenomenon on PVT calculations from shock-wave data is discussed briefly.

Waterstrat, R. M., Dickens, B., The crystal structure of $\mathbf{V}_{3} \mathbf{R} \mathbf{h}_{5}, J$. Less-Common Metals 31,61-67 (1973).

Key words: Atomic ordering; crystal structures; intermetallic compounds; rhodium alloys; vanadium alloys.

The crystal structure of the phase $\mathrm{V}_{3} R \mathrm{~h}_{5}$ has been elucidated. The unit cell is orthorhombic with $a=5.420 \AA, b=9.276 \AA, c=4.320 \AA$ and $Z=2$; the space group is either $C m 2 \mathrm{~m}$ or $\mathrm{Cmcm}$. The structure is close-packed and contains both ordered and disordered atomic sites. It is intermediate between the structures of the $\mathrm{Cu}_{3} \mathrm{Au}$ and $\mathrm{CuAu}$ types except that it possesses a two-layer stacking sequence.

Waterstrat, R. M., Manuszewski, R. C., The chromium-rhodium constitution diagram, J. Less-Common Metals 32, 331-343 (1973).

Key words: Chromium alloys; constitution diagram; equilibrium diagram; phase diagram; rhodium alloys.

The Cr-Rh alloy system has been studied over the entire composition range by metallography, $\mathrm{X}$-ray diffraction and electron microprobe methods. There are two intermediate phases in this system. The $\epsilon$ phase has a hexagonal close-packed structure and is stable over a broad composition range from about 20 at. $\% \mathrm{Cr}$ at 900 ${ }^{\circ} \mathrm{C}$ to 68 at. $\% \mathrm{Cr}$ at $1475{ }^{\circ} \mathrm{C}$. The $\beta$ phase possesses a $\mathrm{Cr}_{3} \mathrm{Si}(A 15)$ type structure and is stable over a narrow composition range from about 77 to 78 at. \% Cr. The location of the face-centered cubic $(\gamma \mathrm{Rh})$ to hexagonal close-packed ( $\epsilon$ phase) transition is strongly temperature dependent. Precipitation of a metastable hexagonal close-packed structure occurs during rapid cooling of the body-centered cubic $(\alpha$ Cr) solid solution. A peritectic reaction exists at $1700 \pm 10{ }^{\circ} \mathrm{C}$, a eutectic reaction occurs at $1475 \pm 10^{\circ} \mathrm{C}$, and peritectoid reaction is located at $1265 \pm 12^{\circ} \mathrm{C}$. 
Wells, J. S., A stabilized HCN laser for infrared frequency synthesis, IEEE Trans. Instrum. Meas. IM-22, No. 2, 113-118 (June 1973).

Key words: HCN laser; infrared frequency synthesis; laser frequency measurements; laser stabilization; laser metrology; phase locked laser.

Infrared frequencies have recently been synthesized in suitable diodes up to $88 \mathrm{THz}$ with accuracies of parts in $10^{9}$. Stabilized lasers are necessary in order to make frequency measurements of higher accuracy. The hydrogen-cyanide laser is the lowest frequency basis laser used in these synthesis schemes, and its stabilization has been the subject of recent interest. The laser is stabilized by locking it to a phase-locked microwave reference chain. Two servo loops are utilized. The first loop is a relatively slow frequency-lock loop with the correction applied to a piezoelectric-translator driver. This loop not only accommodates thermal expansion of the laser, but also serves as an acquisition aiding loop for the second servo. The latter is a phaselocked system with the correction applied to the laser discharge current controller. Data regarding the system stability are presented.
Zimmerman, J. E., Siegwarth, J. D., Portable helium dewars for use with super-conducting magnetometers, Cryogenics 13 , No. 3, 158-159 (Mar. 1973).

Key words: Dewar; gas shielded; helium; liquid; magnetometer; multilayer insulated.

Simple helium dewars have been constructed using gas-cooled radiation shields and multilayer aluminized plastic insulation. They will retain one litre of liquid for up to 40 hours. The shields may be made mostly non-conducting so the dewar can be used with ultrasensitive superconducting magnetometers. For most other applications thin sheet metal such as copper or aluminium is suitable for the shields.

* Publications with prices and SD Catalog numbers may be purchased directly from the Superintendent of Documents, U.S. Government Printing Office, Washington, D.C. 20402 (foreign: onefourth additional). Microfiche copies are available from the National Technical Information Service (NTIS), Springfield, Va. 22151. Reprints from outside journals and the NBS Journal of Research may often be obtained directly from the authors. 